\title{
Do Fairer Elections Increase the Responsiveness of Politicians?*
}

\author{
George Ofosu
}

\author{
Washington University in St. Louis
}

March 26, 2019

\begin{abstract}
Leveraging novel experimental designs and 2,160 months of Constituency Development Fund (CDF) spending by legislators in Ghana, I examine whether and how fairer elections promote democratic responsiveness. The results show that incumbents elected from constituencies that were randomly assigned to intensive election-day monitoring during Ghana's 2012 election spent 19 percentage points more of their CDFs during their terms in office compared to those elected from constituencies with fewer monitors. Legislators from all types of constituencies are equally present in parliament, suggesting that high levels of monitoring do not cause politicians to substitute constituency service for parliamentary work. Tests of causal mechanisms provide suggestive evidence that fairer elections motivate high performance through incumbents' expectations of electoral sanction and not the selection of better candidates. The paper provides causal evidence of the impact of election integrity on democratic accountability.
\end{abstract}

\footnotetext{
*Postdoctoral Research Associate, Department of Political Science, Washington University in St. Louis. Email: gofosu@wustl.edu. Web: www.georgeofosu.com/. I gratefully acknowledge my research partners in Ghana: the Center for Democratic Development and Coalition of Domestic Election Observers. Emmanuel Asante, E. GyimahBoadi, Franklin Oduro, and Regina Amanfo were generous with their time to discuss aspects of the project during my several visits to Ghana. I also thank officials at the Ghana District Assemblies' Common Fund Administration for providing data on legislators' Constituency Development Fund. I received comments on an earlier version of this paper from participants at seminars at the Center on Democracy, Development, and the Rule of Law and the Center for African Studies at Stanford. I am thankful for helpful comments from Omer Ali, Graeme Blair, Sarah Brierley, Darin Christensen, Brian Crisp, Larry Diamond, Marcel Fafchamps, Justin Fox, Barbara Geddes, Chad Hazlett, Galen Murray, Daniel Posner, Michael Thies, Margit Tavits, Andrea Vilán, Jeremy Weinstein, and five anonymous referees. This research benefits from my prior research with Joseph Asunka, Sarah Brierley, Miriam Golden, and Eric Kramon on Ghana's 2012 elections. The initial study was approved by UCLA IRB\# $12-001543$ on October 26, 2012 and the follow-up by UCLA IRB\#15 - 001142 on August 7, 2015. Funding for the initial study came from the U.K.'s Ghana office of the Department for International Development and a National Science Foundation Grant for Rapid Response Research (RAPID) SES-1265247 (Miriam Golden (PI)), none of whom bears responsibility for the results reported here.
} 
Election fraud is widely believed to undermine political responsiveness. Scholars and policymakers assume that vote rigging weakens the two channels through which elections can influence politician behavior: selection and sanction. When politicians can rig elections, it undermines citizens' ability to select competent or public-spirited politicians who share their interests (Fearon, 1999; Besley, 2005). Likewise, voters cannot vote out poorly performing or corrupt incumbents if officeholders can manipulate the polls (Ferejohn, 1986). Vote rigging breaks down the "electoral connection" between citizens and politicians, decreasing incumbents' incentives to work hard to win.

Despite the widespread belief that fair elections generate political responsiveness, and the billions of dollars spent annually to support programs such as domestic election monitoring to bolster electoral integrity (Annan et al., 2012; Norris, 2014), we lack solid evidence regarding whether and how high-quality elections incentivize politicians to be more responsive to citizens' needs. ${ }^{1}$ I provide, to my knowledge, the first systematic analysis of the causal relationship between fair elections and political responsiveness.

I theorize that high-quality elections increase political responsiveness because fair balloting limit politicians' ability to win through outright manipulation. Accordingly, programs such as election observation that constrain vote rigging will encourage officeholders to invest instead in efforts to meet the needs (and earn the support) of their constituents. My argument implies that incumbents who expect limited opportunities for election-day fraud - which increases the possibility of electoral sanction - will be more responsive to citizens' needs. Alternatively, higher quality elections may increase political responsiveness through enabling voters to select high-quality candidates to office.

\footnotetext{
${ }^{1}$ For example, while Collier and Hoeffler (2015) find that fair elections incentivize national governments to deliver good economic performance, van Ham (2009) finds no such association between the two variables. Similarly, Bratton (2013) finds no relationship between citizens' perceptions of election integrity and their assessments of the responsiveness of politicians in sub-Saharan Africa.
} 
Testing whether high-quality elections cause politicians to work harder on behalf of citizens requires exogenously varying the integrity of the election in which an officeholder is elected. This poses an empirical challenge because it is hard for researchers to randomly assign electoral districts (or countries) to different levels of election quality. To overcome this difficulty, I leverage insights from research on election observation, a popular initiative used by civil society groups to reduce election fraud and promote democratic accountability (Bjornlund, 2004).

Specifically, I use data from a field experiment that randomized the intensity of election observation (IO) by Ghana's largest domestic election observation group, the Coalition of Domestic Election Observers (CODEO), across 60 electoral districts in the country's 2012 elections (Asunka et al., 2019). Constituencies received one of three levels of election-monitoring intensities in which 30,50 , and 80 percent of a fixed proportion (30 percent) of polling stations were monitored. Given that observers reduce fraud and that greater intensities of observers reduce fraud more (Hyde, 2008; Ichino and Schündeln, 2012; Enikolopov et al., 2013), I use the IO within a constituency as an exogenous instrument for election integrity. I argue that experience with high IO incentivize democratic responsiveness because incumbents believe they cannot rig their reelection. Because the IO was randomized, differences in the performance of politicians elected in lowversus high- monitored constituencies during their four-year terms in office can be interpreted as the causal effect of fairer elections on responsiveness.

It is not obvious that improving election quality through high-intensity election-day monitoring will generate political responsiveness. First, politicians may simply shift their fraudulent or undemocratic activities to the period prior to the next elections. For example, incumbents can circumvent the need for election-day fraud by inflating the voter list with unqualified voters (Ichino and Schündeln, 2012), bribing their way in legislative primaries (Ichino and Nathan, 2012) or engaging in vote buying (Kramon, 2016). Second, officeholders may simply discount their reelection prospects and maximize their rent-seeking opportunities because they cannot rig (Bates, 2008). Third, irrespective of their quality, elections may fail to motivate politicians to satisfy citizens' 
needs if voters lack information on incumbent performance (Humphreys and Weinstein, 2012; Grossman and Michelitch, 2018) or are indifferent to officeholders' performance, and respond instead to ethnic or party cues, clientelistic arrangements or the instruction of traditional leaders (Posner, 2005; van de Walle, 2003; Wantchekon, 2003). Because of these theoretical possibilities, it is important to establish whether cleaner elections are fundamental to democratic responsiveness.

In many developing countries, including Ghana, scholars suggest that citizens are more likely to demand local public goods and private benefits from their legislators rather than legislation and executive oversight (Barkan et al., 2010; Lindberg, 2010). ${ }^{2}$ Therefore, to measure responsiveness, I collected fined-grained data on Members of Parliament's (MP's) spending of their state-provided individual Constituency Development Funds (CDFs) during their four-year terms. ${ }^{3}$ Similar to legislators in other developing countries, MPs in Ghana established these funds to deliver both private benefits and public goods (infrastructure) to address the gaps in public service delivery in their constituencies (Baskin, 2014). However, prior work in India finds that, because using CDFs requires effort, representatives often do not use these funds unless they face high levels of electoral competition (Keefer and Khemani, 2009). Accordingly, CDF usage rate is an objective measure of responsiveness. The fact that MPs have discretion over the use of these funds also ensures that analyzing CDF spending reveals whether politicians prioritize local public goods or private benefits.

I supplement the information on CDF spending with data from two sources. First, I collected four years of administrative records on MPs' parliamentary attendance. Second, I conducted closed-ended surveys with MPs to investigate their experiences with past election monitoring (and assess their level of other constituency activities). Using a rich set of information on MPs' behavior allows me to examine which legislator roles — constituency service vs. legislative duties - fairer

\footnotetext{
${ }^{2}$ Also, see Figure C.1 in the Appendix C.

${ }^{3}$ In Ghana, these funds are referred to as the MP' Common Fund.
} 
elections impact, and whether there are substitution effects (Ashworth and Bueno de Mesquita, 2006).

My main finding is that higher-quality elections increase the responsiveness of politicians. Specifically, the results show that politicians elected in intensely-monitored constituencies spent 19 percentage points more of their total funds compared to MPs elected in low-monitored constituencies. Additionally, my analysis shows that higher levels of spending on public goods substantially drives the significant difference in overall expenditure between MPs elected in high- versus lowmonitored constituencies. To the best of my knowledge, these findings are the first to show that intensive election monitoring, by decreasing fraud and violence, also produces a downstream effect on political responsiveness, suggesting that cleaner elections generate concrete benefits for citizens. Finally, I find that politicians elected in high-monitored constituencies were equally as present as their counterparts elected in low-monitored constituencies during parliamentary meetings, which suggests that fairer elections do not encourage officeholders to attend more legislative sessions or to substitute constituency service for legislative work.

Tests of mechanisms suggest that incumbents' fear of voter sanction through intense electionday monitoring in the next election may explain my findings. First, survey evidence indicates that a majority of legislators believe that election monitoring reduces their ability to rig elections and that those in intensely-monitored constituencies were more likely to say they experienced more observers in the past elections. I assume that such experience with past monitoring influences an incumbent's belief about future observation and encourages them to work harder. Second, and to systematically test my assumption, I experimentally manipulate the expectations of high-level monitoring in future elections to see if this affects legislators' behavior. I do so by sending individual letters to 30 of the 60 MPs to say that they should expect to receive intense monitoring of their constituencies in the December 2016 parliamentary elections. MPs in the control group did not receive a letter. 
Consistent with my expectation, I find that MPs who received a letter increased their spending by five percentage points, on average, compared to those who did not. Importantly, MPs who were elected in intensely-monitored constituencies and received a letter spent four percentage points more of their funds on public goods compared to legislators in low-monitored constituencies who just received a letter. These effects are substantively (but not statistically) significant, and provide preliminary causal evidence for the proposed mechanism that officeholders who are elected in fairer elections and expect to compete in another one are more responsive to citizens' needs. I do not find that the observer intervention significantly influenced the number of candidates or the profile of those elected, which would suggest a selection mechanism. Finally, I do not find that the IO influences citizens' contact with officeholders, which would indicate a citizens' pressure mechanism, or an increase in the number of challengers in the next elections, which would imply a candidate entry channel of influence (Grossman and Michelitch, 2018).

This study makes three contributions to the literature on electoral accountability. First, it provides new evidence that the quality of elections is an important determinant of political responsiveness. My work complements previous findings that electoral integrity affects outcomes such as political participation (Birch, 2010), regime legitimacy (Berman et al., 2014), and stability (Hyde, 2008). Second, the literature on electoral accountability has thus far considered how institutional factors such as term limits, electoral systems, and rewards from office (see Ashworth, 2012) and information asymmetries (see Dunning et al., 2019) shape the efficacy of elections. I show that election-day manipulation also affects democratic accountability. Finally, I contribute to the literature on election observation, which to date has focused on the effect of observers on voter registration fraud before the polls (Ichino and Schündeln, 2012), and on polling station level fraud and violence on election day (Hyde, 2008; Enikolopov et al., 2013). I show that election observers can affect political outcomes long after election day. 


\section{Electoral integrity and politicians' responsiveness}

Electoral accountability models suggest that elections affect politicians' performance through two distinct but reinforcing principal channels (Ashworth, 2012). First, elections help voters to screen candidates, selecting competent or public-spirited types who voters believe work harder in office (Fearon, 1999; Besley, 2005). Indeed, empirical evidence suggests voters prefer honest and highquality politicians in diverse settings (Besley, 2005; Galasso and Nannicini, 2011; Bratton, 2013).

Second, competitive elections can incentivize officeholders to perform well, irrespective of candidates' quality, because voters can retrospectively sanction poor performance (Ferejohn, 1986). While politicians may be self-interested and rent-seeking, expectations of electoral discipline motivates reelection-seeking incumbents to put in optimal effort, choosing a (costly) level of effort to satisfy voters' endogenously established welfare utility threshold (Mayhew, 1974).

While the selection and sanctioning models of electoral accountability provide plausible explanations for an incumbent's performance in office, both models typically assume that elections are run honestly - that the will of the voters is accurately reflected in the results. I argue that both channels of influence can be subverted by election-day fraud and that the extent to which politicians can rig elections influences their incentives to cater to citizens' demands (Collier and Hoeffler, 2015).

Concerning selection, other things being equal, election-day fraud may undermine citizens' ability to elect politicians who share their interests simply because the candidate most voters cast their votes for is not declared as the winner. Because the "winner" may not share the preferences of voters, (s)he is unlikely to satisfy citizens' needs. Regarding sanctioning, I argue that incumbents can either rig elections to remain in office or "earn" their re-election by working harder to meet voters' expectations. Obviously, incumbents can win office using other means such as vote buying, access to more campaign funds, media coverage (incumbency advantage), or obscuring information about their performance. Nevertheless, because officeholders cannot rely on these methods 
they often supplement these assets at their disposal with vote rigging. All else equal, I argue that when it is easy for incumbents to engage in election-day fraud, they can reduce the time, personal resources, and amount of effort they devote to address constituents' needs, and instead pursue their private business activities to earn outside rents.

In keeping with electoral accountability models, my argument implies that the quality of elections may encourage political responsiveness through two theoretically distinct channels. First, if we observe that an incumbent who was elected in a high-quality election (at time $t$-1) works harder in office (at time $t$ ), it is possible that voters succeeded in selecting a competent candidate who shares their preferences. We can examine this possibility by simply comparing the personal attributes or policy preferences of incumbents elected in cleaner elections to those selected through manipulated ones. Second, incumbents' expectations of competing in fairer election (at time $t+1)$ that would strengthen voters' ability to punish shirking or "select them out" may incentivize higher performance (at time $t$ ). Such prospective beliefs may derive from past constraints on rigging or exogenous changes in election administration that would limit fraud.

Also, the latter channel of influence, expectation of sanction, suggests that an incumbent's incentive to serve the interests of citizens depends not only on being elected in high-quality elections but also on "expecting" to compete in another one (at time $t+1$ ). Even when elected in credible polls, incumbents who believe they can rig future polls may simply shirk their duties.

The effects of fairer elections may vary by levels of electoral competition. In Uganda, Grossman and Michelitch (2018) find that disseminating information about the performance of politicians broadly to citizens increased officeholders' efforts, but only in competitive constituencies where viable alternative candidates were available or encouraged by the initiative to enter the race. Accordingly, it is possible that an attempt to improve the quality of elections to induce political responsiveness may be more effective in competitive compared to non-competitive constituencies. However, if parties and candidates use election fraud and intimidation to maintain their dominance in non-competitive areas (Magaloni, 2006; Simpser, 2008), then improving the 
quality of elections may motivate incumbents to roll up their sleeves (similar to their counterparts in competitive areas).

Political responsiveness involves doing what citizens want or acting in their interests (Powell, 2005; Pitkin, 1967). To get reelected, and unable to rig, I argue that incumbents are likely to exert a higher effort to satisfy voters' priorities. Research on African legislators suggests that citizens prioritize constituency service over parliamentary work (Lindberg, 2010). Therefore, officeholders elected in high-quality elections are likely to increase their supply of constituency service (H1). On the other hand, fairer elections may induce incumbents to reduce the effort they put into parliamentary work (H2), perhaps shifting their efforts to providing constituency service (Ashworth and Bueno de Mesquita, 2006). Scholars consider most African parliaments as weak relative to the executive branch (Barkan, 2009). Thus, if fairer elections further encourage legislators to reduce their attendance in parliament and instead dedicate their time to investigating citizens' local needs and to putting pressure on their local governments or seeking donor funds to provide them, that would be theoretically important to know.

Regarding constituency service, which involves satisfying the non-policy concerns of citizens (Fenno, 1978), MPs can prioritize the provision of public or private goods to maximize their votes. There is no consensus on which type of good - public or private - is more important in determining vote choice in democracies in sub-Saharan Africa. A dominant narrative of African politics would lead us to believe that to win votes in fairer elections MPs resort to providing benefits to individuals or groups (Wantchekon, 2003). Thus, legislators elected in high-quality elections are likely to satisfy citizens' demand for private goods (Hla). However, emerging research suggests that African voters grant their votes to politicians in exchange for local public goods and services (Lindberg, 2010; Ichino and Nathan, 2013). Accordingly, high-quality elections would induce MPs to provide more public goods (i.e., local infrastructure) (H1b) including schools, clinics, bridges, and roads that are easily attributable to their efforts and enable them to satisfy more voters (Harding, 2015). Politicians may also simply provide both public and private goods, targeting the entire 
population with the former while rewarding supporters with the latter (Diaz-Cayeros, Estévez and Magaloni, 2016). I combine original data on legislator spending and parliamentary attendance to examine these theoretical possibilities.

\section{Study context: Ghana}

Ghana is an ideal setting for this study because the level of electoral competitiveness and turnover means that politicians have real incentives to think about how they use their resources when seeking re-election. Similar to many other countries, Ghana adopted multiparty elections in November 1992. Its 2012 general elections, which elected the 2013-2017 Parliament, were the sixth. Ghanaian legislators are elected to four-year terms from single-member districts using plurality rule; they are not subject to term limits. Currently, the Parliament is composed of 275 members. ${ }^{4}$ During the 2013-2016 Parliament, 148 MPs belonged to the ruling National Democratic Congress (NDC), 123 to the main opposition party, the New Patriotic Party (NPP), and one to the People's National Convention. There were three independent MPs. The NPP and NDC have dominated Ghanaian electoral politics since 1996: the two parties have controlled over 98 percent of the seats. However, parliamentary races are increasingly competitive. Between 1996 and 2012, the average vote margin declined by about 11 percentage points. ${ }^{5}$ Also, between 2000 and 2012, the average turnover rates for incumbents seeking re-election was 24 percent. $^{6}$

Despite the increasing electoral competitiveness, Ghanaians provide poor ratings of their legislators. For example, in Afrobarometer Round 6 conducted in 36 African countries, about $63 \%$ of Ghanaians said that they disapprove of their MP's performance compared to the continental average of about $45 \%$. Similarly, $48 \%$ of Ghanaians reported that all or most of their MPs are

\footnotetext{
${ }^{4}$ Between 1993 and 2004, there were 200 MPs. The number rose to 230 in 2005 and 275 in 2012.

${ }^{5}$ The median vote margin decreased from 27.5 percent in 1996 to 17 percent in 2012 (a 38 percent decrease)

${ }^{6}$ The overall turnover rate for the Ghanaian Parliament between 2000 and 2012 is 45.38 percent (i.e., either retiring or losing through party primaries or general elections), and the percentage of seats changing between parties averaged 22.45 percent.
} 
involved in corruption, compared to the continental average of $34 \%$. These poor ratings may be explained by high expectations of Ghanaians of their representatives after more than two decades of democratic elections. However, they may also be due to politicians' ability to manipulate local elections.

Several studies indicate that the country's elections are often characterized by some level of fraud and violence (Gyimah-Boadi, 2007; Jockers, Kohnert and Nugent, 2010; Ichino and Schündeln, 2012; Straus and Taylor, 2012). Scholars argue that the enormous benefits and patronage resources that officeholders receive encourage these practices (Gyimah-Boadi, 2009; Ninsin, 2016). Election fraud (and violence) routinely goes unpunished. For example, following the 2012 general election, the main opposition party (NPP) filed a petition in the country's Supreme Court pointing to several irregularities in the polls. While the Supreme Court acknowledged some of the allegations in its verdict, no election official or party was indicted, and the case was dismissed. Thus, fraud and violence are viable options for officeholders who face stiff competition or seek to ward off strong competitors (in non-competitive constituencies). ${ }^{7}$

To curb electoral fraud, civil society groups such as the Coalition of Domestic Election Observers (CODEO), with support from international donors, have monitored the country's elections since 1996. CODEO has observed all of the country's general and local government elections held since its formation in 2000. The group is composed of 34 independent civil society organizations including religious, professional, and student bodies. In 2012, CODEO deployed about 4,000 observers to polling stations around the country on election day. Similar to other domestic election observation groups, CODEO's aim is to promote election integrity and strengthen political accountability. During the December 2012 elections, Asunka et al. (2019) leveraged CODEO's observation mission to examine the causal effects of election observers on indicators of election

\footnotetext{
${ }^{7}$ While winning legislative party primaries is essential for electoral success in non-competitive constituencies, we still observe election-day fraud and violence in these settings, which suggests that election-day outcomes remain important to politicians. In non-competitive electoral districts, incumbents may be interested in winning large margins of victory in the general elections to portray their "invincibility" and ward off competitors in future primaries and in the general election (Magaloni, 2006; Simpser, 2008).
} 
day fraud and violence. Because observers wear uniforms (i.e., official CODEO T-shirts and caps), they are easily identifiable to election officials, party operatives and voters. Empirical work suggests that the presence of observers deter election-day fraud and violence at polling stations and within constituencies. Because election observation remains a popular approach to promoting election integrity, it is important to examine whether such efforts, by reducing opportunities for fraud, ultimately improve the quality of political representation in new democracies.

\section{Research design}

\subsection{Varying the quality of elections in which politicians are elected}

In Ghana's 2012 election, together with colleagues, we employed a randomized saturation design (Baird et al., 2016) to measure the impact of monitors on election-day fraud and violence at polling stations across electoral constituencies (Asunka et al., 2019). Using this design, we first assigned a regionally representative sample of 60 constituencies to one of three election observation intensities (IO): low (30\%) (13 constituencies), medium (50\%) (24), and high (80\%) (23). The IO is the proportion of a fixed percentage (30 percent) of polling centers in a constituency to deploy monitors. Second, within these constituencies, CODEO deployed about 1,300 observers to the sampled polling stations with probabilities determined by the first-stage randomly assigned saturation. The observers stayed at their assigned stations throughout election day. Our study constituencies were nested within four of the country's ten regions: Ashanti, Volta, Central, and Western regions, which we chose to get a mix of competitive (23) and non-competitive (37) constituencies. ${ }^{8}$

In addition to estimating the unbiased direct effect of observers on fraud and violence, the randomized saturation design allows us to calculate the total causal effect (TCE) of monitors in constituencies, accounting for possible spillover effects (Baird et al., 2016). The key idea is that

\footnotetext{
${ }^{8}$ We excluded the Greater Accra region, which contains the capital, to reduce the potential contamination of our treatment by foreign observers and smaller groups (Carothers, 1997). Details of the design (and relevant results) are presented in Online Appendix H. Table A.1 shows that the sampled constituencies are regionally representative.
} 
since monitors often cover only a fraction of stations within a constituency, political party operatives can move their fraudulent activities to unmonitored stations (i.e., displacement effect), or desist from electoral malpractices in nearby polling stations (i.e., deterrence effect) (Ichino and Schündeln, 2012). By assigning some constituencies to receive fewer monitors and others to receive significantly more observers, we can estimate the net effect of observers on fraud and violence within constituencies by comparing average electoral outcomes for (monitored and unmonitored) polling stations in intensely-monitored districts to control stations in districts with fewer monitors, which by design are less susceptible to spillover effects.

Our estimates of the spillover-corrected direct and total effect of observers on electionday fraud suggests that intense election-day monitoring reduced the overall level of fraud and intimidation or made manipulation costly and risky for political parties. Specifically, we find that in medium and high IO constituencies observers reduced turnout rates by 7 and 6 percentage points (significant at the five percent level), respectively at polling station to which they were deployed. Regarding the TCE, we find that increasing the IO from low to medium or high reduced turnout by $5.6(p=0.08)$ and $5.5(p=0.07)$ percentage points, respectively (see Table H.1). Table H.1 also breaks the TCE results by level of electoral competition. The results show that the decreases in fraud are substantially large in competitive electoral districts (significant at the ten percent level) but small and not statistically significant in non-competitive electoral areas. As we argue in Asunka et al. (2019), these results suggest that while observers were able to reduce the overall level of fraud in competitive areas, they displaced it in non-competitive areas. Accordingly, in non-competitive constituencies, politicians were able to recover deterred fraudulent votes, but the presence of more observers likely increased the cost and risk of manipulation.

Concerning intimidation of voters, election monitors reduced violence by 4 and 6 percentage points at polling stations to which they were deployed in medium and high IO constituencies, respectively. These results are significant at the five percent level. However, we find that the TCE of monitors was only substantially large in non-competitive constituencies where observer 
reduced the incidents of voter intimidation by $7(p=0.16)$ and $9(p=0.06)$ percentage points in medium and high IO constituencies, respectively from a baseline of 13.5 percent. In competitive constituencies, the TCEs were an increase of $10.4(p=0.19)$ and $1.5(p=0.59)$ in medium and high IO electoral districts, respectively from 3.9 precent in the low IO, which suggest a potential displacement of violence. Accordingly, in the full sample, we find that observers reduced the overall level of voter intimidation by 5.4 percentage points in high-IO constituencies from 10.2 percent in low-IO electoral districts, a 53 percent decrease. The results is only statistically significant at $p=0.14$. In medium-IO constituencies the TCE is essentially zero.

In sum, higher IO reduced overall fraud or increased the cost of election manipulation across constituencies, on average. Important for my study, I assume that experiences with such intense monitoring will influence the prospective beliefs of incumbents about their ability to rig future polls and shape their behavior in office. I argue that because the IO was randomized, it offers a relevant exogenous instrument for the quality of elections - the intensity of election observationin constituencies from which incumbents were elected. I refer to this initial random assignment of the intensity of election-day monitoring as Actual Intensity of Observation (AIO). Regarding election-day fraud, the effects of medium and high monitoring are not statistically distinguishable from one another. Given the limited initial sample of constituencies $(\mathrm{N}=60)$ and the constraints it places on the statistical power on a follow-up experiment (described next) to examine causal mechanisms, I consider both medium and high constituencies as high-AIO districts (47). Accordingly, in the analysis I compare the behavior of politicians elected in these intensely-monitored constituencies to those from low-AIO (13) electoral districts during their terms in office (at time t). ${ }^{9}$

\footnotetext{
${ }^{9}$ Results for the three treatment arms are presented in Appendix E.
} 


\subsection{Varying expectations about future election quality}

In comparing the performance of incumbents elected in low-AIO to those in high-AIO, I assume that officeholders' expectations of intensity of monitoring in the next polls coincide with previous levels. I provide evidence in Section 5 that such an assumption is plausible. However, to test whether such beliefs influence performance, I complemented the initial experiment by dispatching letters to a random set of 30 of the initial 60 MPs (blocking on their initial AIO); MPs in the control group did not receive a letter. In keeping with recent research on monitoring corruption, the letter was designed to alter officeholders' beliefs about the chances of election-day fraud detection (Olken, 2007; Callen et al., 2016). In consultation with CODEO, the letters stated that evidence from academic research on the country's 2012 elections shows that more observers in a constituency reduced the overall levels of fraud (i.e., suspicious turnout rates) and voter intimidation. The legislators were then told that, to corroborate these results, I was collaborating with CODEO to replicate the study because, if true, the findings hold promise for democratic consolidation in the country. Appendix B shows copies of these letters.

The letter then informed the MPs that as part of the study, CODEO plans to deploy observers to 80 percent of polling stations in some constituencies in the upcoming (2016) elections, and that theirs happens to be one of those. The letter was stated in probabilistic terms because the number of observers CODEO could eventually deploy depended on the availability of donor funds, which was not known at the time I circulated the letters. However, I sent out the letters in November 2015 to give incumbents enough time to respond to the treatment in meaningful ways. ${ }^{10}$

\footnotetext{
${ }^{10}$ Note that it is the effect of the expectation of intense observation in their constituencies that is relevant for this part of the study, not the actual intensity. In 2016, observers were deployed to all constituencies, but CODEO deployed more observers to potential "trouble spots" in addition to their nationally representative sample to conduct a parallel vote tabulation (for more detail, see: https://ufahamuafrica.com/2017/01/07/ from-episode-1-what-were-reading-this-week/, accessed April 14, 2017). Also, in contrast to my lettertreatment, CODEO traditionally announce the total number of observers it will deploy to polling stations across the entire country on the eve of election day (mine was a year ahead), which provides no variation in expectation of intensity of observation. MPs had mixed reactions to their letters. Some MPs simply said they know of CODEO's activities and look forward to receiving them. Others said they would alert the local party about the situation. One MP sent me a list of polling stations to which CODEO should deploy monitors by email.
} 
Indeed, CDF programs take time to implement. For example, Harris and Posner (2019) find that in Kenya 56 percent of the projects implemented by MPs using their CDFs took a year, while about a quarter took 2 years. Accordingly, the probabilistic nature of the letter represents a compromise with CODEO and implies that the treatment may be weak. Nevertheless, it provides a useful first step to understand the effects and potential causal channels through which quality elections influence political responsiveness. ${ }^{11}$

I refer to the letter treatment as expected intensity of observation (EIO). I delivered letters to treated MPs in person and read the content of the letter to them. ${ }^{12}$ As a reminder, another letter was sent to MPs' mailboxes (followed by phone calls to confirm receipt) in April 2016. By sending letters to MPs who received intensive and less-intensive observation during the 2012 elections, during their last year in office, my experiments yield a $2 \times 2$ design with four types of incumbents (see Table 1).

Table 1: Experimental design

\begin{tabular}{|c|c|c|c|}
\hline & \multicolumn{3}{|c|}{ Expected Intensity of Observation (EIO) (2016) } \\
\hline & \multicolumn{2}{|c|}{ Received letter $(t)$} & $N$ \\
\hline Actual Intensity of Observation (2012) & $\operatorname{Yes}(l=1)$ & $N o(l=0)$ & \\
\hline $\operatorname{High}(a=1)$ & $Y_{11}(21)$ & $Y_{10}(26)$ & 47 \\
\hline $\operatorname{Low}(a=0)$ & $Y_{01}(9)$ & $Y_{00}(4)$ & 13 \\
\hline$N$ & 30 & 30 & \\
\hline
\end{tabular}

In 2016, the two treatments at times $t$-1 (AIO (a)) and $t$ (EIO $(l))$ generate four sets of MPs $\left(Y_{a l}\right)$ represented by the row and column cells of Table 1 as follows:

\footnotetext{
${ }^{11}$ It is possible that MPs in the control group will hear about my intervention and expect that their constituencies will also be intensely monitored on election day. While this is plausible and, if true, poses a threat to inferences about the unbiased effect of the treatment on legislator responsiveness, two key factors mitigate such concerns. First, I personalized my letters to individual MPs and did not say that CODEO will not deploy observers to other constituencies. The letter simply notified treated MPs that the presence of observers in their constituencies would be higher compared to others. Second, if some control MPs mimic the behavior of treated MPs by increasing their level of responsiveness, this will reduce the treatment effect.

${ }^{12}$ For the few (five) MPs who my research assistants could not meet in person, I first delivered their letters to their mailboxes in Ghana's Parliament House and followed up with a call to inform them of the letter and its content.
} 
1. $Y_{11}$ : MPs elected in high-AIO constituencies in 2012 who received a letter to expect a large number of observers in their constituency in the 2016 elections

2. $Y_{10}$ : MPs elected in high-AIO constituencies in 2012 who did not receive a letter

3. $Y_{01}$ : MPs elected in low-AIO constituencies in 2012 who received a letter to expect high IO in 2016

4. $Y_{00}$ : MPs elected in low-AIO constituencies who did not receive a letter to expect high IO.

This set of potential outcomes allows us to examine causal mechanisms linking intenselymonitored election and the responsiveness of officeholders. First, if receiving a letter to expect greater monitoring boosts performance (i.e., $\mathrm{E}\left[Y_{01}\right]-\mathrm{E}\left[Y_{00}\right] \neq 0$, and $\mathrm{E}\left[Y_{11}\right]-\mathrm{E}\left[Y_{10}\right] \neq 0$ ), it would be consistent with the "expectation of sanction" channel of influence. Second, a higher EIO effect among legislators elected in high-AIO compared to low-AIO would provide further evidence to indicate that being elected in fairer elections and expecting to compete in another one is what drives political responsiveness. In contrast, if the letter does not affect performance, it would provide support for a potential selection effect - that it was the initial selection of an officeholder in high-AIO that mattered.

However, the analyses generated by the two treatments are limited to the final year of each MP's four-year term and is further constrained by the limited number of cases in each of the treatment conditions (as shown in parentheses). Moreover, if legislators respond to different demands of citizens at various points in the electoral cycle (e.g., providing public goods early in their terms in office and supplying private benefits during an election year), the dimension of incumbents' efforts that the EIO may affect could differ from that of the AIO that was implemented before the MP took office (Michelitch and Utych, 2018). However, these analyses provide an essential complement to the primary analysis on whether or not improving the quality of the election at time $t$-1 increases the responsiveness of incumbents to explore causal mechanisms. The research design also provides a model for future investigation. 


\subsection{Measuring politicians' responsiveness}

To obtain direct measures of politician effort on constituency service and parliamentary work, I use data on legislators' spending of their CDFs and attendance in parliament, respectively.

CDF spending provides an appropriate measure of responsiveness with which to test my theoretical predictions about the influence of quality elections on different types of constituency services for two reasons. First, MPs have to exert a significant amount of effort to use their funds, and their spending directly benefits members of their constituency. ${ }^{13}$ Ghana established its MPs' CDF in 1992 as part of the country's District Assembly Common Fund (DACF) [Article 252 of the 1992 constitution]. The DACF represents a proportion (at least 5 percent) of national revenues disbursed to the country's 216 local governments for community development projects. ${ }^{14}$

The central government sets aside a portion of the DACF, which it then allocates equally among MPs as CDFs each year. The national Fund Administrator (FA) deposits an MP's money into a bank account maintained by the local government that serves the legislator's constituency. To use these funds, MPs need to submit their plans to the local government and satisfy both legal and bureaucratic requirements. For example, to construct a bridge or repair a road in a local community, an MP must submit at least three price quotations from different vendors (Section 43 of the Public Procurement Act 663, 2003). The mayor and the procurement committee of the local government will then approve payment for the winner of the bid. These processes take time and energy. ${ }^{15}$ In the case of providing personal assistance such as paying the school fees or medical

\footnotetext{
${ }^{13}$ As Keefer and Khemani (2009) argue, CDF spending contrasts with other proxies for legislator effort such as politicians' subjective assessments, committee memberships, and sponsorship of bills, which tell us little about the actual amount of work an individual representative did, and who directly benefited.

${ }^{14}$ Electoral constituencies are embedded in administrative districts. In 2012, there were 275 constituencies and 216 districts. Accordingly, while some districts had more than one constituency, many were coterminous with a single constituency. In my sample of 60 constituencies, only 4 pairs shared a district. The results reported below are robust to clustering the errors at the district level (see Appendix Table E.7).

${ }^{15}$ Appendix Table E.5 shows that legislators who are co-partisans with the presidentially-appointed head of the local government spend more of their funds compared to opposition MPs, who sometimes get frustrated with strict requirements to comply with procurement laws. For example, see "Suhum MP and MCE haggle over the release of Common Fund," last accessed, May 14, 2016. However, Table E.5 also shows that the main results are robust to controlling for MP-mayor co-partisanship.
} 
bills of individual constituents, MPs must write letters providing reasons for the requests and the lists of selected recipients. Because MPs can decide whether to use these funds, the rate of usage provides a reasonable measure of effort. In this regard, this study joins an emerging literature that uses politician spending of CDFs or other central government transfers in their electoral districts as a measure of responsiveness (e.g. Keefer and Khemani, 2009; Asunka, 2017; Harris and Posner, 2019).

Second, when MPs decide to use their funds, they have discretion over the allocation. They can either decide to provide public goods or private benefits to their constituents. Analyzing how MPs allocate their funds provides a way to examine which types of citizen demands they prioritize. I consider the proportion of funds that each legislator spends on public goods and private benefits with the assumption that spending on the former is more responsive because it aligns with what majority of voters want.

Between 2014 and 2016, each Ghanaian MP was allocated GHC1,264,987 $(\approx \$ 316,246) .{ }^{16}$ Unspent funds are rolled over to the next year. I gained access to and digitized 36 months of spending records for each of $60 \mathrm{MPs}$ - totaling more than 9,400 ledger records that had been submitted to the FA.

I then constructed a database that contains the totals of how MPs allocated their funds among five principal expense categories: personal assistance to constituents (e.g., school fees, medical bills, business support, house renovation, etc.); local public goods (e.g., construction or repairs of local roads, construction or rehabilitation of schools and clinics, streetlights, bridges); monitoring of constituency projects and office expenses; transfers towards local government projects and activities (e.g., funds for national independence day or farmers' day celebration); and donations to support local groups to undertake projects or activities (e.g., traditional authorities, reli-

\footnotetext{
${ }^{16}$ The government allocated each MP GHC348,667, GHC403,688, and GHC512,632 in 2014, 2015, and 2016, respectively. Data for the first year are incomplete because new administrative districts that were established prior to the elections were not fully functional. Accordingly, data from 2013 are not included in the study.
} 
gious groups, and youth associations). A last category of expenditure, which I code as unclear, include expenses for which the purpose or beneficiary was not clear from the ledger.

Online Appendix I details my coding rules (Table I.1) and gives examples of the expenses sheets (Figures I.1 and I.2), as well as the summary statistics of these data (Table I.2). In the main analysis, I focus on the total amount of CDF spent and the part allocated to public and private goods to test my hypotheses. While the other sets of expenses provide further insights on how legislators spend their CDFs in Ghana, these allocations only emerged from my detailed coding and did not form part of my initial expectations. Therefore, while Table 2 shows the summaries of the amounts incumbents spent on these items, Appendix Section E.3 provides detailed discussions of these expenses and results regarding the effects of fairer elections.

Also, although I did not physically verify reported projects or surveyed individuals reported to have received personal assistance, MPs do not control these data; the local government that supervises the corresponding legislator report the spending and is directly held accountable for missing funds or mishandling of reports by the country's auditor general (Williams, 2017). Thus, these data are reliable for my analysis. ${ }^{17}$

\subsection{Balance statistics}

Appendix Table A.2 shows the balance statistics for a set of pre-treatment covariates across the two levels of election monitoring (i.e., low and high). ${ }^{18}$ Because of the small sample size, I use the Kolmogorov-Smirnov test to ensure robustness. I also display covariate balance by way of quantile-quantile plots in Appendix Figures A.1 and A.2. I find that constituencies across the treatment conditions are similar in most including vote margin in 2008, number of candidates in the 2012 polls, distance from the Parliament House ${ }^{19}$, and the geographical distribution of party

\footnotetext{
${ }^{17}$ When I asked, many MPs referred me to the CDF administrator for details of their projects and expenses.

${ }^{18}$ I also show balance across the three treatment arms in Table A.3.

${ }^{19}$ Scholars find that the distance to an MP's district influences how often they visit, which indicates levels of constituency service (e.g., Mayhew, 1974).
} 
support (using Entropy $(H)\left(\right.$ Reardon and O'Sullivan, 2004). ${ }^{20}$ There is also a balance across treatments in citizens' assessments of the performance of the previous MP on constituency service, as well as support for the major parties (Table A.4), which suggest that the treatment did not affect previous performance or the support of major party candidates, respectively.

Disaggregating the balance statistics by the three treatment arms (Appendix Table A.3) shows some imbalances on the following covariates: voter density (\# voters/Area (Km. sq.)), margin of victory 2008, and the proportion of individuals with primary education or less, employed, living in cement housing, and working in agriculture. My results are robust to controlling for these variables (Appendix Table E.8).

\section{Results}

In this section, I present the results from the initial assignment of actual intensity of election-day observation on the behavior of MPs during their four-year (2013-2016) terms. Because the followup experiment (EIO) that randomized letters to MPs was implemented during legislators' last year (2016) in office and was designed to explore possible mechanisms, I discuss its results in Section 5, where I examine the possible causal explanations for the main results.

\subsection{Estimating the causal effect of AIO on constituency service}

I estimate the average intention-to-treat (ITT) effect of the AIO on legislators' responsiveness. ${ }^{21}$ Specifically, I compare the average outcomes for representatives elected in constituencies ran-

\footnotetext{
${ }^{20}$ Scholars suggest that the spatial distribution of partisans or co-ethnics may affect the targeting and, perhaps, incentives of politicians to use their funds to provide local public goods (Harris and Posner, 2019; Ejdemyr, Kramon and Robinson, 2017). I use polling station level parliamentary results for 2016 for my calculation because I do not have similar data for 2008 or 2012.

${ }^{21}$ Ideally, one would estimate the Local Average Treatment Effect (LATE) in a Two-Stage Least Squares (2SLS) regression. The ITT is appropriate in this context because there are no direct measures of overall "election fairness" at the constituency level. The AIO therefore serves as a weak instrument for election fairness (see Chernozhukov and Hansen, 2008), and the results can be interpreted as a lower-bound estimate of the intensity of observation on responsiveness.
} 
domly assigned to high-AIO to those elected in low-AIO electoral districts. Formally, let $Y_{i}\left(M_{i}\right)$ denote the outcome of interest for legislator $i$ elected from a constituency with an intensity of observation $M$. I estimate:

$$
I T T=\mathrm{E}\left[Y_{i} \mid M_{i}=\text { high }\right]-\mathrm{E}\left[Y_{i} \mid M_{i}=\text { low }\right],
$$

where $\mathrm{E}\left[Y_{i} \mid M_{i}=\right.$ high $]$ is the average level of responsiveness of legislators elected in intensely monitored elections and $\mathrm{E}\left[Y_{i} \mid M_{i}=\right.$ low $]$ represents that of legislators elected in low-AIO constituencies. Because of the small sample size, I use the HC3 version of the heteroskedasticity-consistent covariance matrix (HCCM) as described and suggested by Long and Ervin (2000) to estimate the standard errors associated with all the ITT estimates to check incorrect inferences. I also use randomization inference to generate $p$-values associated with the sharp null hypothesis of no treatment effect for each unit (Gerber and Green, 2012). I estimate the 95\% confidence intervals of the effects using bootstrapping to provide further confidence that a few constituencies do not drive the results. $^{22}$

\subsection{Average ITT effect of AIO on CDF spending}

Table 2 shows a breakdown of the average total amounts spent by legislators of their allocated GHC1,264,987 in the various expenditure categories by treatment (between 2014 and 2016). I also disaggregate MPs' expenditures over time to examine possible time trends. ${ }^{23}$ Table 2 displays four interesting patterns.

First, MPs elected from intensely monitored constituencies spent more of their allocated funds (GHC573,548 (45.3 percent)), on average, compared to those from low-AIO constituencies, who spent only GHC336,630 (26.6 percent). While the level of spending increased over time across treatments, MPs in intensely monitored constituencies consistently outspent their counter-

\footnotetext{
${ }^{22}$ Appendix $\mathrm{K}$ report the power analysis of the main analysis.

${ }^{23}$ Table E. 1 shows the distribution of spending across the three treatment arms.
} 
parts elected in low-AIO constituencies (see Table E.6 in the Appendix). Insofar as the level of expenditure is indicative of an MP's effort, higher AIO elections increase democratic responsiveness.

Second, disaggregating the total expenditure into categories, I find that MPs elected from high-AIO constituencies spent significantly more of their CDFs on local public goods. However, MPs in high-AIO group appear to spend only slightly more of their funds on providing private benefits to citizens compared to those in the control group. Third, MPs elected in higher-quality elections donate more to organized groups, spend more on local government activities, and spend more on monitoring local projects and running their constituency offices. Finally, MPs elected in low-intensity monitored constituencies spent more on items that were hard to detect a purpose or who benefited based on the expenditure records, but further analysis show no statistically significant differences across treatment (see Table E.9 in appendix).

In line with my hypotheses, I focus on the causal effects of AIO on MPs' total expenditures (utilization) and allocations to public and private goods (i.e., the first two items in Table 2). ${ }^{24}$

Figure 1 shows that MPs elected in intensely-monitored constituencies spent more of their available CDFs compared to those elected from electoral districts with fewer observers. The left side of Figure 1 shows average use of CDFs by legislators in the two treatment conditions along with 95 percent confidence intervals (CIs). The average CDF spending in the low-AIO constituencies is 26.6 percent (s.e. 3.2), while the average use in intensely monitored constituencies is 45.7 percent (s.e. 3.3). ${ }^{25}$ The right side of Figure 1 shows the ITT effect (difference-in-means) as well as the 95 percent CI. The results show that MPs elected in high-AIO constituencies spent 19 percentage points (s.e. $4.7, p=0.006,95 \% \mathrm{CI}: 10.2-28.2$ ) more of their allocated CDFs during the

\footnotetext{
${ }^{24}$ Appendix $D$ shows the density plots for my dependent variables in treatment and control groups. Table E.9 shows the results for the other expense categories.

25 The failure to spend all allocated CDFs and other centrally allocated funds (i.e. "passing on pork") has been noted by scholars in a variety of settings including India (Keefer and Khemani, 2009) and Kenya (Harris and Posner, 2019). In Ghana the lack of spending may reflect the lack of public attention paid to the use of CDFs (no systematic study or report of MPs' use of CDFs is currently available), as well as the low levels or delay of actual disbursements. For example, in 2014 only 40 percent of the promised funds were disbursed to MPs.
} 
Table 2: Average CDF spending across six expenditure categories by the intensity of election observation

\begin{tabular}{|c|c|c|c|c|c|c|c|c|}
\hline & \multicolumn{2}{|c|}{$\begin{array}{l}\text { Total } \\
\text { GHC }\end{array}$} & \multicolumn{2}{|c|}{$\begin{array}{l}2014 \\
\text { GHC }\end{array}$} & \multicolumn{2}{|c|}{$\begin{array}{l}2015 \\
\text { GHC }\end{array}$} & \multicolumn{2}{|c|}{$\begin{array}{l}2016 \\
\text { GHC }\end{array}$} \\
\hline & Intensity $o$ & Dbservation & Intensity & bservation & Intensity & Observation & Intensity & Observation \\
\hline Expenditure Category & $\begin{array}{c}\text { Low } \\
\text { (1) }\end{array}$ & $\begin{array}{c}\text { High } \\
\text { (2) }\end{array}$ & $\begin{array}{c}\text { Low } \\
\text { (3) }\end{array}$ & $\begin{array}{c}\text { High } \\
\text { (4) }\end{array}$ & $\begin{array}{c}\text { Low } \\
(5)\end{array}$ & $\begin{array}{c}\text { High } \\
\text { (6) } \\
\end{array}$ & $\begin{array}{c}\text { Low } \\
(7)\end{array}$ & $\begin{array}{c}\text { High } \\
(8) \\
\end{array}$ \\
\hline Public goods & $\begin{array}{l}140,041 \\
(85,995)\end{array}$ & $\begin{array}{c}332,007 \\
(244,539)\end{array}$ & $\begin{array}{c}17,744 \\
(19,296)\end{array}$ & $\begin{array}{c}48,671 \\
(47,725)\end{array}$ & $\begin{array}{c}70,845 \\
(54,498)\end{array}$ & $\begin{array}{c}146,377 \\
(122,106)\end{array}$ & $\begin{array}{c}51,451 \\
(30,471)\end{array}$ & $\begin{array}{c}139,937 \\
(122,257)\end{array}$ \\
\hline Private goods & $\begin{array}{l}122,003 \\
(95,047)\end{array}$ & $\begin{array}{l}129,832 \\
(92,055)\end{array}$ & $\begin{array}{c}15,735 \\
(17,445)\end{array}$ & $\begin{array}{c}21,175 \\
(21,167)\end{array}$ & $\begin{array}{c}45,434 \\
(34,476)\end{array}$ & $\begin{array}{c}48,830 \\
(37,000)\end{array}$ & $\begin{array}{c}60,834 \\
(54,550)\end{array}$ & $\begin{array}{c}61,127 \\
(65,488)\end{array}$ \\
\hline Donations to local groups & $\begin{array}{c}15,113 \\
(16,207)\end{array}$ & $\begin{array}{c}35,651 \\
(40,518)\end{array}$ & $\begin{array}{c}1,500 \\
(3,030)\end{array}$ & $\begin{array}{c}3,088 \\
(5,962)\end{array}$ & $\begin{array}{c}6,333 \\
(10,098)\end{array}$ & $\begin{array}{c}15,643 \\
(28,063)\end{array}$ & $\begin{array}{c}7,279 \\
(9,140)\end{array}$ & $\begin{array}{c}17,288 \\
(23,119)\end{array}$ \\
\hline Transfers to local government & $\begin{array}{c}9,675 \\
(17,452)\end{array}$ & $\begin{array}{c}45,057 \\
(73,067)\end{array}$ & $\begin{array}{c}1,316 \\
(2,571)\end{array}$ & $\begin{array}{c}8,833 \\
(15,787)\end{array}$ & $\begin{array}{c}1,735 \\
(3,748)\end{array}$ & $\begin{array}{c}17,489 \\
(47,380)\end{array}$ & $\begin{array}{c}6,625 \\
(16,268)\end{array}$ & $\begin{array}{c}19,142 \\
(49,670)\end{array}$ \\
\hline Monitoring and office expense & $\begin{array}{c}3,282 \\
(3,862)\end{array}$ & $\begin{array}{c}9,778 \\
(15,230)\end{array}$ & $\begin{array}{c}1,119 \\
(1,898)\end{array}$ & $\begin{array}{c}2,645 \\
(8,691)\end{array}$ & $\begin{array}{c}829 \\
(1,909)\end{array}$ & $\begin{array}{c}2,867 \\
(5,867)\end{array}$ & $\begin{array}{c}1,334 \\
(2,404)\end{array}$ & $\begin{array}{c}4,359 \\
(9,075)\end{array}$ \\
\hline Unclear purposed expenditure & $\begin{array}{c}46,516 \\
(61,455) \\
\end{array}$ & $\begin{array}{c}21,223 \\
(35,019)\end{array}$ & $\begin{array}{c}4,806 \\
(16,501) \\
\end{array}$ & $\begin{array}{c}2,396 \\
(5,941) \\
\end{array}$ & $\begin{array}{c}15,330 \\
(27,414)\end{array}$ & $\begin{array}{c}8,733 \\
(18,409) \\
\end{array}$ & $\begin{array}{c}26,380 \\
(43,123) \\
\end{array}$ & $\begin{array}{c}10,313 \\
(27,671) \\
\end{array}$ \\
\hline Total & $\begin{array}{c}336,630 \\
(144,758)\end{array}$ & $\begin{array}{c}573,548 \\
(291,687)\end{array}$ & $\begin{array}{c}42,221 \\
(28,445)\end{array}$ & $\begin{array}{c}86,808 \\
(64,019)\end{array}$ & $\begin{array}{l}140,506 \\
(67,151)\end{array}$ & $\begin{array}{c}239,939 \\
(143,604)\end{array}$ & $\begin{array}{l}153,903 \\
(89,591)\end{array}$ & $\begin{array}{c}252,166 \\
(160,371)\end{array}$ \\
\hline
\end{tabular}

Notes:

1. Table 2 shows the average amount of CDF funds spent by Members of Parliament (MPs) in the sample between 2014 and 2016 by treatment conditions. Standard deviations are reported in parentheses. Amounts are in Ghana Cedis (GHC) ( $\$ 1 \approx 4$ in August 2014 according to http://freecurrencyrates.com/en/ exchange-rate-history/USD-GHS/2014/yahoo).

2. Source: Author's coding of original expenditure sheets collected from Ghana's District Assemblies' Common Fund Administration. 
period, on average, which represents a roughly 71 percent increase from a baseline of 26.6 percent in low-AIO constituencies. ${ }^{26}$ These results support the hypothesis that an increase in the intensity of observation causes politicians to exert more effort $(H 1)$.

Figure 1: Average ITT effect of AIO on the use of CDF

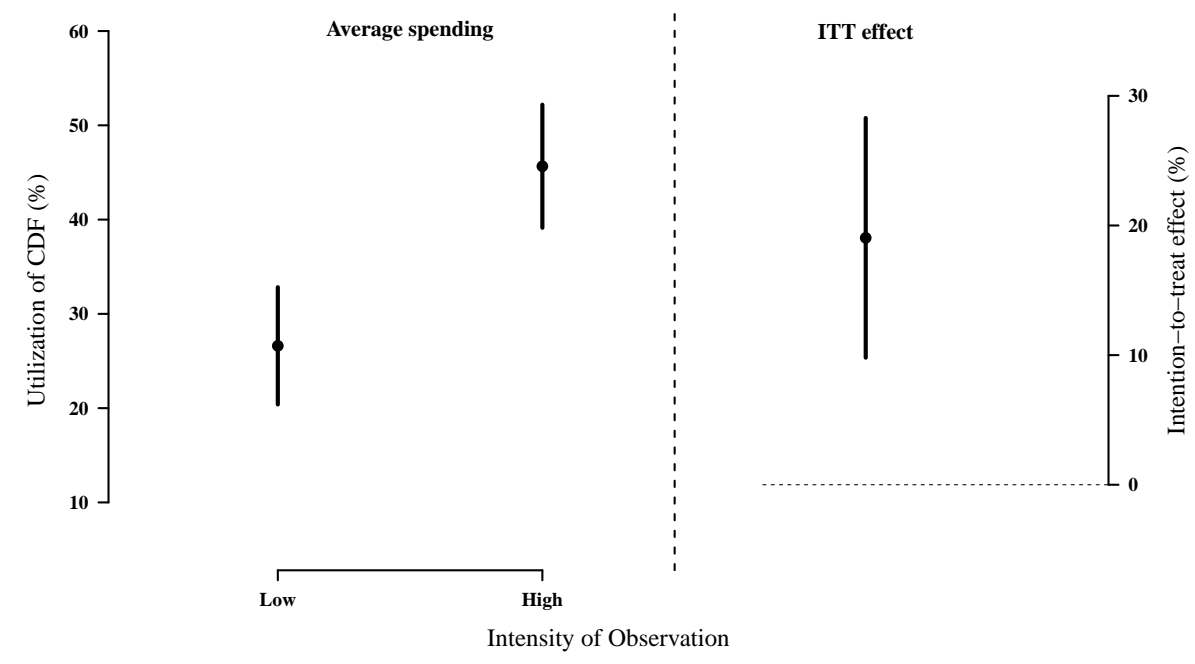

Notes: The left panel shows the mean of the percentage of available CDF (GHC 1,264,987) between 2014 and 2016 by AIO level. The right panel shows the average ITT effect of high election observation on CDF spending. Robust standard errors (HC3) are used to generate the 95 percent intervals around the average ITT effect.

In Figure 2, I disaggregate the results by the type of expenditure: public goods (left) and private benefits (right). I find that higher-intensity monitoring increases legislator spending on public goods, consistent with hypothesis $H 1 b$, but not on private goods $(H 1 a)$. The left panel illustrates that the average use of CDF for public goods is 11.1 (s.e. 1.9) and 26.4 (2.8) percent in low- and high-AIO constituencies, respectively. An increase in the treatment from low to high led to an increase of about 15 percentage points in spending on public goods, which is substantially and statistically significant $(p=0.008,95 \%$ CI: $9.1-22.3$ ). An increase in the intensity of observation more than doubles legislators' spending on local public goods, suggesting that higherintegrity elections improve spending on public works. The right panel displays the results for spending on private goods. The average spending in low- and high-AIO constituencies is 9.6 (s.e.

\footnotetext{
${ }^{26}$ Appendix Figure E.2 shows the distribution of the bootstrapped estimates of the average ITT effects.
} 
2.1) and 10.3 (s.e. 1.1), respectively; this difference is not statistically significant ( $p=0.774$, 95\% CI: $-4.1-5.1$ ). This implies that AIO does not lead to a significant increase (or decrease) in spending on private benefits for constituents. In sum, the findings indicate that an increase in the quality of elections, induced by increased election monitoring, raises the responsiveness of politicians to constituents' demands for public goods.

Figure 2: Average ITT effect of AIO by expenditure type
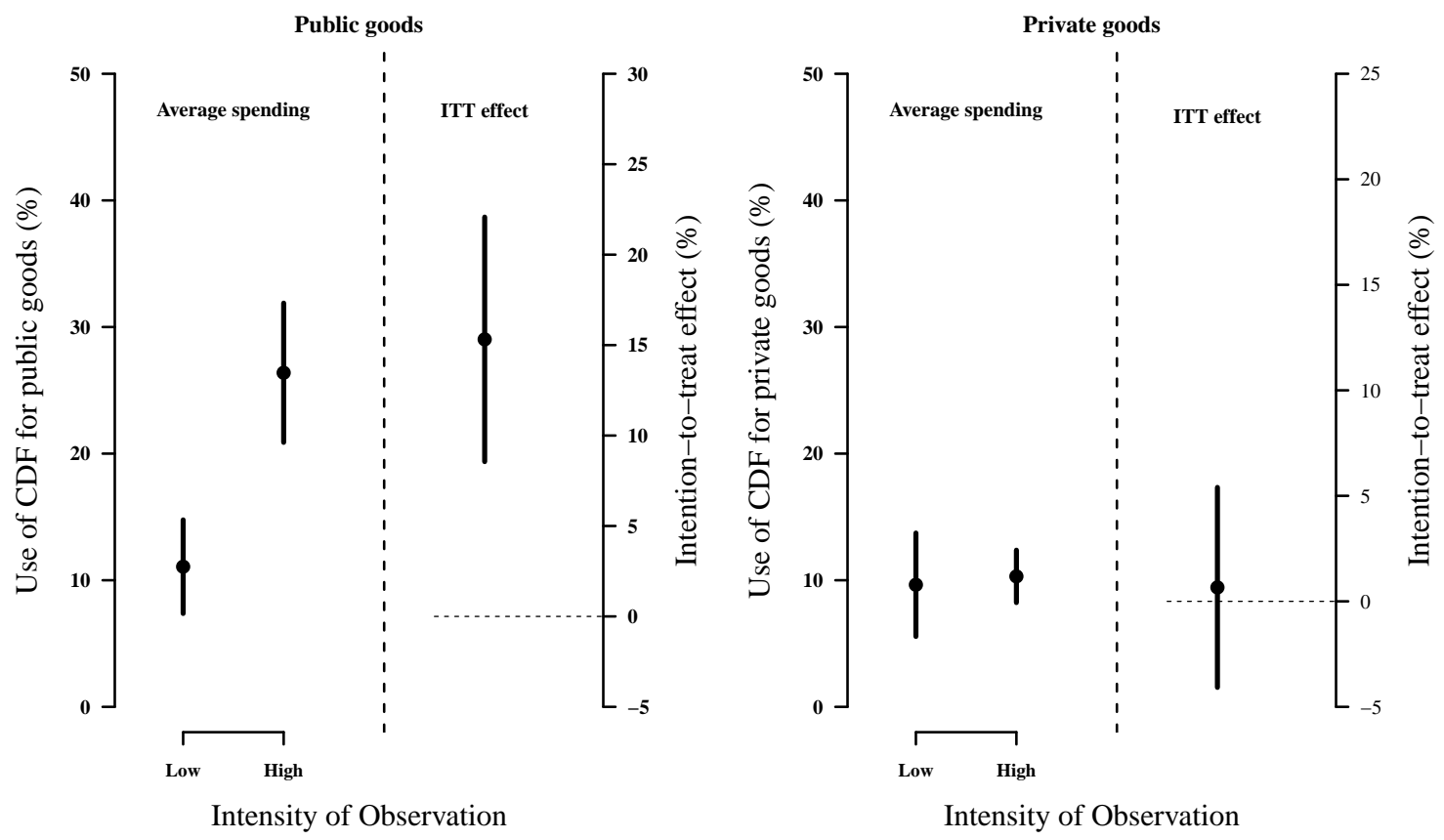

Notes: The figure shows the results of MPs' use of CDFs for local public goods (left panel) and private goods (right panel) for constituents. In both cases, the left side of the figure displays the average for constituencies in each treatment condition along with 95 percent CIs. The right side of each panel shows the ITT effect estimates as the difference-inmeans between low- and high-intensity monitored constituencies. Robust standards errors (HC3) are used to generate the 95 percent CIs around these ITT estimates.

Appendix Table E.4 examines whether or not the treatment effects vary by levels of electoral competition. The results show that the average ITT effect is not statistically different across the levels of electoral competition. However, MPs in competitive constituencies do respond to the treatment by spending more than colleagues in less competitive constituencies. Nevertheless, these results should be treated with caution because of the limited number of cases across the different 
electoral settings, especially in the control condition. It would be fruitful for future research to investigate potential differential effects more systematically.

The results on CDF spending support MPs'self-reported frequency of visits to their constituencies and the activities they prioritize when they visit, which are used in the literature as indicators of constituency service. These results are presented in the Online Appendix $\mathbf{J}$ and further indicate that MPs elected through intensely-monitored elections report to work harder to provide local public goods.

\subsection{Do legislators substitute for legislative work with constituency services?}

Finally, I estimate the average ITT effect of high AIO on legislator absence from parliamentary meetings. Ghana's Parliament meets four times a week (Tuesday to Friday). ${ }^{27}$ For each session, an MP may be present, absent with permission, or absent without permission. Using Parliamentary Hansards, I code legislator absence (without permission) for 346 parliamentary meetings between January 2013 and October $2016 .{ }^{28}$ I compare the absence rates for legislators elected from constituencies that received low vs. high levels of observation.

Table 3 shows the average absence rate in the full sample in Column (1), and in low- and high-AIO constituencies in Columns (2) and (3), respectively. Standard errors of these estimates are shown in parentheses. The results show that MPs in the sample were absent about a quarter (26 percent) of the time during their four-year terms in office, on average. The absence rate was 25.4 and 26.2 percent in low- and high-AIO districts, respectively. The difference-in-means estimate indicates no significant difference in the absence rates among legislators across the two treatments, providing no support for hypothesis $H 2$.

These results suggest that higher-quality elections neither cause MPs to shirk nor attend parliamentary meetings more regularly. The results also indicate that cleaner elections do not

\footnotetext{
${ }^{27}$ MPs must seek permission from the Speaker to excuse themselves from these meetings (Article 97(1c), 1992 Constitution).

${ }^{28}$ The rate of absence with permission was about 3 percent, and including such absences does not impact the results.
} 
motivate politicians to substitute constituency service for legislative effort. The results may be explained by the fact that MPs can deliver constituency services when they visit their districts on the weekends or on Mondays when Parliament is not in session, or during their recess.

Table 3: Similar absence rates in parliament among MPs elected from low and high intensely- monitored constituencies

\begin{tabular}{lcccc}
\hline \hline & \multicolumn{4}{c}{ Intensity of Observation } \\
& Full sample & Low & High & ITT \\
& $(1)$ & $(2)$ & $(3)$ & $(4)$ \\
\hline Average absence rate & 0.260 & 0.254 & 0.262 & 0.009 \\
& $(0.019)$ & $(0.030)$ & $(0.023)$ & $(0.039)$ \\
$\mathrm{N}$ & 60 & 13 & 47 & \\
\hline
\end{tabular}

Notes: Table 3 reports the intention-to-treat effect of intensity of observation on the absence of MPs from Parliamentary sessions. Columns (1)- (3) shows the means and standard errors for absence rate in the full sample, and the low and high intensities, respectively. Columns 4 reports the average ITT effect. Each unit is weighted by the inverse of its treatment probability. Robust standard errors are reported in parentheses. Significance level indicated by ${ }^{*} \mathrm{p}<0.1$; ${ }^{* *} \mathrm{p}<0.05 ;{ }^{* * *} \mathrm{p}<0.01$ are based on two-sided hypothesis test.

\section{Exploring the causal mechanism between election quality and responsive- ness}

What might explain the causal relationship between high-quality elections, generated by intense election monitoring, and improved political responsiveness regarding constituency service? I argued that election observation may strengthen the electoral connection by empowering citizens to either select quality candidates who in turn work hard in office, or by shaping incumbents' expectations that voters might sanction their poor performance. To distinguish between the two channels, I first draw on features of the initial randomization of AIOs, electoral outcomes, and data collected through closed-ended interviews with 47 of the 60 MPs in the study. Second, I report results from randomizing letters to 30 (of 60) MPs in the initial sample that informed them to expect intense monitoring in the next election. 
My analyses suggest that the selection of better candidates through intensely monitored election may only play a minimal role in explaining the behavior of incumbents in this case for two main reasons. First, the intensity of election observation was not announced ahead of the 2012 elections when the initial experiment was implemented. Thus, the treatment could not have influenced the candidate pool in the first stage of selection (Besley, 2005). Appendix A Table A.2 shows that an equal number of candidates contested across constituencies in each treatment condition. Second, although we show that the presence of observers reduced the level of fraud and violence at polling stations, I do not believe the effects were sufficient to influence who won the elections (second stage). While the treatment reduced the vote margins at the constituency level, especially in competitive districts, this reduction was not statistically significant. Also, the treatment did not produce legislators who were qualitatively different, on average, across multiple characteristics such as education, age, party affiliation, or term in office as I show in Appendix F Table F.1. While voters' choices may have been influenced by other candidate features that I do not capture here, based on the empirical evidence presented, the treatment is unlikely to have had a major influence on responsiveness through the selection of "quality" politicians.

Turning to the sanction mechanism, I provide tentative evidence to suggest that it provides a more plausible explanation for incumbents' behavior in this study. I argue that, for election observation at time $t$-1, to affect incumbents' performance during their terms in office (in time $t$ ), at least two conditions must hold. First, incumbents must be aware of the intensity of election observation in their constituencies in the prior election (at time $t$-1) and believe that monitoring was effective at reducing electoral fraud. Second, incumbents must believe that the intensity of election observation in their constituencies will be repeated during their reelection race (at time $t+1$ ), thus reducing their ability to rig their re-election balloting.

To test the first condition, I conducted closed-ended interviews with MPs to determine whether they were aware of the intensity of observation in their constituencies. I asked them if they saw observers at polling stations they visited during the 2012 polls. I find a positive association 
between a higher AIO and MPs reporting that they saw observers. A higher concentration of observers in a constituency increased the probability that an MP reported that he or she personally saw an observer at polling stations they visited by about 17 percentage points (41.67 percent in low-AIO compared to 58.82 percent in high-AIO districts) $(p=0.31) .{ }^{29}$ Moreover, MPs elected in intensely monitored elections reported that a higher proportion of polling stations (28 percent) was monitored in their constituencies, on average, compared to those who had fewer monitors (who reported that only 13 percent of stations were monitored), which represents a 15 percentage points increase. ${ }^{30}$ These estimates are similar to the concentration of monitors, on average, as shown in Table F.4 in Appendix F. While these results are not statistically significant at conventional levels they provide suggestive evidence that incumbents noticed the significant presence of observers in their constituencies during the 2012 election. I argue that this awareness, coupled with the reduction in fraud and violence induced by observers or the significant challenge in executing fraud pose by intense monitoring, signaled to MPs that they could not rely on future rigging.

Testing the second condition, that MPs' past experiences influence their beliefs about the future, is more challenging. It is not clear that incumbents' experiences with observers in their constituencies at time $t-1$ will automatically shape their beliefs about the intensity of observation in time $t+1$. While we can safely assume that MPs would expect some future monitoring in their constituencies because CODEO is credibly committed to observing each election, we cannot be certain about the intensity of observation that MPs would expect. Furthermore, we cannot be sure that these expectations map onto the treatment assignment in the 2012 elections. While the above results on the effect of AIO on politician performance imply incumbents were behaving as if they expected intense election observation, a randomized treatment to manipulate beliefs about future monitoring would allow making causal claims about the expectation of sanctioning mechanism.

\footnotetext{
${ }^{29}$ See Appendix F Table F.3.

${ }^{30}$ See Appendix F Table F.4. Since only 18 MPs responded to this survey question, this result is not statistically significant and only suggestive.
} 
To test the causal effect of expected intense monitoring on responsiveness, I analyze the outcome of my follow-up experiment that sent letters to half of the MPs in the sample a year before the 2016 elections. ${ }^{31}$ Columns (1) and (2) of Table 4 display the average proportion of CDF spent in 2016 by incumbents according to whether or not they received a letter to expect more observers, respectively and by the initially assigned intensity of monitoring. Column (3) shows the conditional effects of the letters by the prior AIO while Column (4) report the weighted average treatment effect. To assess potential interaction effects, I conduct a difference-in-difference (D-ID) analysis comparing the impact of the letters among legislators who were elected in low-versus high-intensely monitored elections. Column (5) report the results. Panels A, B, and C report the results for the total use of $\mathrm{CDF}$ (utilization), public goods, and private benefits, respectively. In all cells, standard errors of the estimates are reported in parentheses.

Consistent with expectations, the results presented in Panel A show that receiving a letter increased the proportion of CDF spent in 2016 by 4.9 (s.e. 8) percentage points (pp) (one-tailed test, $p=0.265)$, on average. The effect of the letter was slightly higher (1.2 pp (12.4) increase) among incumbents elected in low-AIO (5.9 pp (s.e. 8)) compared to those in high-AIO (4.6 (s.e. 9.4)) constituencies, but not precisely estimated. Nonetheless, these conditional effects are large (although not statistically significant), representing about a 23 and 10 percent increase in low- and high-AIO, respectively.

Disaggregating these results into public goods (Panel B) and private goods (Panel C), the latter seems to drive the average increase in CDF spending. Specifically, while, on average, MPs who received a letter did not substantially change their expenditure on public goods, they increased their spending on private benefits. Specifically, the letter treatment increased spending on private benefit by 3.6 (s.e. 3.2) pp (one-tailed test, $p=0.14$ ). For MPs who were elected in low-AIO districts, sending them a letter boosted their spending on individual benefits by $4.9 \mathrm{pp}$, a 58 percent increase. Those in high-intensity constituencies spent 3.2 pp more, a 30 percent increase in their

\footnotetext{
${ }^{31}$ Table G.1 in Appendix G presents the actual spending levels.
} 
expenditure on private benefits, compared to if they had not received the letter. These weighted average treatment effects masked the potential interaction between the AIO and EIO treatments.

A D-I-D analysis suggests that compared to legislators elected in low-AIO constituencies, the letter caused a further increase in spending on public goods by 4.1 (s.e. 7.8) pp and a decrease in the proportion of funds allocated to private benefits by 1.6 (s.e. 6.6) pp. These results suggest an interaction effect between the high-AIO and the letter treatments to increase spending on public goods further. Specifically, consistent with my argument, these results indicate that legislators who were elected in fairer elections and expected to contest their reelection in another one were more responsive to the priorities of their constituents which provide tentative causal evidence the threat of sanctioning through fairer election increase democratic responsiveness. However, I acknowledge that a design with greater statistical power is required to confirm these results.

Nevertheless, the fact that the EIO treatment led to an increase in spending on private benefits raises concerns about the potential for fairer elections to promote clientelistic exchanges. However, the timing of the letter treatment may explain this finding (i.e., an electoral cycle effect) (Michelitch and Utych, 2018). The letters were sent one year before the elections. Scholarly work on the accountability pressures that legislators face in clientelistic polities such as Ghana suggests that voters demand more private benefits during election years (Lindberg, 2010; Michelitch and Utych, 2018). Indeed, Appendix Figure E.6 shows that MPs spending on private transfers doubled during the election year (from $6 \%$ in 2014, on average, to 12\% in 2015 and 2016, a 100 percent rise) while that on public goods decreased (12\% in 2014, 32\% in 2015 and $24 \%$ in 2016, a 25\% decrease between 2015 and 2016). Accordingly, the treatment may have further incentivized incumbents to respond to these demands. 
Table 4: Effect of expectation of intense election monitoring conditional on prior intensity of observation

\begin{tabular}{|c|c|c|c|c|c|c|}
\hline \multirow[b]{2}{*}{ Type of spending } & \multirow[b]{2}{*}{ Intensity of observation } & \multicolumn{2}{|c|}{ Expected IO } & \multirow{2}{*}{$\begin{array}{l}\text { Conditional ATEs } \\
\text { EOI (letters) } \\
\text { (3) }\end{array}$} & \multirow{2}{*}{$\begin{array}{l}\text { Weighted ATE } \\
\text { EOI (letters) } \\
\text { (4) }\end{array}$} & \multirow{2}{*}{$\begin{array}{l}\text { D-I-D } \\
\text { estimate } \\
\text { (5) }\end{array}$} \\
\hline & & $\begin{array}{l}\text { Received letter } \\
\text { (1) }\end{array}$ & $\begin{array}{l}\text { No letter sent } \\
(2)\end{array}$ & & & \\
\hline \multicolumn{7}{|c|}{ Panel A: Utilization (total) } \\
\hline & High & $\begin{array}{c}0.517 \\
(0.071) \\
(\mathrm{N}=21)\end{array}$ & $\begin{array}{c}0.471 \\
(0.062) \\
(\mathrm{N}=26)\end{array}$ & $\begin{array}{c}0.046 \\
(0.094)\end{array}$ & $\begin{array}{c}\text { 0.049 } \\
(\mathbf{0 . 0 7 5})\end{array}$ & $\begin{array}{l}-0.012 \\
(\mathbf{0 . 1 2 4})\end{array}$ \\
\hline & Low & $\begin{array}{c}0.318 \\
(0.068) \\
(\mathrm{N}=9)\end{array}$ & $\begin{array}{c}0.259 \\
(0.045) \\
(\mathrm{N}=4)\end{array}$ & $\begin{array}{c}0.059 \\
(0.082)\end{array}$ & $\begin{array}{c}\text { CI 90\%: }[-0.074,0.171] \\
\text { P-value }=0.265\end{array}$ & $\begin{array}{c}\text { CI 90\%: }[-0.217,0.193] \\
\text { P-value }=0.529\end{array}$ \\
\hline \multicolumn{7}{|c|}{ Panel B: Public Goods } \\
\hline & High & $\begin{array}{l}0.282 \\
(0.056) \\
(\mathrm{N}=21)\end{array}$ & $\begin{array}{c}0.266 \\
(0.045) \\
(\mathrm{N}=26)\end{array}$ & $\begin{array}{c}0.016 \\
(0.072)\end{array}$ & $\begin{array}{c}0.007 \\
(\mathbf{0 . 0 5 6})\end{array}$ & $\begin{array}{c}0.041 \\
(0.078)\end{array}$ \\
\hline & Low & $\begin{array}{c}0.092 \\
(0.022) \\
(\mathrm{N}=9)\end{array}$ & $\begin{array}{c}0.118 \\
(0.024) \\
(\mathrm{N}=4) \\
\end{array}$ & $\begin{array}{l}-0.026 \\
(0.033)\end{array}$ & $\begin{array}{c}\text { CI 90\%: }[-0.083,0.010] \\
\text { P-value }=0.459\end{array}$ & $\begin{array}{c}\text { CI 90\%: }[-0.082,0.173] \\
\text { P-value }=0.40\end{array}$ \\
\hline \multicolumn{7}{|c|}{ Panel C: Private Goods } \\
\hline & High & $\begin{array}{c}0.137 \\
(0.029) \\
(\mathrm{N}=21)\end{array}$ & $\begin{array}{c}0.105 \\
(0.025) \\
(\mathrm{N}=26)\end{array}$ & $\begin{array}{c}0.032 \\
(0.038)\end{array}$ & $\begin{array}{r}\mathbf{0 . 0 3 6} \\
(\mathbf{0 . 0 3 2})\end{array}$ & $\begin{array}{r}-0.016 \\
(\mathbf{0 . 0 6 6})\end{array}$ \\
\hline & Low & $\begin{array}{c}0.134 \\
(0.039) \\
(\mathrm{N}=9)\end{array}$ & $\begin{array}{c}0.084 \\
(0.038) \\
(\mathrm{N}=4)\end{array}$ & $\begin{array}{c}0.049 \\
(0.055)\end{array}$ & $\begin{array}{c}\text { CI 90\%: }[-0.016,0.089] \\
\text { P-value }=0.138\end{array}$ & $\begin{array}{c}\text { CI 90\%: }[-0.127,0.092] \\
\text { P-value }=0.416\end{array}$ \\
\hline
\end{tabular}

Notes: Table 4 shows the proportion of legislator spending in each experimental cell. It also shows the effect of expectation of intense observation on spending conditional on prior intensity of election monitoring in MPs' constituencies (blocking variable), and the corresponding weighted ATEs. Randomization inference (accounting for the blocks) is used to generate the standard errors and the one-tailed test of the sharp null of no effect for each MP for the estimated weighted ATEs. 90\% confidence intervals are estimated using boostrapping. I conducted 10,000 simulations. 
I do not find support for two alternative explanations for the effect of the initial treatment on political responsiveness. The first indicates that the AIO treatment may have strengthened citizens' pressure on the incumbent to supply constituency service. Using Afrobarometer data of respondents sampled from my study constituencies, I show in Appendix Table F.5 that the treatment had no influence on the number of times constituents report to have contacted their MPs, attended community meetings, joined a group to raised an issue, request government action, contacted local government officials, or their beliefs that it the duty of voters to ensure MPs do their work once elected. ${ }^{32}$ Second, the AIO treatment did not affect the number of candidates competing in the next election in 2016, which would indicate incumbents' fear of the entry of new challengers encouraged by cleaner elections (Besley, 2005; Grossman and Michelitch, 2018) (see Table F.6). Ghana's strong two-party system ensures that similar number of candidates usually run in each constituency. ${ }^{33}$

\section{Conclusion}

In this article, I combine experimental research designs and original data on legislator spending and records on parliamentary attendance to investigate whether and how fair elections incentivize political responsiveness. The results indicate that legislators elected in electoral districts that were randomly assigned to intense election-day monitoring, and thus had limited opportunities for fraud, worked harder during their four-year terms in office to satisfy their constituents' demand for local public goods and services compared to those elected in constituencies with fewer observers. The treatment did not change MP's provision of private benefits to constituents. Experimental and observational data suggest that the effect of fairer election, induced by intense election observation,

\footnotetext{
${ }^{32} \mathrm{The} \mathrm{AB}$ data is not representative at the constituency level, but my analysis here captures the attitudes of citizens sampled from electoral districts in the different treatment conditions.

${ }^{33} \mathrm{Also}$, it is unlikely that treatment influenced the performance of incumbents through their expectation that CODEO, the observation group, will monitor their spending and attendance in parliament because the organization does not conduct such audits.
} 
is better explained by incumbents' beliefs about their potential inability to rig their reelection balloting, and that citizens' selection of better candidates to office, in the first place, played a minimal role. Together, these results provide, to my knowledge, one of the first systematic analysis of the causal relationship between election integrity and political responsiveness.

The results have implications for both pro-democracy actors and scholars of democratic consolidation and electoral fraud. For promoters of democracy, they suggest that systematic election monitoring by local civil society groups plays a significant role in promoting electoral integrity, which corroborates earlier findings, and that election observation eventually promotes democratic accountability. However, Ghana's strong two-party system and a well-established civil society groups, which regularly monitor national and local elections and make the threat of electoral sanction more credible, may drive these results. Accordingly, efforts to strengthen such independent civil society organizations, which now operates in more than 60 developing countries around the world (see Grömping, 2017), may be required to achieve similar results elsewhere. Future research in such settings using the research designed proposed in this study would provide a more robust test of the external validity of the findings. Also, while I focus on election observation, the primary findings suggest that institutions such as independent election management bodies, and biometric voter registration and voting systems that significant reduce electoral fraud hold the potential to improve political responsiveness. However, the timing of such interventions along the electoral cycle may be relevant to the type of response. Finally, my findings suggests that because elections remain the primary mechanism through which citizens demand accountability from their representatives in many settings, attention must be paid not only to the regular conduct of elections, but also to strengthening their integrity.

Finally, while these results provide optimism about our beliefs regarding the connection between fairer elections and democratic responsiveness, the limited number of cases in the study, and the challenge to replicating the design under same conditions, implies that this article does not provide a final word on the topic. My goal was to leverage a rare opportunity to provide 
initial insights on a critical assumption - fairer elections incentivize democratic responsiveness - that motivates many theories of electoral accountability. I hope that this study will motivate other scholars to employ similar research designs to further investigate this topic. These additional studies will provide greater confidence in the main findings of the paper. 


\section{References}

Annan, Kofi, Ernesto Z. Ponce de Léon, Martti Ahtisaari, Madeleine K. Albright et al. 2012. "Deepening democracy: a strategy for improving the integrity of elections worldwide. Report of the Global Commission on Elections." Democracy and Security, Stockholm .

Ashworth, Scott. 2012. "Electoral accountability: recent theoretical and empirical work." Annual Review of Political Science 15:183-201.

Ashworth, Scott and Ethan Bueno de Mesquita. 2006. "Delivering the goods: Legislative particularism in different electoral and institutional settings." Journal of Politics 68(1):168-179.

Asunka, Joseph. 2017. "Non-discretionary resource allocation as political investment: evidence from Ghana." The Journal of Modern African Studies 55(1):29-53.

Asunka, Joseph, Sarah Brierley, Miriam Golden, Eric Kramon and George Ofosu. 2019. "Electoral fraud or violence: The effect of observers on party manipulation strategies." British Journal of Political Science pp. 1-23.

Baird, Sarah, J Aislinn Bohren, Craig McIntosh and Berk Özler. 2016. "Optimal design of experiments in the presence of interference." Review of Economics and Statistics (0).

Baldwin, Kate. 2013. "Why vote with the chief? Political connections and public goods provision in Zambia.” American Journal of Political Science 57(4):794-809.

Barkan, Joel D. 2009. "African legislatures and the "Third Wave” of democratization." Legislative power in emerging African democracies pp. 1-31.

Barkan, Joel D., Robert Mattes, Shaheen Mozaffar and Kimberly Smiddy. 2010. The African Legislatures Project: First Findings. Centre for Social Science Research.

Baskin, Mark. 2014. Introduction: Are Constituency Development Funds a Policy Tool. Lexington Books chapter 1, pp. 1-26.

Bates, Robert H. 2008. When Things Fell Apart: State Failure in Late-Century Africa. Cambridge University Press.

Berman, Eli, Michael J. Callen, Clark Gibson and James D Long. 2014. Election fairness and government legitimacy in Afghanistan. Technical report National Bureau of Economic Research.

Besley, Timothy. 2005. "Political selection." The Journal of Economic Perspectives 19(3):43-60.

Birch, Sarah. 2010. "Perceptions of electoral fairness and voter turnout." Comparative Political Studies 43(12):1601-1622.

Bjornlund, Eric. 2004. Beyond free and fair: Monitoring elections and building democracy. Woodrow Wilson Center Press. 
Bratton, Michael. 2013. Voting and democratic citizenship in Africa. Lynne Rienner Publishers chapter Where do elections lead in Africa?, pp. 17-38.

Bruhn, Miriam and David McKenzie. 2009. "In pursuit of balance: Randomization in practice in development field experiments." American economic journal: applied economics 1(4):200-232.

Callen, Michael, Clark C Gibson, Danielle F Jung and James D Long. 2016. “Improving electoral integrity with information and communications technology." Journal of Experimental Political Science 3(01):4-17.

Carothers, Thomas. 1997. “The observers observed.” Journal of Democracy 8(3):17-31.

Chernozhukov, Victor and Christian Hansen. 2008. "The reduced form: A simple approach to inference with weak instruments." Economics Letters 100(1):68-71.

Collier, Paul and Anke Hoeffler. 2015. "Do elections matter for economic performance?" Oxford Bulletin of Economics and Statistics 77(1):1-21.

Diaz-Cayeros, Alberto, Federico Estévez and Beatriz Magaloni. 2016. The political logic of poverty relief: Electoral strategies and social policy in Mexico. Cambridge University Press.

Dunning, Thad, Guy Grossman, Macartan Humphreys, Susan Hyde and Craig McIntosh. 2019. Metaketa I: The Limits of Electoral Accountability. Cambridge University Press.

Ejdemyr, Simon, Eric Kramon and Amanda Lea Robinson. 2017. "Segregation, ethnic favoritism, and the strategic targeting of local public goods." Comparative Political Studies p. 0010414017730079.

Enikolopov, Ruben, Vasily Korovkin, Maria Petrova, Konstantin Sonin and Alexei Zakharov. 2013. "Field experiment estimate of electoral fraud in Russian parliamentary elections." Proceedings of the National Academy of Sciences 110(2):448-452.

Fearon, James D. 1999. Electoral accountability and the control of politicians: selecting good types versus sanctioning poor performance. In Democracy, Accountability, and Representation, ed. Adam Przeworski, Susan C. Stokes and Bernard Manin. New York: Cambridge University Press pp. 55-97.

Fenno, Richard F. 1978. Home style: House members in their districts. Pearson College Division.

Ferejohn, John. 1986. "Incumbent performance and electoral control.” Public Choice 50(1):5-25.

Galasso, Vincenzo and Tommaso Nannicini. 2011. “Competing on good politicians.” American Political Science Review 105(01):79-99.

Gerber, Alan S and Donald P Green. 2012. Field experiments: Design, analysis, and interpretation. WW Norton. 
Grömping, Max. 2017. "Domestic Election Monitoring and Advocacy: An Emerging Research Agenda." Nordic Journal of Human Rights 35(4):407-423.

Grossman, Guy and Kristin Michelitch. 2018. "Information Dissemination, Competitive Pressure, and Politician Performance between Elections: A Field Experiment in Uganda." American Political Science Review pp. 1-22.

Gyimah-Boadi, Emmanuel. 2007. Votes, money and violence: political parties and elections in Sub-Saharan Africa. Nordiska Afrikainstitutet; Kwazulu-Natal Press, South Africa chapter Political parties, elections and patronage: Random thoughts on neo-patrimonialism and African democratization, pp. 21-33.

Gyimah-Boadi, Emmanuel. 2009. “Another step forward for Ghana.” Journal of Democracy 20(2):138-152.

Harding, Robin. 2015. "Attribution and accountability: Voting for roads in Ghana." World Politics 67(04):656-689.

Harris, J. Andrew and Daniel N. Posner. 2019. "(Under what conditions) Do politicians reward their supporters? Evidence from Kenya's Constituency Development Fund." American Political Science Review.

Humphreys, Macartan and Jeremy M. Weinstein. 2012. "Policing Politicians: Citizen Empower and Political Accountability in Uganda (Preliminary Analysis)." Working paper http://cucsds.org/wp-content/uploads/2009/10/ABCDE-paper.pdf.

Hyde, Susan D. 2008. "The Obsever Effect in International Politics:Evidence from a Natural Experiment." World Politics 60(1):37-63.

Ichino, Nahomi and Matthias Schündeln. 2012. "Deterring or displacing electoral irregularities? Spillover effects of observers in a randomized field experiment in Ghana." The Journal of Politics 74(01):292-307.

Ichino, Nahomi and Noah L Nathan. 2012. "Primaries on demand? Intra-party politics and nominations in ghana." British Journal of Political Science 42(4):769-791.

Ichino, Nahomi and Noah L Nathan. 2013. "Crossing the line: Local ethnic geography and voting in Ghana." American Political Science Review 107(2):344-361.

Jockers, Heinz, Dirk Kohnert and Paul Nugent. 2010. "The successful Ghana election of 2008: a convenient myth?" The Journal of Modern African Studies 48(01):95-115.

Keefer, Philip and Stuti Khemani. 2009. "When Do Legislators Pass on Pork? The Role of Political Parties in Determining Legislator Effort.” American Political Science Review 103:99-112.

Kramon, Eric. 2016. "Electoral Handouts as Information: Explaining Unmonitored Vote Buying." World Politics 68(3):454-498. 
Lindberg, Staffan I. 2010. "What accountability pressures do MPs in Africa face and how do they respond? Evidence from Ghana." The Journal of Modern African Studies 48(01):117-142.

Long, J Scott and Laurie H Ervin. 2000. "Using heteroscedasticity consistent standard errors in the linear regression model." The American Statistician 54(3):217-224.

Magaloni, Beatriz. 2006. Voting for autocracy: Hegemonic party survival and its demise in Mexico. Cambridge University Press Cambridge.

Mayhew, David R. 1974. Congress: The electoral connection. Yale University Press.

Michelitch, Kristin and Stephen Utych. 2018. "Electoral cycle fluctuations in partisanship: Global evidence from eighty-six countries." The Journal of Politics 80(2):412-427.

Ninsin, Kwame A. 2016. Issues in Ghana's Electoral Politics. Dakar: CODESRIA chapter Elections and Representation in Ghana's Democracy, pp. 115-134.

Norris, Pippa. 2014. Why electoral integrity matters. Cambridge University Press.

Olken, Benjamin A. 2007. "Monitoring corruption: evidence from a field experiment in Indonesia." Journal of Political Economy 115(2):200-249.

Pitkin, Hanna Fenichel. 1967. The concept of representation. Univ of California Press.

Posner, Daniel N. 2005. Institutions and ethnic politics in Africa. Cambridge University Press.

Powell, G. Bingham. 2005. Assessing the quality of democracy. The Johns Hopkins University Press chapter The chain of responsiveness, pp. 61-76.

Reardon, Sean F and David O'Sullivan. 2004. "Measures of spatial segregation.” Sociological methodology 34(1):121-162.

Simpser, Alberto. 2008. "Cheating big: On the logic of electoral corruption in developing countries." University of Chicago, Department of Political Science .

Straus, Scott and Charlie Taylor. 2012. Democratization and Electoral Violence in Sub-Saharan Africa, 1990-2008. In Voting in Fear, ed. Dorina A. Bekoe. Washington, D.C.: United States Institute of Peace.

van de Walle, Nicolas. 2003. "Presidentialism and clientelism in Africa's emerging party systems." The Journal of Modern African Studies 41(02):297-321.

van Ham, Carolien. 2009. Beyond Electoralism? Electoral fraud in third wave regimes PhD thesis University of Leiden.

Vieta, Kojo T. 2013. Know Your MPs (2013-2017). Flagbearers Publishers.

Wantchekon, Leonard. 2003. "Clientelism and voting behavior: Evidence from a field experiment in Benin.” World Politics 55(03):399-422. 
Williams, Martin J. 2017. "The political economy of unfinished development projects: corruption, clientelism, or collective choice?" American Political Science Review 111(4):705-723. 


\section{Online Appendix}

\section{A Summary statistics of sampled constituences and covariate balance}

Table A.1: Summary statistics of sampled constituencies

\begin{tabular}{|c|c|c|c|c|c|}
\hline \multirow[b]{2}{*}{ Variable } & \multicolumn{2}{|c|}{ Constituencies } & \multirow[b]{2}{*}{ Min } & \multirow[b]{2}{*}{ Max } & \multirow[b]{2}{*}{ P-value (KS-test) } \\
\hline & $\begin{array}{c}\text { Study region } \\
\mathrm{N}=122\end{array}$ & $\begin{array}{c}\text { Sample } \\
\mathrm{N}=60\end{array}$ & & & \\
\hline \multicolumn{6}{|c|}{ Part A: Constituency electoral characteristics } \\
\hline \# Polling stations & $\begin{array}{c}96.074 \\
(30.707)\end{array}$ & $\begin{array}{c}99.333 \\
(30.049)\end{array}$ & 36 & 174 & 0.989 \\
\hline Log \# Voters & $\begin{array}{l}10.788 \\
(0.402)\end{array}$ & $\begin{array}{l}10.830 \\
(0.376)\end{array}$ & 9.399 & 11.630 & 0.598 \\
\hline \# Candidates (2012) & $\begin{array}{l}4.496 \\
(0.887)\end{array}$ & $\begin{array}{c}4.517 \\
(0.868)\end{array}$ & 3 & 8 & 0.996 \\
\hline Area (km. sq.) & $\begin{array}{c}651.986 \\
(605.497)\end{array}$ & $\begin{array}{c}711.375 \\
(653.081)\end{array}$ & 3.064 & $3,710.232$ & 0.996 \\
\hline Distance to constituency (Km) & $\begin{array}{l}185.681 \\
(60.560)\end{array}$ & $\begin{array}{l}183.182 \\
(65.234)\end{array}$ & 27.951 & 321.141 & 0.989 \\
\hline Voter density (\# voters/Area (km. sq.)) & $\begin{array}{c}817.401 \\
(2,837.714)\end{array}$ & $\begin{array}{c}501.435 \\
(1,117.443)\end{array}$ & 3.256 & $25,611.890$ & 1.000 \\
\hline \multicolumn{6}{|c|}{ Part B: Constituency characteristics-district census } \\
\hline Rural population & $\begin{array}{c}0.587 \\
(0.291)\end{array}$ & $\begin{array}{c}0.557 \\
(0.290)\end{array}$ & 0.00003 & 1 & 0.887 \\
\hline Proportion of pop. with electricity & $\begin{array}{c}0.586 \\
(0.188)\end{array}$ & $\begin{array}{c}0.584 \\
(0.177)\end{array}$ & 0.258 & 0.893 & 0.985 \\
\hline Fuel (electric and gas) & $\begin{array}{c}0.112 \\
(0.112)\end{array}$ & $\begin{array}{c}0.111 \\
(0.110)\end{array}$ & 0.006 & 0.358 & 1.000 \\
\hline Cement walls & $\begin{array}{c}0.532 \\
(0.227)\end{array}$ & $\begin{array}{c}0.539 \\
(0.210)\end{array}$ & 0.076 & 0.886 & 0.911 \\
\hline Muslim population & $\begin{array}{c}0.105 \\
(0.063)\end{array}$ & $\begin{array}{c}0.107 \\
(0.074)\end{array}$ & 0.009 & 0.445 & 1.000 \\
\hline Population in Agriculture & $\begin{array}{c}0.463 \\
(0.247)\end{array}$ & $\begin{array}{c}0.465 \\
(0.240)\end{array}$ & 0.033 & 0.846 & 0.998 \\
\hline$\%$ Ashanti & $\begin{array}{c}0.256 \\
(0.295)\end{array}$ & $\begin{array}{c}0.257 \\
(0.303)\end{array}$ & 0.001 & 0.855 & 1.000 \\
\hline$\%$ Fante & $\begin{array}{c}0.165 \\
(0.250)\end{array}$ & $\begin{array}{c}0.147 \\
(0.231)\end{array}$ & 0.001 & 0.945 & 0.907 \\
\hline$\%$ Ewe & $\begin{array}{c}0.188 \\
(0.300)\end{array}$ & $\begin{array}{c}0.197 \\
(0.318)\end{array}$ & 0.004 & 0.957 & 0.970 \\
\hline$\%$ Dagomba & $\begin{array}{c}0.007 \\
(0.011)\end{array}$ & $\begin{array}{c}0.008 \\
(0.013)\end{array}$ & 0 & 0.088 & 1.000 \\
\hline Education (primary or less) & $\begin{array}{c}0.905 \\
(0.062)\end{array}$ & $\begin{array}{c}0.902 \\
(0.068)\end{array}$ & 0.674 & 0.983 & 1.000 \\
\hline Employed & $\begin{array}{c}0.498 \\
(0.047)\end{array}$ & $\begin{array}{c}0.495 \\
(0.046)\end{array}$ & 0.396 & 0.634 & 1.000 \\
\hline
\end{tabular}

Notes: Table A.1 shows the summary statistics of constituencies in the four regions of the study and the sample. I obtained data on the electoral characteristics of constituencies from Ghana's Electoral Commission. To calculate distances from the capital to constituencies, I use the geocode function in the ggmap package in R to take the geocordinates of constituency capitals. Using the geo-coordinates of Ghana's parliament, I calculated the euclidean distances between constituency capitals and the Parliament. Data on the socio-economic characteristics of constituencies are from Ghana's 2010 national census. 
Table A.2: Covariate balance: AIO treatment (two treatment arms)

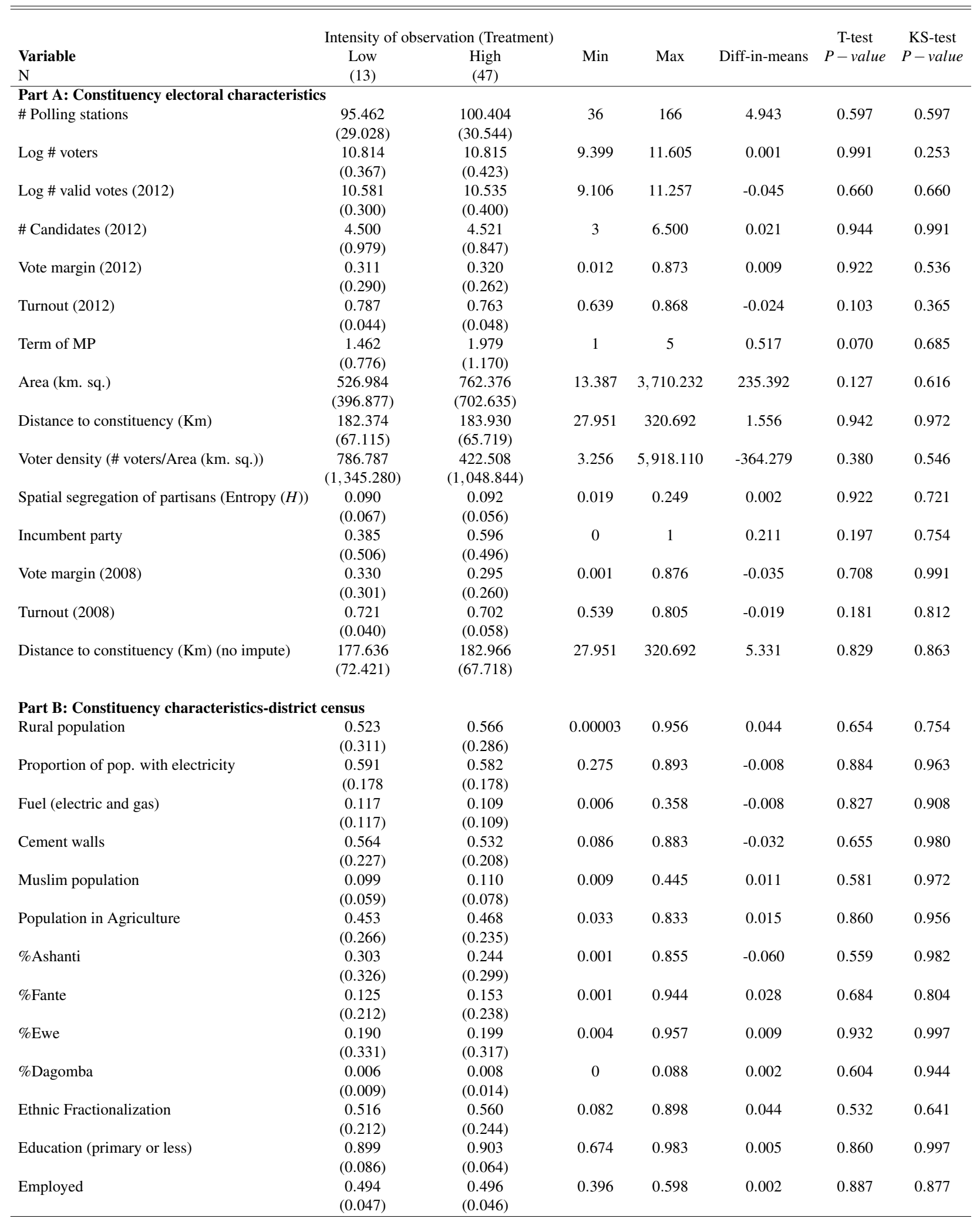


Table A.3: Covariate balance: AIO treatment (three treatment arms)

\begin{tabular}{|c|c|c|c|c|c|c|}
\hline \multirow[b]{2}{*}{$\begin{array}{l}\text { Variable } \\
\mathrm{N}\end{array}$} & \multicolumn{3}{|c|}{ Intensity of observation (Treatment) } & \multicolumn{3}{|c|}{ P-value (KS-test) } \\
\hline & $\begin{array}{l}\text { Low } \\
\text { (13) }\end{array}$ & $\begin{array}{l}\text { Medium } \\
(24)\end{array}$ & $\begin{array}{c}\text { High } \\
(23)\end{array}$ & Low vs. Medium & Low vs. High & Medium vs. High \\
\hline \multicolumn{7}{|l|}{ Part A: Constituency electoral characteristics } \\
\hline \# Polling stations & $\begin{array}{c}95.462 \\
(29.028)\end{array}$ & $\begin{array}{l}100.083 \\
(31.887)\end{array}$ & $\begin{array}{l}100.739 \\
(29.791)\end{array}$ & 0.484 & 0.483 & 0.958 \\
\hline Log \# Voters & $\begin{array}{l}10.814 \\
(0.367)\end{array}$ & $\begin{array}{c}10.788 \\
(0.500)\end{array}$ & $\begin{array}{l}10.844 \\
(0.333)\end{array}$ & 0.467 & 0.241 & 0.864 \\
\hline Log valid votes (2012) & $\begin{array}{l}10.581 \\
(0.300)\end{array}$ & $\begin{array}{l}10.486 \\
(0.470)\end{array}$ & $\begin{array}{l}10.587 \\
(0.313)\end{array}$ & 0.577 & 0.706 & 0.833 \\
\hline \# Candidates (2012) & $\begin{array}{c}4.500 \\
(0.979)\end{array}$ & $\begin{array}{c}4.542 \\
(0.920)\end{array}$ & $\begin{array}{c}4.500 \\
(0.783)\end{array}$ & 1.000 & 0.957 & 1.000 \\
\hline Vote margin (2012) & $\begin{array}{c}0.311 \\
(0.290)\end{array}$ & $\begin{array}{c}0.264 \\
(0.238)\end{array}$ & $\begin{array}{c}0.378 \\
(0.278)\end{array}$ & 0.729 & 0.566 & 0.273 \\
\hline Turnout (2012) & $\begin{array}{c}0.787 \\
(0.044)\end{array}$ & $\begin{array}{c}0.758 \\
(0.044)\end{array}$ & $\begin{array}{c}0.768 \\
(0.052)\end{array}$ & 0.329 & 0.631 & 0.792 \\
\hline Term of MP & $\begin{array}{c}1.462 \\
(0.776)\end{array}$ & $\begin{array}{c}2.167 \\
(1.373)\end{array}$ & $\begin{array}{c}1.783 \\
(0.902)\end{array}$ & 0.745 & 0.841 & 0.932 \\
\hline Area (km. sq.) & $\begin{array}{c}526.984 \\
(396.877)\end{array}$ & $\begin{array}{c}929.261 \\
(858.774)\end{array}$ & $\begin{array}{c}588.236 \\
(446.287)\end{array}$ & 0.360 & 0.963 & 0.345 \\
\hline Distance to constituency $(\mathrm{Km})$ & $\begin{array}{l}182.374 \\
(67.115)\end{array}$ & $\begin{array}{l}182.697 \\
(61.085)\end{array}$ & $\begin{array}{l}185.216 \\
(71.597)\end{array}$ & 0.997 & 0.880 & 1.000 \\
\hline Voter density (\# voters/Area (km. sq.)) & $\begin{array}{c}786.787 \\
(1,345.280)\end{array}$ & $\begin{array}{c}498.218 \\
(1,327.712)\end{array}$ & $\begin{array}{c}343.505 \\
(666.657)\end{array}$ & 0.139 & 0.864 & 0.098 \\
\hline Spatial segregation of partisans (Entropy $(H))$ & $\begin{array}{c}0.090 \\
(0.067)\end{array}$ & $\begin{array}{c}0.084 \\
(0.036)\end{array}$ & $\begin{array}{c}0.101 \\
(0.071)\end{array}$ & 0.617 & 0.906 & 0.339 \\
\hline Incumbent party & $\begin{array}{c}0.385 \\
(0.506)\end{array}$ & $\begin{array}{c}0.708 \\
(0.464)\end{array}$ & $\begin{array}{c}0.478 \\
(0.511)\end{array}$ & 0.340 & 1.000 & 0.563 \\
\hline Vote margin (2008) & $\begin{array}{c}0.330 \\
(0.301)\end{array}$ & $\begin{array}{c}0.213 \\
(0.208)\end{array}$ & $\begin{array}{c}0.381 \\
(0.285)\end{array}$ & 0.484 & 0.768 & 0.097 \\
\hline Turnout (2008) & $\begin{array}{l}0.721 \\
(0.040\end{array}$ & $\begin{array}{l}0.702 \\
(0.054\end{array}$ & $\begin{array}{c}0.703 \\
(0.064\end{array}$ & 0.513 & 0.784 & 0.553 \\
\hline Distance to constituency (Km) (no impute) & $\begin{array}{c}177.636 \\
(72.421)\end{array}$ & $\begin{array}{l}182.817 \\
(63.867)\end{array}$ & $\begin{array}{l}183.102 \\
(72.544)\end{array}$ & 0.939 & 0.843 & 0.996 \\
\hline \multicolumn{7}{|c|}{ Part B: Constituency characteristics-district census } \\
\hline Rural population & $\begin{array}{c}0.523 \\
(0.311)\end{array}$ & $\begin{array}{c}0.588 \\
(0.309)\end{array}$ & $\begin{array}{c}0.544 \\
(0.265)\end{array}$ & 0.513 & 0.933 & 0.698 \\
\hline Proportion of pop. with electricity & $\begin{array}{c}0.591 \\
(0.178)\end{array}$ & $\begin{array}{c}0.556 \\
(0.192)\end{array}$ & $\begin{array}{c}0.610 \\
(0.162)\end{array}$ & 0.636 & 0.841 & 0.189 \\
\hline Fuel (electric and gas) & $\begin{array}{c}0.117 \\
(0.117)\end{array}$ & $\begin{array}{c}0.103 \\
(0.120)\end{array}$ & $\begin{array}{c}0.116 \\
(0.098)\end{array}$ & 0.543 & 0.933 & 0.174 \\
\hline Cement walls & $\begin{array}{c}0.564 \\
(0.227)\end{array}$ & $\begin{array}{c}0.497 \\
(0.216)\end{array}$ & $\begin{array}{c}0.570 \\
(0.196)\end{array}$ & 0.364 & 1.000 & 0.089 \\
\hline Muslim population & $\begin{array}{c}0.099 \\
(0.059)\end{array}$ & $\begin{array}{c}0.099 \\
(0.046)\end{array}$ & $\begin{array}{c}0.121 \\
(0.101)\end{array}$ & 0.991 & 0.880 & 0.573 \\
\hline Population in Agriculture & $\begin{array}{c}0.453 \\
(0.266)\end{array}$ & $\begin{array}{c}0.510 \\
(0.249)\end{array}$ & $\begin{array}{c}0.424 \\
(0.216)\end{array}$ & 0.513 & 0.439 & 0.089 \\
\hline$\%$ Ashanti & $\begin{array}{c}0.303 \\
(0.326)\end{array}$ & $\begin{array}{c}0.209 \\
(0.292)\end{array}$ & $\begin{array}{c}0.279 \\
(0.309)\end{array}$ & 0.956 & 0.995 & 0.938 \\
\hline$\%$ Fante & $\begin{array}{c}0.125 \\
(0.212)\end{array}$ & $\begin{array}{c}0.217 \\
(0.287)\end{array}$ & $\begin{array}{c}0.086 \\
(0.153)\end{array}$ & 0.574 & 0.813 & 0.359 \\
\hline$\%$ Ewe & $\begin{array}{c}0.190 \\
(0.331)\end{array}$ & $\begin{array}{c}0.176 \\
(0.291)\end{array}$ & $\begin{array}{c}0.222 \\
0.348)\end{array}$ & 1.000 & 0.992 & 0.979 \\
\hline$\%$ Dagomba & $\begin{array}{c}0.006 \\
(0.009)\end{array}$ & $\begin{array}{c}0.006 \\
(0.008)\end{array}$ & $\begin{array}{c}0.010 \\
(0.019)\end{array}$ & 0.995 & 0.608 & 0.464 \\
\hline Ethnic Fractionalization & $\begin{array}{c}0.516 \\
(0.212)\end{array}$ & $\begin{array}{c}0.571 \\
(0.256)\end{array}$ & $\begin{array}{c}0.548 \\
(0.236)\end{array}$ & 0.513 & 0.827 & 0.760 \\
\hline Education (primary or less) & $\begin{array}{c}0.899 \\
(0.086)\end{array}$ & $\begin{array}{c}0.919 \\
(0.055)\end{array}$ & $\begin{array}{c}0.887 \\
(0.069)\end{array}$ & 0.513 & 0.657 & 0.017 \\
\hline Employed & $\begin{array}{c}0.494 \\
(0.047)\end{array}$ & $\begin{array}{c}0.510 \\
(0.043)\end{array}$ & $\begin{array}{c}0.481 \\
(0.046)\end{array}$ & 0.652 & 0.359 & 0.017 \\
\hline
\end{tabular}


Figure A.1: Quantile-quantile plots of covariates by treatment (electoral characteristics)

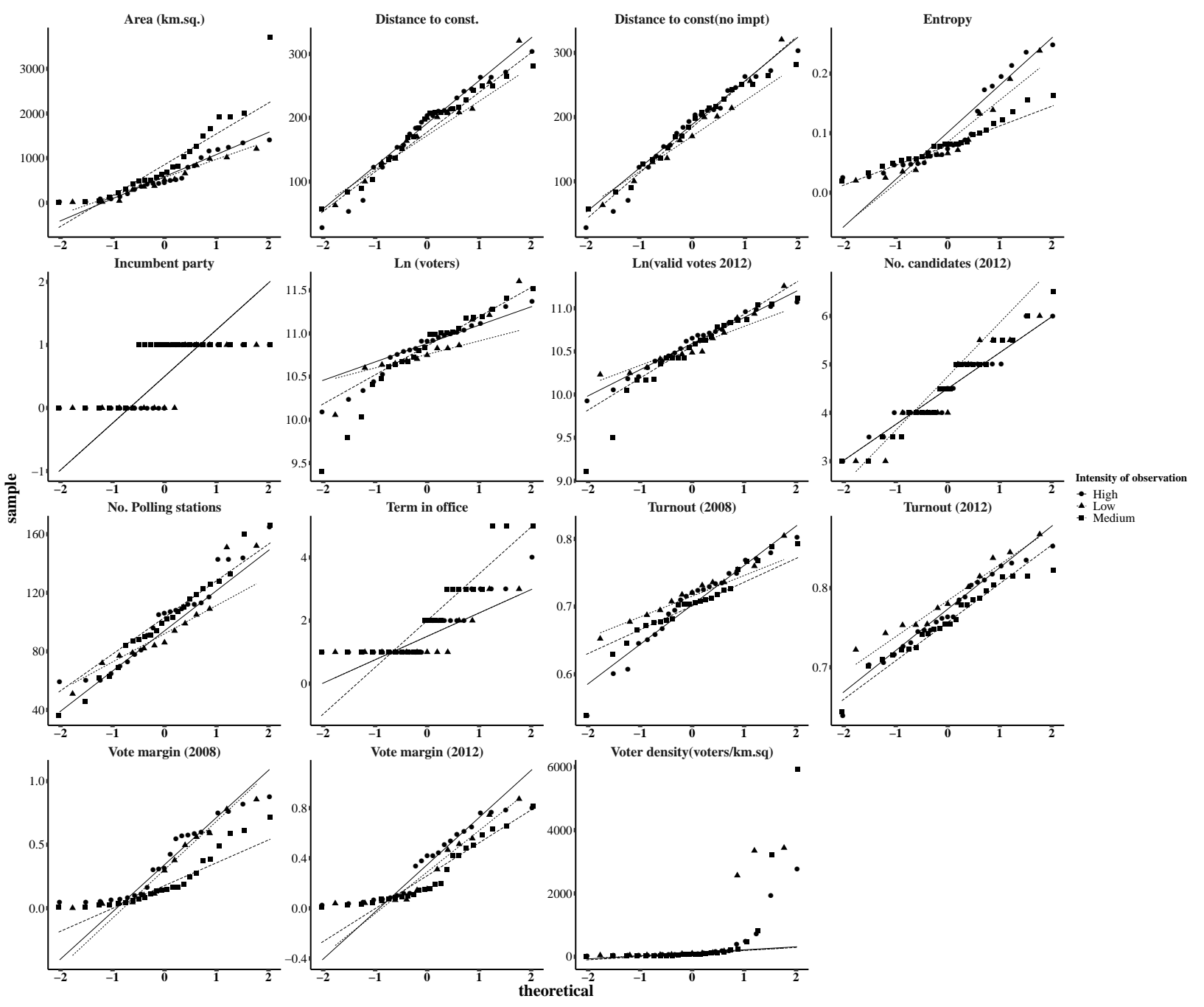


Figure A.2: Quantile-quantile plots of covariates by treatment (district census)
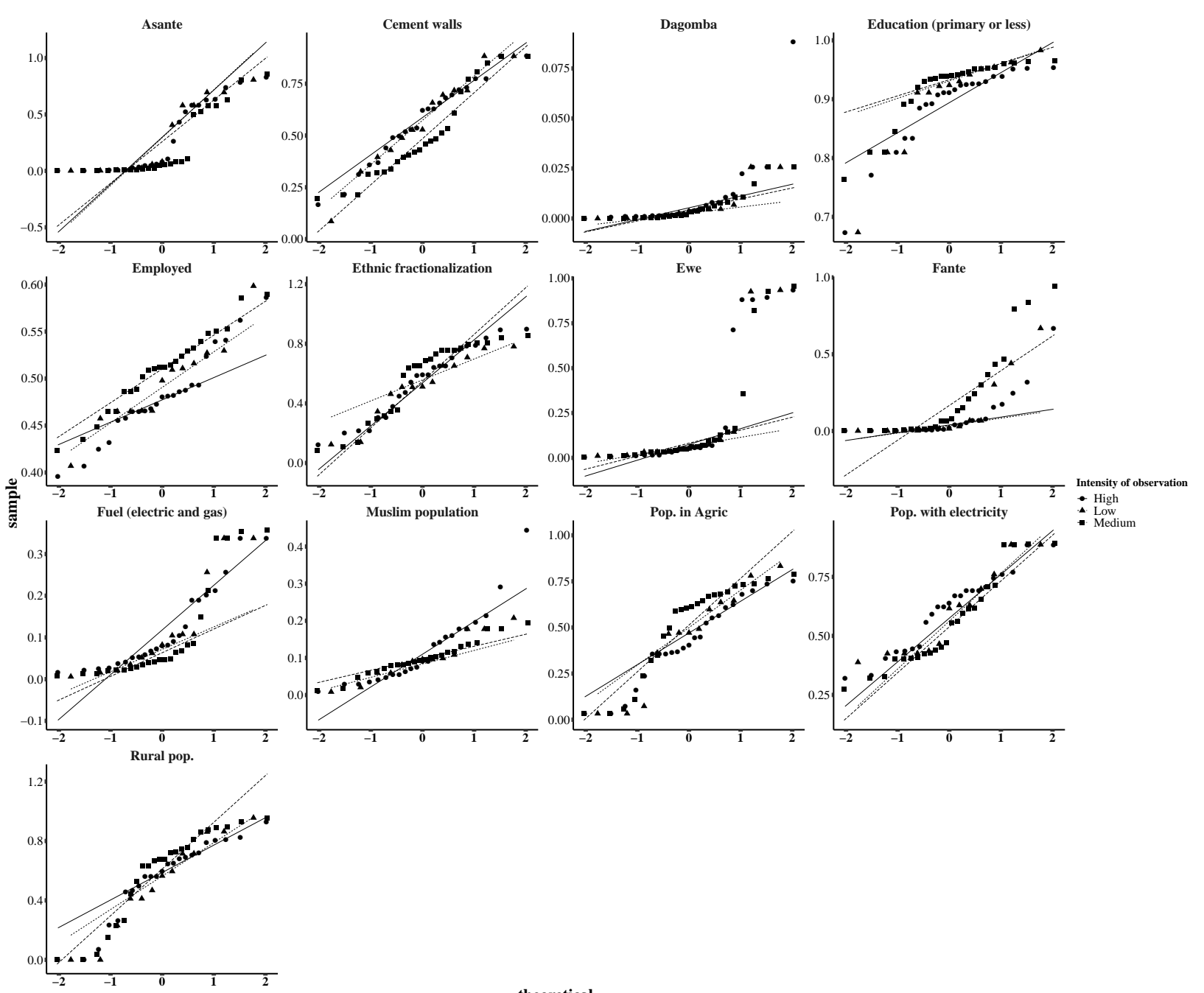

theoretical 
Table A.4: Covariate balance: post-election survey of citizens' assessments of the performance of 2012 incumbent MPs and reported vote choice in 2008

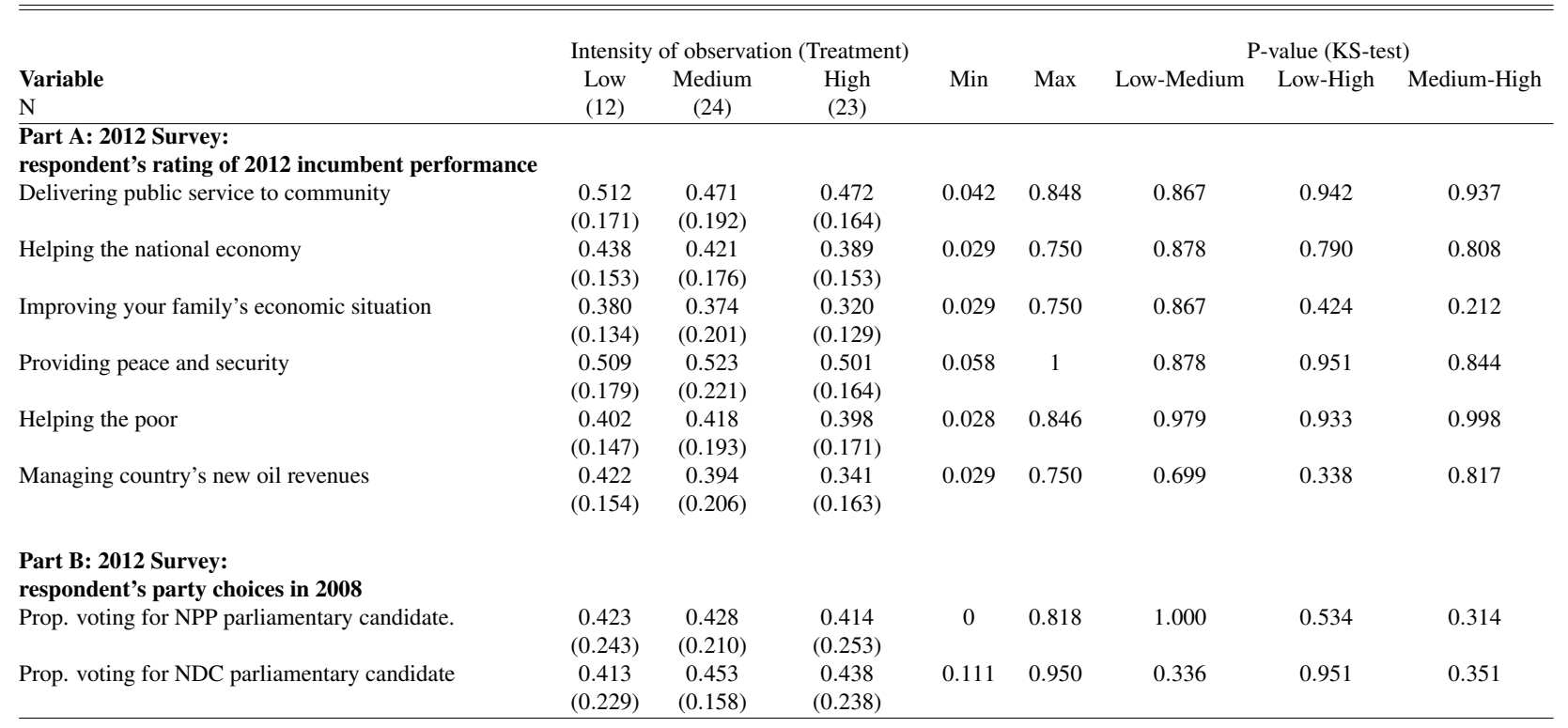

Notes: Part A of Table A.4 shows balance for citizens' ratings for their MP who served 2009-2013 terms in a postelection survey $(\mathrm{N}=6176)$ that I conducted with my collaborators immediately after the 2012 elections. These ratings were in response to the question was: "How would you rate your incumbent MP's performance in the following areas?" Respondents had five options: "excellent," "good," "fair," "poor," and "don't know." I created a dummy with the the first two options taking a value of 1 . Accordingly, the average across treatment represents the proportion of respondents who believed the incumbent had performed "excellent" or "good." Part B of Table A.4 reports voters' reported vote choice in the prior (2008) parliamentary elections. The data is then summarized at the constituency level. Standard standard deviations of the group means are reported in parentheses. P-values corresponding to a two-sample T-tests and Kolmogorov-Smirnov test are reported. 
Figure A.3: Quantile-quantile plots of covariates by treatment: post-election survey of citizens' assessments of the performance of 2012 incumbent MPs and reported vote choice in 2008

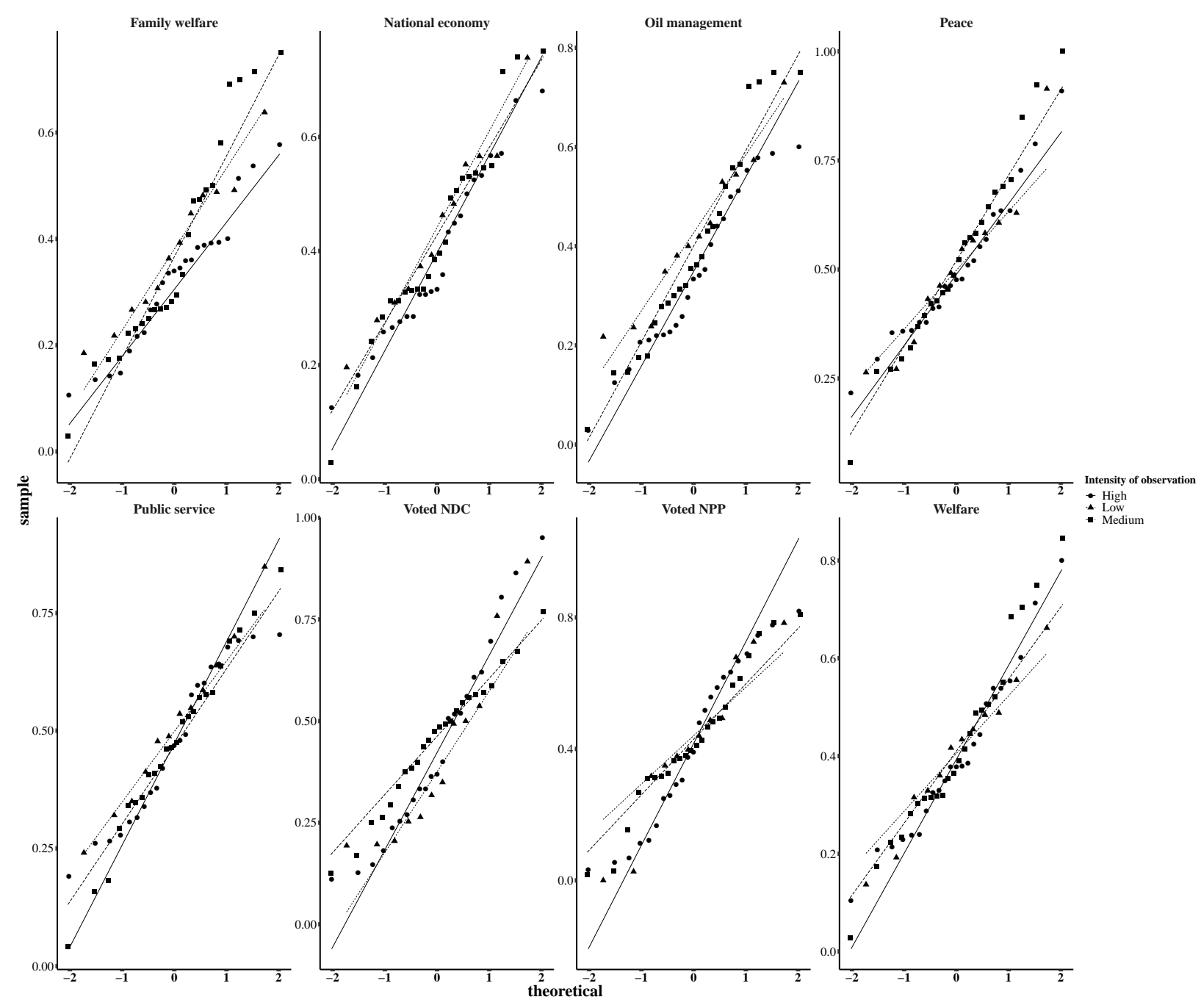


Table A.5: Covariate balance: letter treatment (EIO)

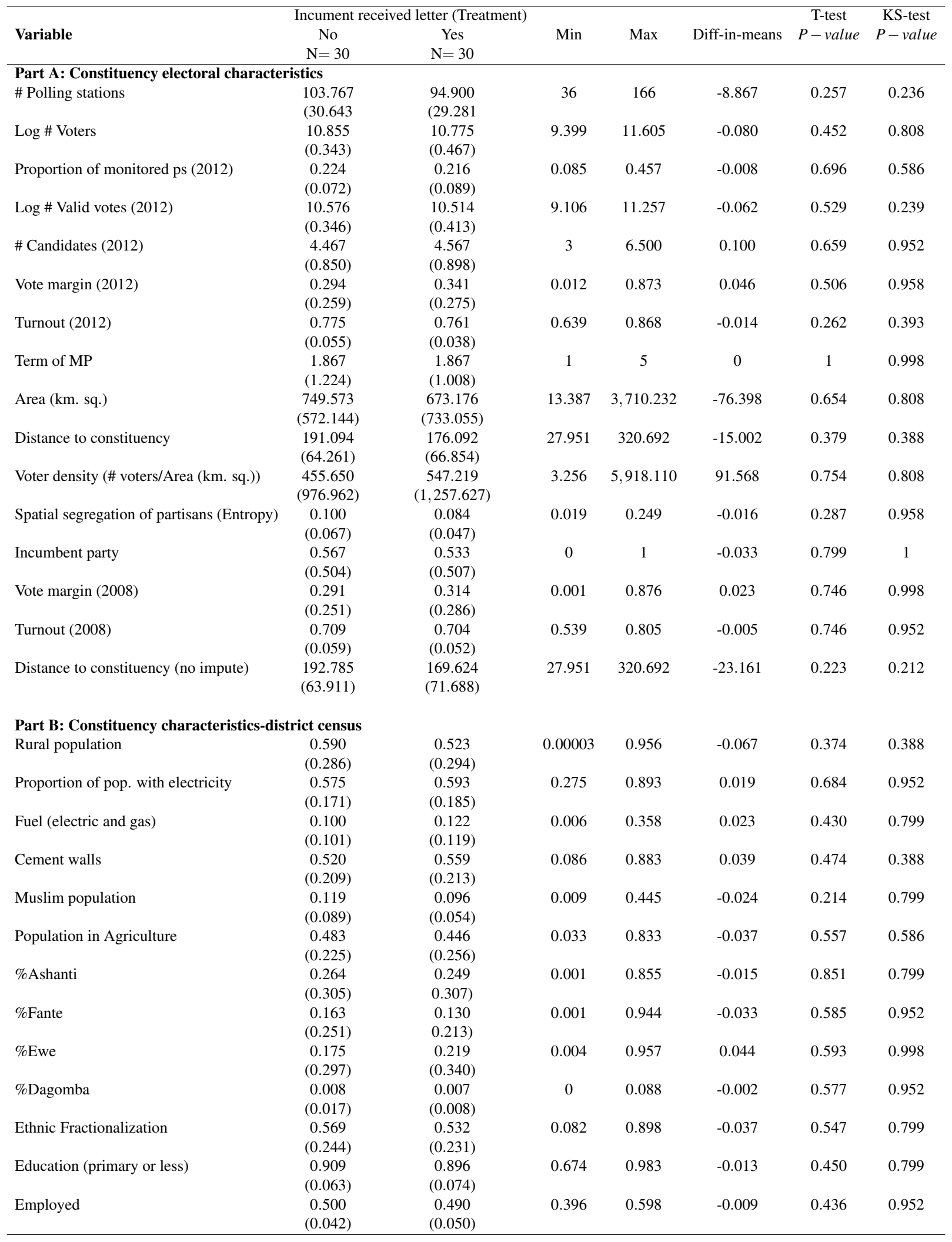

Notes: Table A.5 shows the covariate balance for electgal and geographic variables across treatments. I ran 58 iterations of randomization until I obtained a treatment and control group where the smallest p-value associated with the covariates' difference in means was $p$-value $\geq 0.21$. This approach is referred to as "big stick" method (Bruhn and McKenzie, 2009). I used the randomize function from the ri package in R specifying the AIO as the block. 


\section{B Treatment letters}

Figure B.1: Treatment: letter to Members of Parliament

PHONE:

EMAIL:

November 15, 2015

Dear Hon. «MP»:

As you may recall, I asked during our interview whether you or your agents saw independent election observers at polling stations in your constituency during last year's elections. In 2012, I was part of a research team from [redacted] that worked with CODEO to study the impact of observers on election day irregularities at a sample of the polling stations in the country. As part of this study, some constituencies were randomly selected to have a higher proportion (about 80 percent) of their polling stations monitored by observers during the polls.

We found that constituencies that had a higher proportion of their polling stations monitored by observers had lower incidence of electoral fraud. This was a credit to domestic election observation and the important role they play in promoting electoral integrity and democracy in Ghana.

To validate our finding, I am seeking to collaborate with CODEO to repeat this study in a random set of constituencies. While I await confirmation to implement this study, I have already selected my sample of constituencies and randomly assigned some to have about 80 percent of stations observed. As a courtesy, I want to inform you that your constituency happened to be one of those that will receive observers at 80 percent of stations.

I will get back in touch with you once I have confirmation that the study will go ahead, but I am at this point very hopeful that it will happen.

Sincerely, 
Figure B.2: Treatment: follow-up letter to Members of Parliament

PHONE:

EMAIL:

April 15, 2016

«title» «MP_name_new»

«CON_NAME»

«address»

«location».

Dear Hon. «MP_name_new»:

Thank you for your participation in my MPs' survey last year (November and December, 2015).

As you may recall, I mentioned that I am seeking to collaborate with the Coalition of Domestic Election Observers (CODEO) to study the impact of domestic election observers on election day processes in Ghana's November 2016 general elections. While I await confirmation to implement this study, I have already selected my sample of constituencies and randomly assigned some to have about 80 percent of stations observed by CODEO monitors.

As a courtesy, I want to remind you that your constituency is one of those that would receive observers at 80 percent of polling stations on election day.

I will get back in touch with you once I have confirmation that the study will go ahead, but I am at this point very hopeful that it will happen.

Sincerely, 


\section{What constituents want from their Members of Parliament in Ghana}

Figure C.1: Constituents' preferences

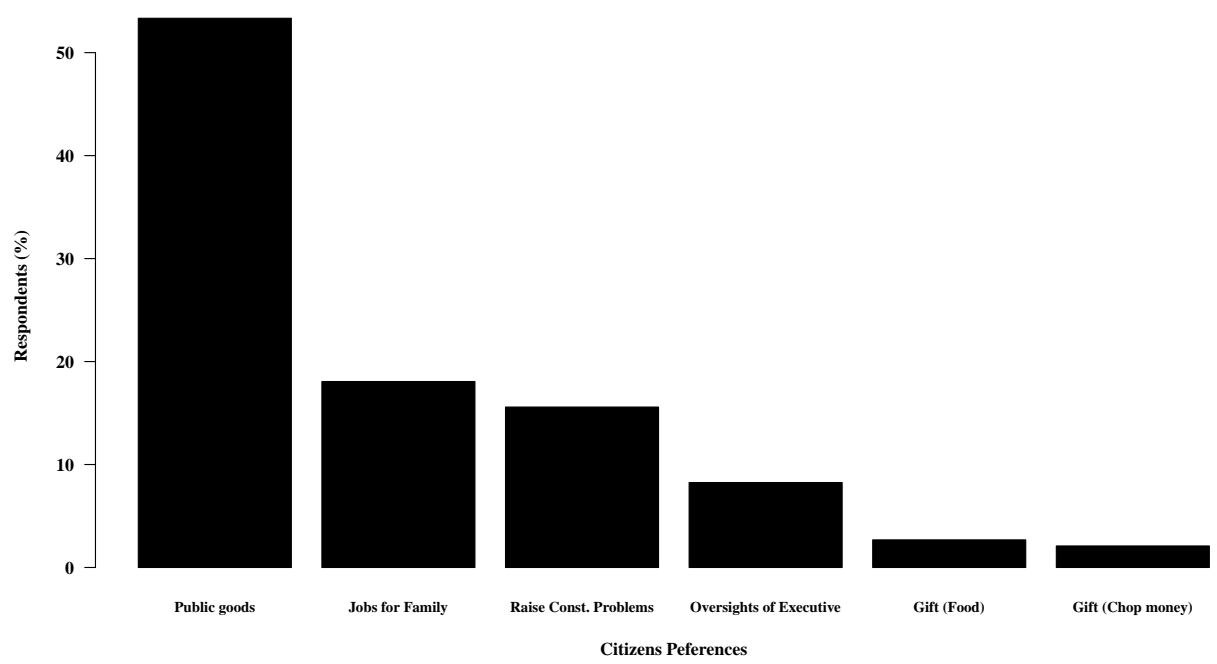

Notes:

1. Response to the question: "You said you would probably vote for the parliamentary candidate of ... if the election was held today. Consider if another candidate from another party did one of the following things, and tell me which ONE could possibly make you switch."

2. Source: Data shared by Cheeseman, Lynch, and Wallis (2015)

\section{Density distribution of dependent variables across treatment conditions}


Figure D.1: Density plots of the percentages of CDFs used by MPs across treatments conditions
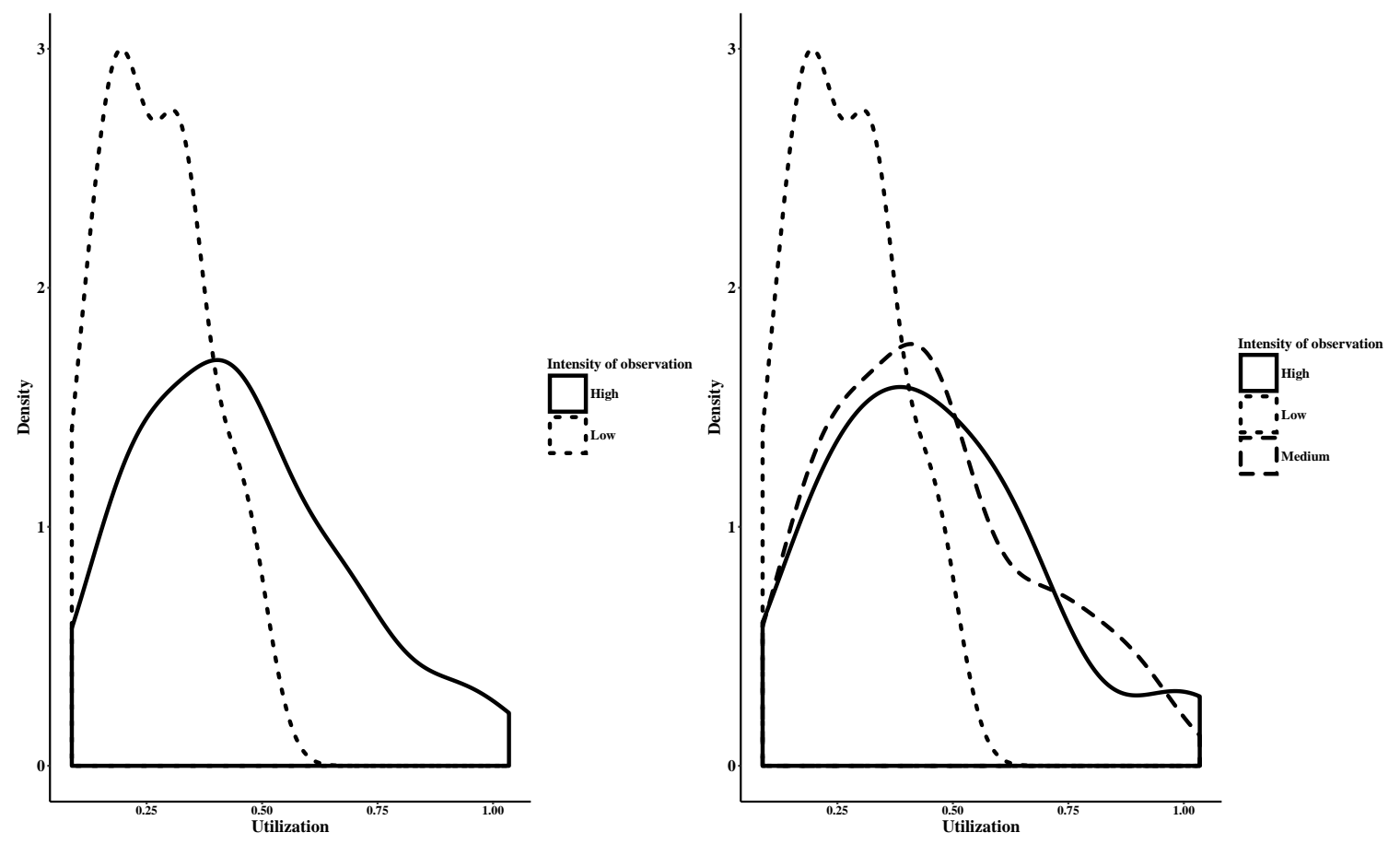

Figure D.2: Density plots of the percentages of CDFs used by MPs for public and private goods provision by treatment conditions
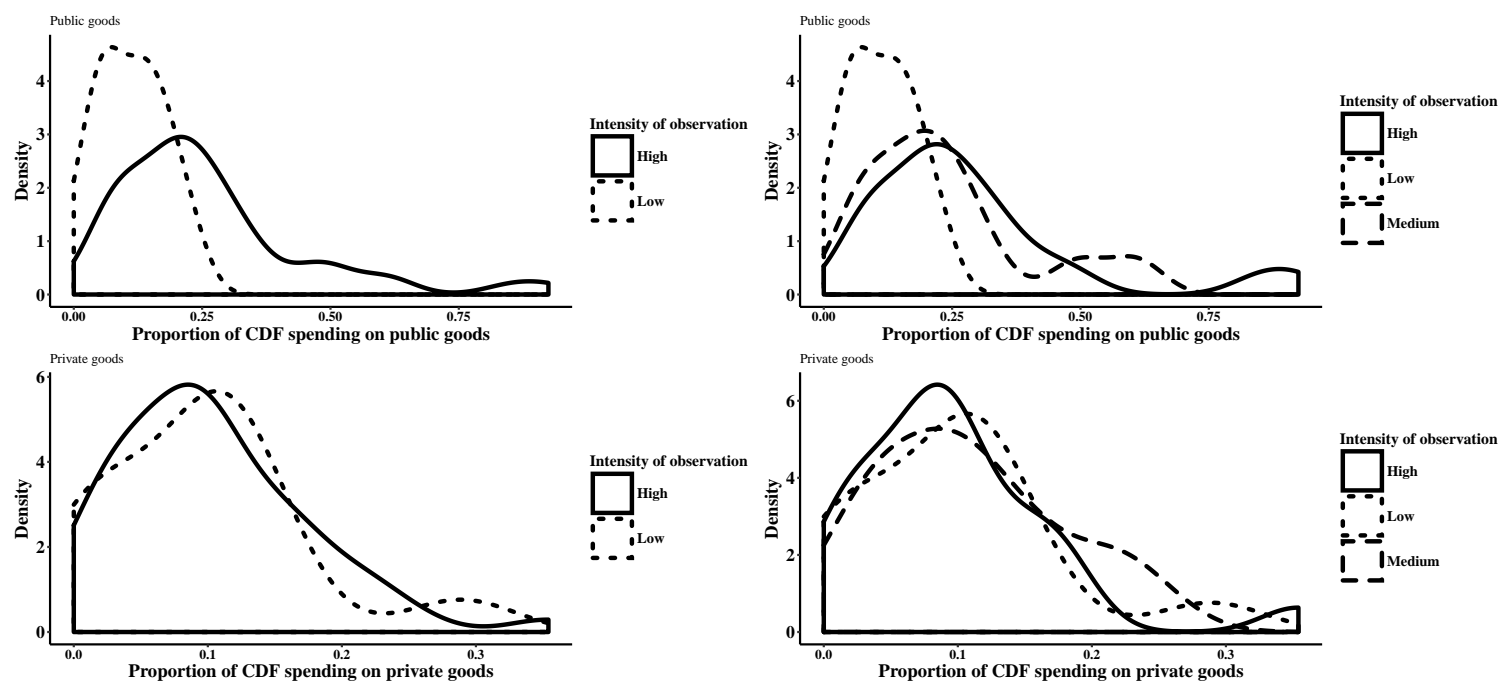


\section{E Main Effect Tables and Robustness checks}

In this section, I show that the main results reported in Section 4 across the three treatment arms. I also show that a handful of constituencies or outliers do not drive the results. Specifically, to ensure that the results presented in Section 4 are not artifacts of the small sample size, I use randomization inference to estimate 10,000 average ITTs under the sharp null hypothesis of no effect for each unit. Figure E.1 and E.4 show the distribution for the two and three treatment arms, respectively. To examine whether the results presented in Section 4 is not driven by one influential case, I reestimate the average ITT effects coefficients 59 times sequentially removing one observation at a time. The estimated ITT effects for utilization, and public and private expenditures are displayed in Figures E.3. Finally, I use bootstrapping to estimate the $95 \%$ confidence intervals that bounds these estimates, which ensures the inclusion and exclusion of few constituencies do not drive the result. Figures E.2 and E.4 show the distribution of the estimated average ITT effects in 10,000 re-randomization of the the sample of constituencies with replacement.

\section{E.1 Main results}


Table E.1: Average CDF spending across six expenditure categories by the intensity of election observation

\begin{tabular}{|c|c|c|c|c|c|c|c|c|c|c|c|c|}
\hline & \multicolumn{3}{|c|}{$\begin{array}{l}\text { Total } \\
\text { GHC }\end{array}$} & \multicolumn{3}{|c|}{2014} & \multicolumn{3}{|c|}{2015} & \multicolumn{3}{|c|}{2016} \\
\hline & Inte & sity of Observ & tion & Inter & ity of Obser & ation & & sity of Obse & ation & & sity of Obse & ation \\
\hline Expenditure Category & $\begin{array}{l}\text { Low } \\
\text { (1) }\end{array}$ & $\begin{array}{l}\text { Medium } \\
\text { (2) }\end{array}$ & $\begin{array}{c}\text { High } \\
\text { (3) }\end{array}$ & $\begin{array}{c}\text { Low } \\
\text { (4) }\end{array}$ & $\begin{array}{l}\text { Medium } \\
\text { (5) }\end{array}$ & $\begin{array}{c}\text { High } \\
\text { (6) }\end{array}$ & $\begin{array}{l}\text { Low } \\
\text { (7) }\end{array}$ & $\begin{array}{l}\text { Medium } \\
\text { (8) }\end{array}$ & $\begin{array}{c}\text { High } \\
\text { (9) }\end{array}$ & $\begin{array}{l}\text { Low } \\
(10)\end{array}$ & $\begin{array}{l}\text { Medium } \\
\text { (11) }\end{array}$ & $\begin{array}{c}\text { High } \\
(12)\end{array}$ \\
\hline Public goods & $\begin{array}{l}140,041 \\
(85,995)\end{array}$ & $\begin{array}{c}299,421 \\
(209,280)\end{array}$ & $\begin{array}{c}366,009 \\
(277,270)\end{array}$ & $\begin{array}{c}17,744 \\
(19,296)\end{array}$ & $\begin{array}{c}45,913 \\
(47,724)\end{array}$ & $\begin{array}{c}51,548 \\
(48,625)\end{array}$ & $\begin{array}{c}70,845 \\
(54,498)\end{array}$ & $\begin{array}{l}119,611 \\
(87,539)\end{array}$ & $\begin{array}{c}174,306 \\
(146,857)\end{array}$ & $\begin{array}{c}51,451 \\
(30,471)\end{array}$ & $\begin{array}{c}139,719 \\
(113,964)\end{array}$ & $\begin{array}{r}140,155 \\
(132,608)\end{array}$ \\
\hline Private goods & $\begin{array}{l}122,003 \\
(95,047)\end{array}$ & $\begin{array}{l}136,081 \\
(88,798)\end{array}$ & $\begin{array}{l}123,311 \\
(96,892)\end{array}$ & $\begin{array}{c}15,735 \\
(17,445)\end{array}$ & $\begin{array}{c}22,896 \\
(24,496)\end{array}$ & $\begin{array}{c}19,379 \\
(17,404)\end{array}$ & $\begin{array}{c}45,434 \\
(34,476)\end{array}$ & $\begin{array}{c}48,530 \\
(36,506)\end{array}$ & $\begin{array}{c}49,144 \\
(38,327)\end{array}$ & $\begin{array}{c}60,834 \\
(54,550)\end{array}$ & $\begin{array}{c}67,466 \\
(59,401)\end{array}$ & $\begin{array}{c}54,788 \\
(71,832)\end{array}$ \\
\hline Donations to local groups & $\begin{array}{c}15,113 \\
(16,207)\end{array}$ & $\begin{array}{c}33,041 \\
(32,489)\end{array}$ & $\begin{array}{c}38,373 \\
(48,103)\end{array}$ & $\begin{array}{c}1,500 \\
(3,030)\end{array}$ & $\begin{array}{c}2,678 \\
(3,353)\end{array}$ & $\begin{array}{c}3,516 \\
(7,886)\end{array}$ & $\begin{array}{c}6,333 \\
(10,098)\end{array}$ & $\begin{array}{c}12,579 \\
(25,800)\end{array}$ & $\begin{array}{c}18,839 \\
(30,494)\end{array}$ & $\begin{array}{c}7,279 \\
(9,140)\end{array}$ & $\begin{array}{c}18,557 \\
(23,077)\end{array}$ & $\begin{array}{c}16,018 \\
(23,608)\end{array}$ \\
\hline Transfers to local government & $\begin{array}{c}9,675 \\
(17,452)\end{array}$ & $\begin{array}{c}57,709 \\
(75,222)\end{array}$ & $\begin{array}{c}31,856 \\
(69,932)\end{array}$ & $\begin{array}{c}1,316 \\
(2,571)\end{array}$ & $\begin{array}{c}12,897 \\
(19,345)\end{array}$ & $\begin{array}{c}4,593 \\
(9,647)\end{array}$ & $\begin{array}{c}1,735 \\
(3,748)\end{array}$ & $\begin{array}{c}30,102 \\
(64,134)\end{array}$ & $\begin{array}{c}4,328 \\
(6,246)\end{array}$ & $\begin{array}{c}6,625 \\
(16,268)\end{array}$ & $\begin{array}{c}15,349 \\
(21,367)\end{array}$ & $\begin{array}{c}22,935 \\
(67,526)\end{array}$ \\
\hline Monitoring and office expense & $\begin{array}{c}3,282 \\
(3,862)\end{array}$ & $\begin{array}{c}12,569 \\
(17,890)\end{array}$ & $\begin{array}{c}6,865 \\
(11,533)\end{array}$ & $\begin{array}{c}1,119 \\
(1,898)\end{array}$ & $\begin{array}{c}2,925 \\
(11,025)\end{array}$ & $\begin{array}{c}2,353 \\
(5,539)\end{array}$ & $\begin{array}{c}829 \\
(1,909)\end{array}$ & $\begin{array}{c}4,248 \\
(7,215)\end{array}$ & $\begin{array}{c}1,425 \\
(3,644)\end{array}$ & $\begin{array}{c}1,334 \\
(2,404)\end{array}$ & $\begin{array}{c}5,631 \\
(10,792)\end{array}$ & $\begin{array}{c}3,087 \\
(6,972)\end{array}$ \\
\hline Unclear purposed expenditure & $\begin{array}{c}46,516 \\
(61,455)\end{array}$ & $\begin{array}{c}22,506 \\
(40,568)\end{array}$ & $\begin{array}{c}19,885 \\
(28,982)\end{array}$ & $\begin{array}{c}4,806 \\
(16,501)\end{array}$ & $\begin{array}{c}3,551 \\
(7,536)\end{array}$ & $\begin{array}{c}1,192 \\
(3,386)\end{array}$ & $\begin{array}{c}15,330 \\
(27,414)\end{array}$ & $\begin{array}{c}8,126 \\
(15,310)\end{array}$ & $\begin{array}{c}9,367 \\
(21,510)\end{array}$ & $\begin{array}{c}26,380 \\
(43,123)\end{array}$ & $\begin{array}{c}11,300 \\
(34,554)\end{array}$ & $\begin{array}{c}9,326 \\
(19,238)\end{array}$ \\
\hline Total & $\begin{array}{c}336,630 \\
(144,758)\end{array}$ & $\begin{array}{c}561,328 \\
(284,893)\end{array}$ & $\begin{array}{c}586,299 \\
(304,484)\end{array}$ & $\begin{array}{c}42,221 \\
(28,445)\end{array}$ & $\begin{array}{c}90,860 \\
(69,452)\end{array}$ & $\begin{array}{c}82,580 \\
(59,078)\end{array}$ & $\begin{array}{l}140,506 \\
(67,151)\end{array}$ & $\begin{array}{c}223,197 \\
(141,639)\end{array}$ & $\begin{array}{c}257,409 \\
(146,699)\end{array}$ & $\begin{array}{c}153,903 \\
(89,591)\end{array}$ & $\begin{array}{c}258,022 \\
(159,395)\end{array}$ & $\begin{array}{r}246,310 \\
(164,706)\end{array}$ \\
\hline
\end{tabular}

Notes:

1. Table 2 shows the average amount of CDF funds spent by Members of Parliament (MPs) in the sample between 2014 and 2016 by treatment conditions. Standard deviations are reported in parentheses. Columns (1)-(2) shows total for the three year period while columns (3)-(8) breaks the spending for each year by treatment. These estimates suggest that MPs elected through intensely monitored election spent more of their available funds overall and in each year compared to their counterparts elected in constituencies with fewer monitors. Amounts are in Ghana Cedis $(\mathrm{GHC})(\$ 1 \approx 4)$.

2. Source: Author's coding of original expenditure sheets collected from Ghana's District Assemblies' Common Fund Administration.

Table E.2: ITT effect of intensity of observation on the use of CDF

\begin{tabular}{lcccc}
\hline \hline & \multicolumn{2}{c}{ Intensity of Observation } & ITT & P-value (RI) \\
\hline & Low & High & & \\
\hline Utilization & 0.266 & 0.457 & $0.190^{* * *}$ & 0.006 \\
& $(0.032)$ & $(0.033)$ & $(0.047)$ & \\
Public Goods & 0.111 & 0.264 & $0.153^{* * *}$ & 0.0079 \\
& $(0.019)$ & $(0.028)$ & $(0.034)$ & \\
Private Goods & 0.096 & 0.103 & 0.007 & 0.7739 \\
& $(0.021)$ & $(0.011)$ & $(0.024)$ & \\
\hline
\end{tabular}

Notes: Members of Parliament elected in high intensely monitored constituencies spent more of their available CDFs between 2014 and 2016 compared to those elected from low-intensely monitored electoral districts. Two-tailed randomization inference (RI) based on 10,000 permutation of the initial randomization. ${ }^{*} \mathrm{p}<0.1 ;{ }^{* *} \mathrm{p}<0.05 ;{ }^{* * *} \mathrm{p}<0.01$ 
Figure E.1: Distribution of average ITTs generated using randomization inference under the null hypothesis tests for main results (two treatment arms)
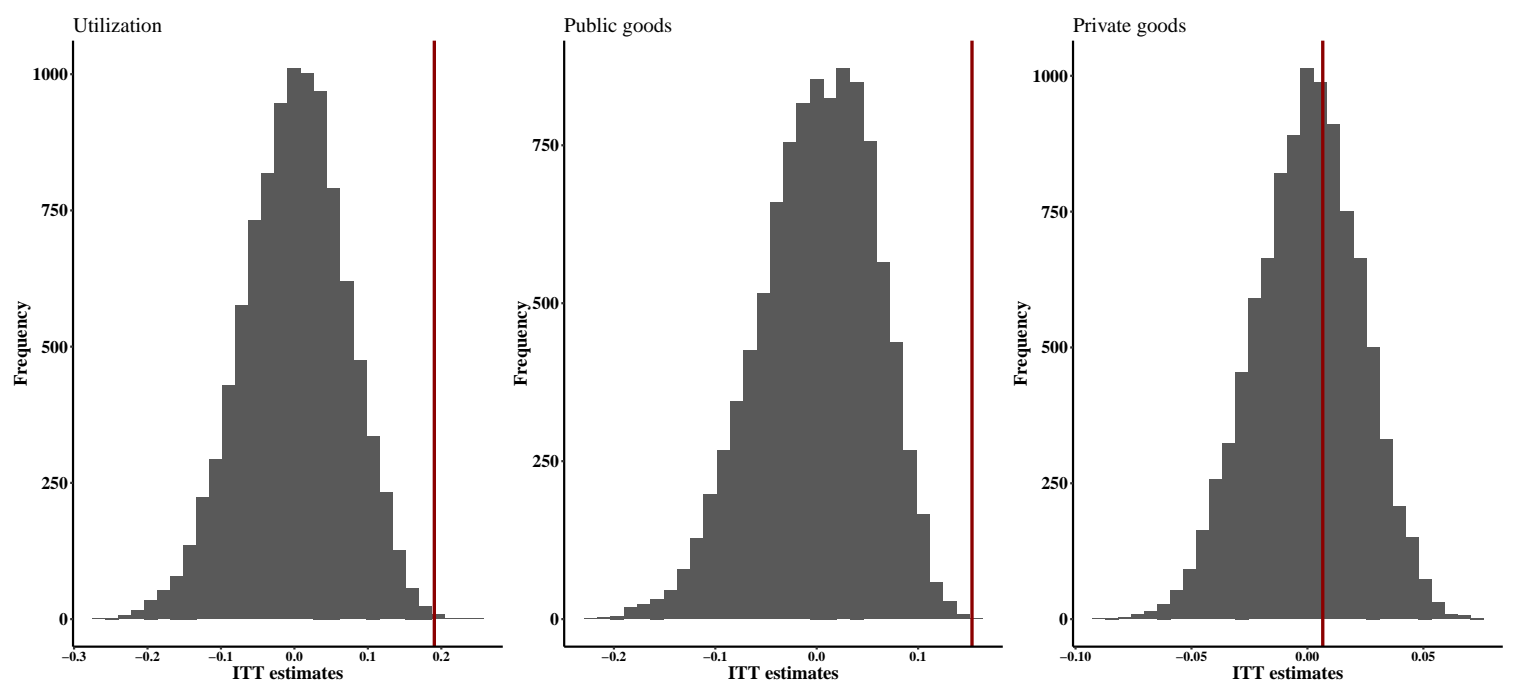

Notes: The red vertical lines indicate the estimated average ITT effect.

Figure E.2: Distribution of bootstrapped estimates of the average ITT effects (two treatment arms)
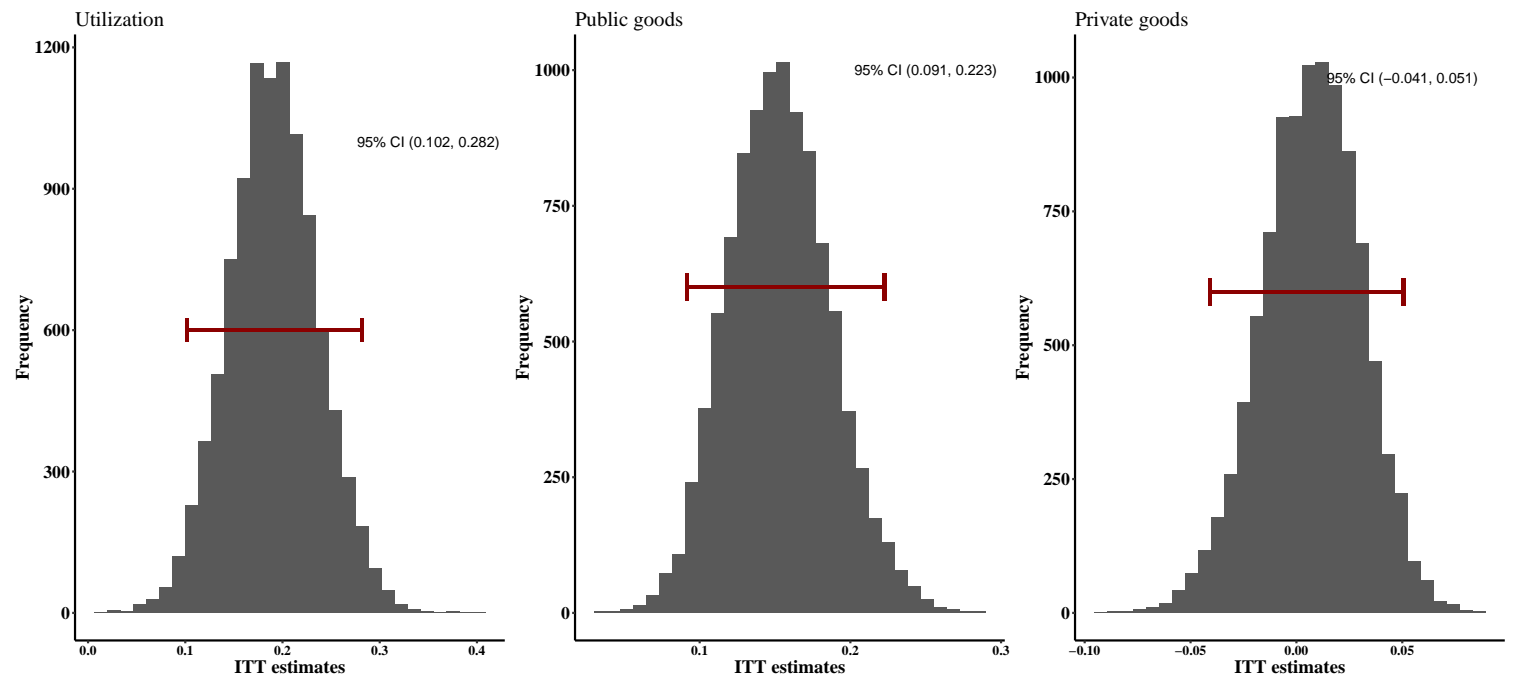

Notes: The red horizontal lines show the $95 \%$ confidence interval (i.e., 0.025 and .975 quantiles) of the distribution of the bootstrapped estimates of the average ITT effects. 
Figure E.3: Estimates of the ITT effect of intensity of observation on MPs' use of CDFs is not driven by a single case
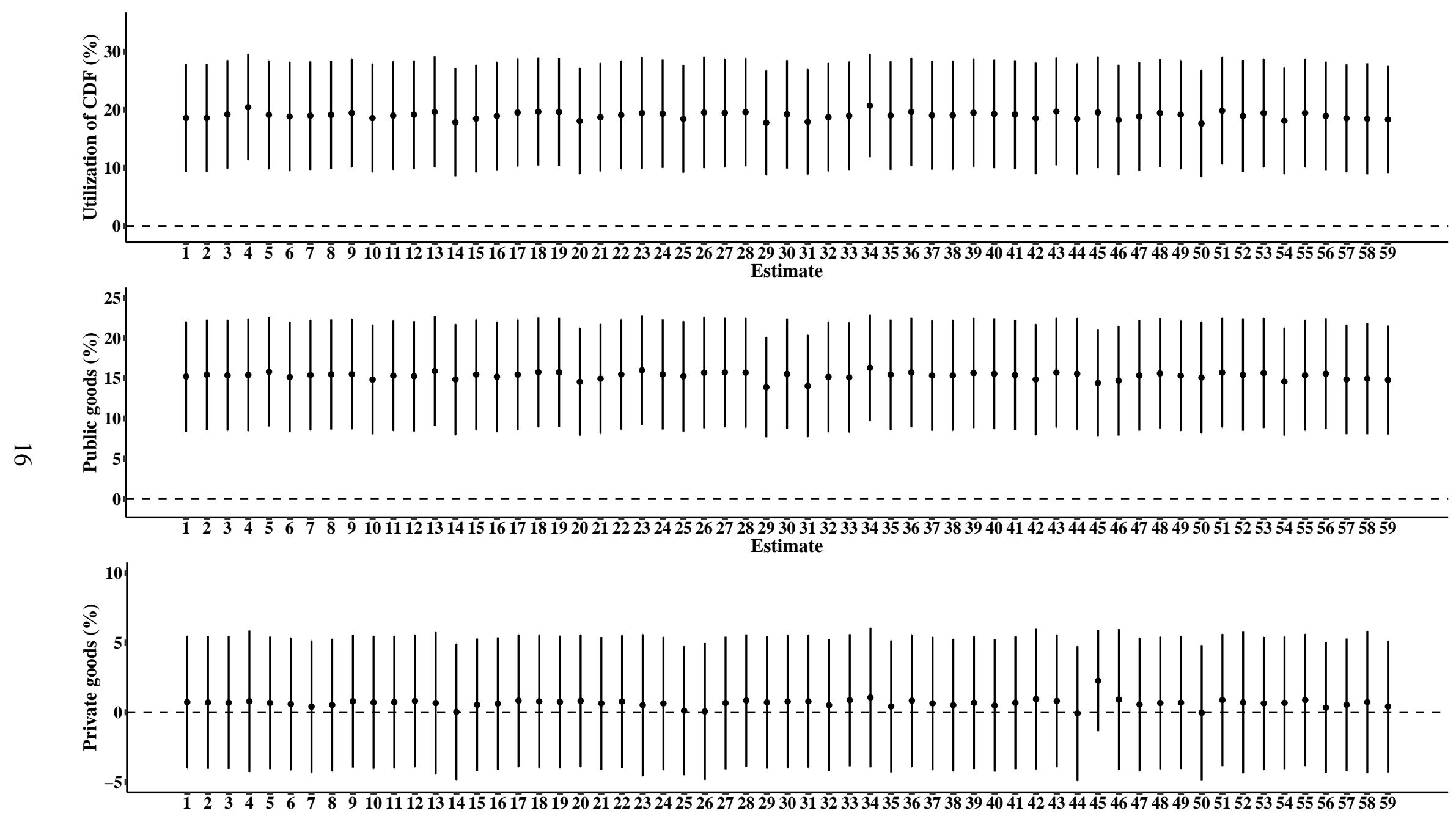
Table E.3: ITT effect of intensity of observation on CDF use across three treatment arms

\begin{tabular}{lccc}
\hline & \multicolumn{3}{c}{ Dependent variable: } \\
\cline { 2 - 4 } & Utilization & Public goods & Private goods \\
& $(1)$ & $(2)$ & $(3)$ \\
\hline Medium AIO & $0.184^{* * *}$ & $0.129^{* * *}$ & 0.012 \\
& $(0.057)$ & $(0.039)$ & $(0.026)$ \\
& {$[0.015]$} & {$[0.037]$} & {$[0.629]$} \\
High AIO & $0.197^{* * *}$ & $0.179^{* * *}$ & 0.001 \\
& $(0.061)$ & $(0.051)$ & $(0.027)$ \\
& {$[0.008]$} & {$[0.004]$} & {$[0.969]$} \\
Constant & $0.266^{* * *}$ & $0.111^{* * *}$ & $0.096^{* * *}$ \\
& $(0.033)$ & $(0.020)$ & $(0.022)$ \\
\hline Observations & 60 & 60 & 60 \\
$\mathrm{R}^{2}$ & 0.184 & 0.191 & 0.006 \\
Adjusted $\mathrm{R}^{2}$ & 0.155 & 0.163 & -0.029 \\
\hline \hline
\end{tabular}

Notes: $P$-values generated from a two-tailed RI tests based on 10,000 permutation of the initial randomization are reported in brackets for each ITT estimate. ${ }^{*} \mathrm{p}<0.1{ }^{* *} \mathrm{p}<0.05 ;{ }^{* * *} \mathrm{p}<0.01$ 
Figure E.4: Distribution of ITTs generated from randomization inference under the null hypothesis tests using the three treatment arms
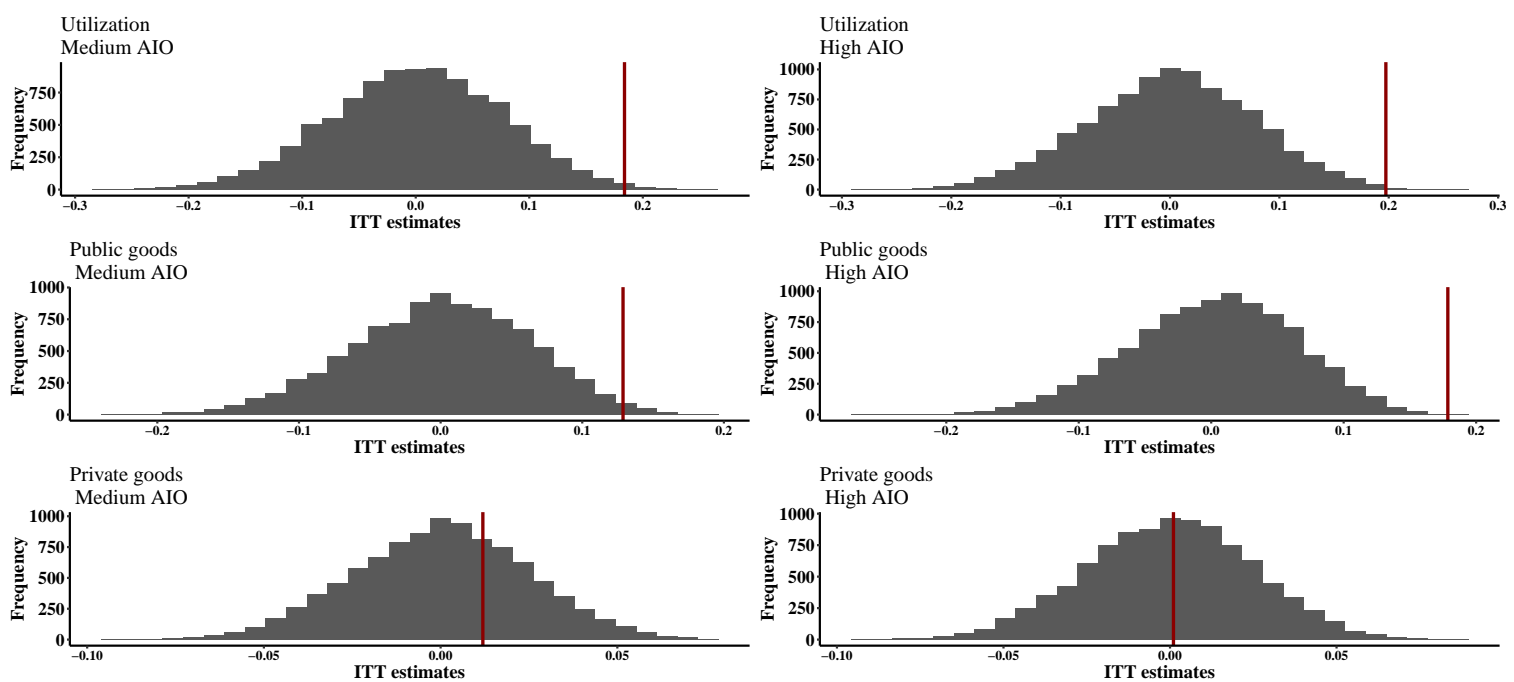

Notes: The red vertical lines indicate the estimated ITT effect.

Figure E.5: Distribution of bootstrapped estimates of the average ITT effects (three treatment arms)
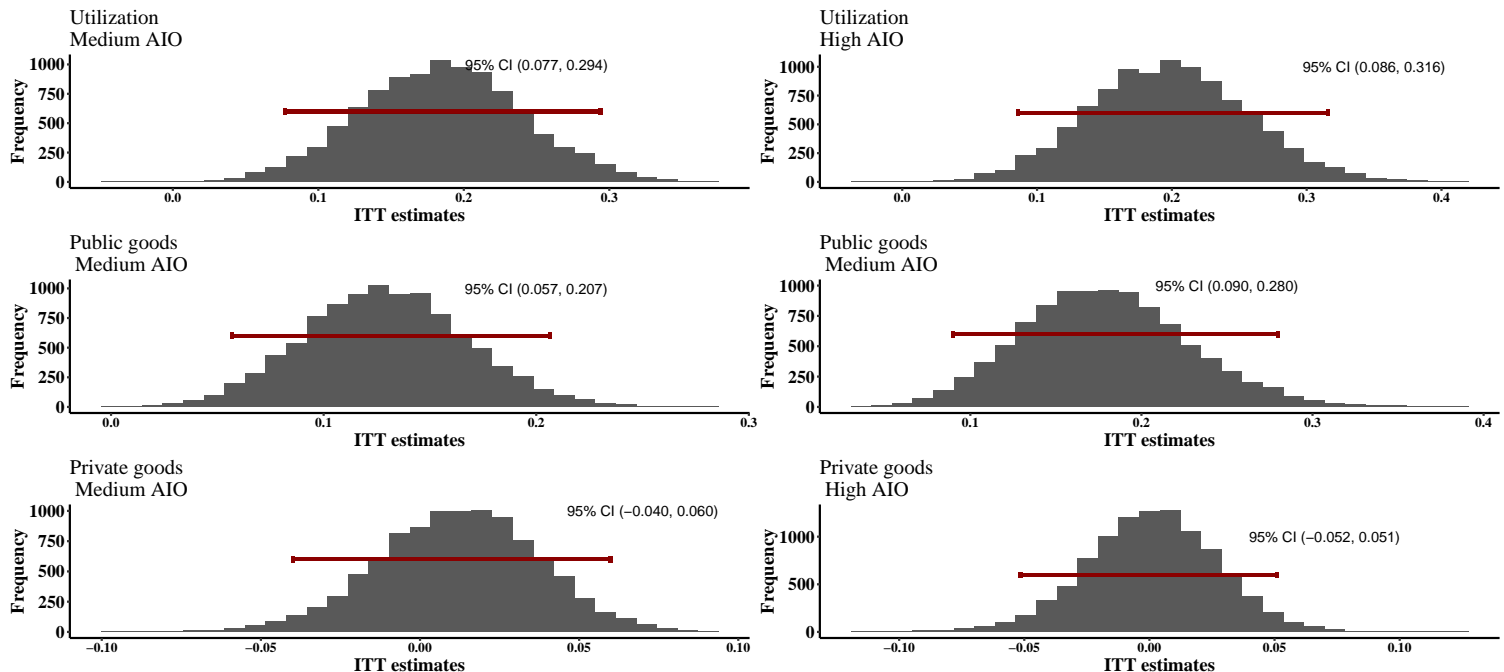

Notes: The red horizontal lines show the $95 \%$ confidence interval (i.e., 0.025 and .975 quantiles) of the distribution of the bootstrapped estimates of the average ITT effects.

E.2 Average ITT effects of AIO: over time, control for co-partisanship with local mayor, and clustering errors at district-level 
Table E.4: Heterogeneous effect: Average ITT effect of intensity of observation on the use of CDF by electoral competition

\begin{tabular}{lccc}
\hline \hline & \multicolumn{3}{c}{ Dependent variable: } \\
\cline { 2 - 4 } & Utilization & Public goods & Private goods \\
& $(1)$ & $(2)$ & $(3)$ \\
\hline High AIO & $0.211^{* *}$ & $0.141^{* *}$ & 0.043 \\
& $(0.084)$ & $(0.058)$ & $(0.030)$ \\
Vote margin (2008) & 0.074 & -0.005 & $0.119^{*}$ \\
& $(0.162)$ & $(0.104)$ & $(0.062)$ \\
High AIO: vote margin (2008) & -0.062 & 0.041 & -0.111 \\
& $(0.218)$ & $(0.168)$ & $(0.073)$ \\
Constant & & & \\
& $0.242^{* * *}$ & $0.112^{* * *}$ & $0.057^{* *}$ \\
\hline Observations & $(0.060)$ & $(0.029)$ & $(0.025)$ \\
$\mathrm{R}^{2}$ & 60 & 60 & 60 \\
Adjusted $\mathrm{R}^{2}$ & 0.129 & 0.122 & 0.052 \\
\hline \hline
\end{tabular}

Notes: Robust standard errors (HC 3 ) reported in parentheses. ${ }^{*} \mathrm{p}<0.1 ;{ }^{* *} \mathrm{p}<0.05 ;{ }^{* * *} \mathrm{p}<0.01$

Table E.5: ITT effect of intensity of observation on the use of CDF use adjusting for partisan affiliation

\begin{tabular}{|c|c|c|c|c|c|c|c|}
\hline & \multicolumn{7}{|c|}{ Dependent variable: } \\
\hline & $\begin{array}{c}\text { Utilization } \\
\text { (1) }\end{array}$ & $\begin{array}{l}\text { Public goods } \\
\text { (2) }\end{array}$ & $\begin{array}{l}\text { Private goods } \\
\text { (3) }\end{array}$ & $\begin{array}{c}\text { Donations } \\
(4)\end{array}$ & $\begin{array}{c}\text { Transfers to LG } \\
\text { (5) }\end{array}$ & $\begin{array}{c}\text { Monitoring/Office expenses } \\
\text { (6) }\end{array}$ & $\begin{array}{c}\text { Unclear } \\
(7)\end{array}$ \\
\hline Medium AIO & $\begin{array}{l}0.117^{*} \\
(0.062)\end{array}$ & $\begin{array}{l}0.094^{* *} \\
(0.046)\end{array}$ & $\begin{array}{c}0.005 \\
(0.026)\end{array}$ & $\begin{array}{c}0.010 \\
(0.007)\end{array}$ & $\begin{array}{l}0.026^{* *} \\
(0.012)\end{array}$ & $\begin{array}{l}0.005^{*} \\
(0.003)\end{array}$ & $\begin{array}{l}-0.023 \\
(0.017)\end{array}$ \\
\hline High AIO & $\begin{array}{c}0.178^{* * *} \\
(0.053)\end{array}$ & $\begin{array}{c}0.169^{* * *} \\
(0.047)\end{array}$ & $\begin{array}{l}-0.001 \\
(0.027)\end{array}$ & $\begin{array}{l}0.017^{*} \\
(0.009)\end{array}$ & $\begin{array}{c}0.014 \\
(0.011)\end{array}$ & $\begin{array}{c}0.002 \\
(0.002)\end{array}$ & $\begin{array}{l}-0.022 \\
(0.015)\end{array}$ \\
\hline Incumbent party $(\mathrm{NDC}=1)$ & $\begin{array}{c}0.206^{* * *} \\
(0.053)\end{array}$ & $\begin{array}{l}0.106^{* *} \\
(0.047)\end{array}$ & $\begin{array}{c}0.022 \\
(0.020)\end{array}$ & $\begin{array}{l}0.014^{*} \\
(0.008)\end{array}$ & $\begin{array}{c}0.042^{* * *} \\
(0.012)\end{array}$ & $\begin{array}{c}0.008^{* * *} \\
(0.002)\end{array}$ & $\begin{array}{c}0.014 \\
(0.009)\end{array}$ \\
\hline Constant & $\begin{array}{c}0.187^{* * *} \\
(0.039)\end{array}$ & $\begin{array}{l}0.070^{* *} \\
(0.029)\end{array}$ & $\begin{array}{c}0.088^{* * *} \\
(0.025)\end{array}$ & $\begin{array}{c}0.007 \\
(0.006)\end{array}$ & $\begin{array}{l}-0.008 \\
(0.006)\end{array}$ & $\begin{array}{l}-0.001 \\
(0.001)\end{array}$ & $\begin{array}{c}0.031^{* * *} \\
(0.012)\end{array}$ \\
\hline Observations & 60 & 60 & 60 & 60 & 60 & 60 & 60 \\
\hline $\mathrm{R}^{2}$ & 0.327 & 0.212 & 0.028 & 0.109 & 0.227 & 0.206 & 0.100 \\
\hline Adjusted $\mathrm{R}^{2}$ & 0.291 & 0.170 & -0.024 & 0.061 & 0.185 & 0.164 & 0.051 \\
\hline
\end{tabular}

Notes: ${ }^{*} \mathrm{p}<0.1 ;{ }^{* *} \mathrm{p}<0.05 ;{ }^{* * *} \mathrm{p}<0.01$ 
Figure E.6: Composition of CDF spending by year

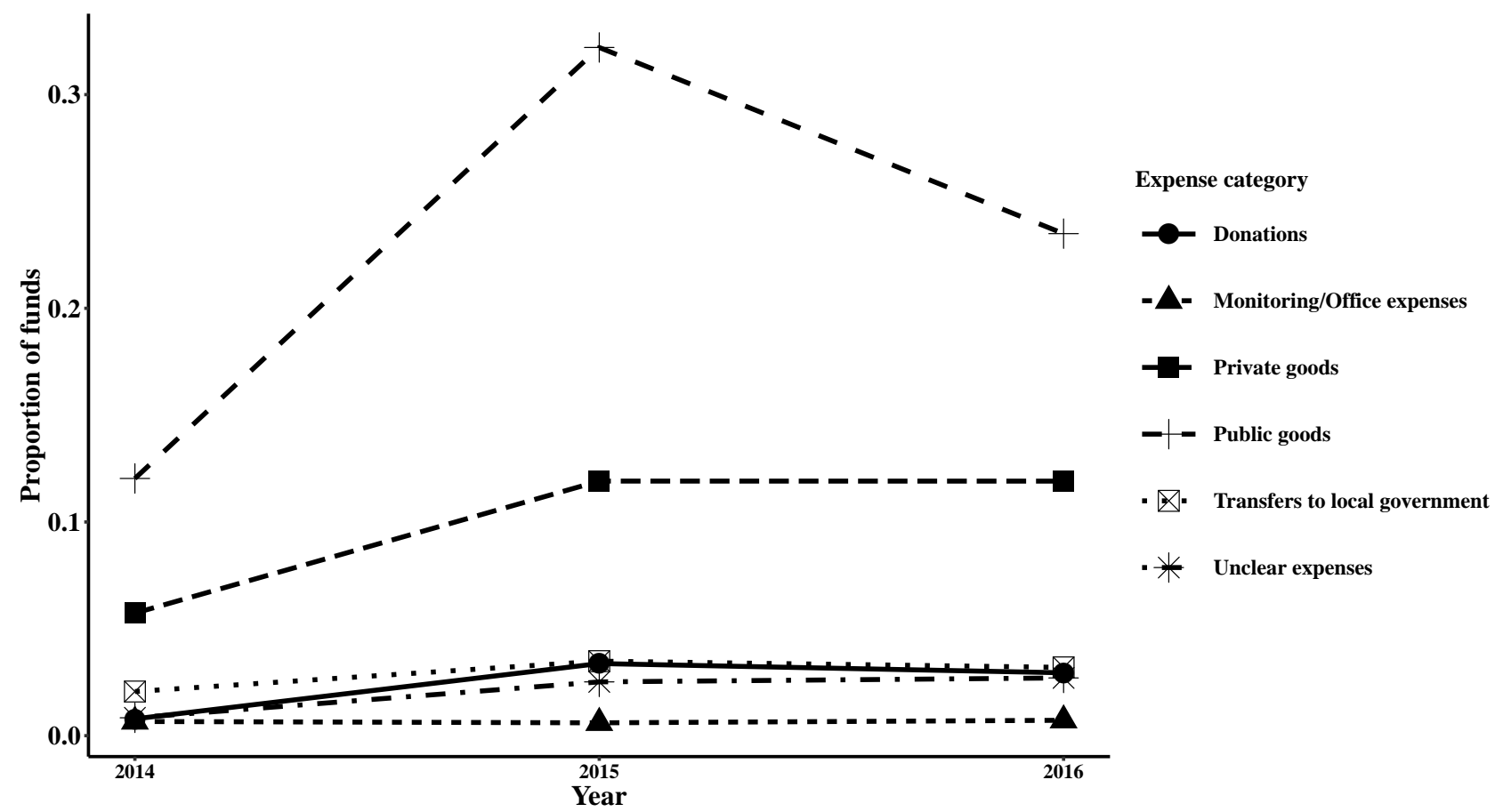

Notes: Figure E.6 shows the average proportion of CDFs spent on the various types of expenses over time. On average, MPs spent $12 \%$ of the funds on public goods in 2014, which rose to $32 \%$ in 2015 and decreased to $24 \%$ in 2016. Regarding private goods, in 2014, MPs spent $6 \%$, on average, which increase to $12 \%$ in 2015 and 2016, a 100 percent increase. Donation to groups and unclear expenses also increased over time from $0.8 \%$ in 2014 to about $3 \%$ in 2015 and 2016. The remaining categories remained the same over time. 
Table E.6: Average ITT effects of intensity of observation on the use of CDF by year

\begin{tabular}{|c|c|c|c|c|c|c|c|}
\hline & \multicolumn{7}{|c|}{ Dependent variable: } \\
\hline & $\begin{array}{l}\text { Utilization } \\
\text { (1) }\end{array}$ & $\begin{array}{l}\text { Public goods } \\
\text { (2) }\end{array}$ & $\begin{array}{l}\text { Private goods } \\
\text { (3) }\end{array}$ & $\begin{array}{l}\text { Donations } \\
\text { (4) }\end{array}$ & $\begin{array}{l}\text { Transfers to LG } \\
\text { (5) }\end{array}$ & $\begin{array}{c}\text { Monitoring/Office expenses } \\
\text { (6) }\end{array}$ & $\begin{array}{c}\text { Unclear } \\
(7)\end{array}$ \\
\hline \multicolumn{8}{|l|}{ Panel A: 2014} \\
\hline Medium AIO & $\begin{array}{c}0.140^{* * * *} \\
(0.048)\end{array}$ & $\begin{array}{l}0.081^{* *} \\
(0.033)\end{array}$ & $\begin{array}{c}0.021 \\
(0.021)\end{array}$ & $\begin{array}{c}0.003 \\
(0.003)\end{array}$ & $\begin{array}{c}0.033^{* * *} \\
(0.012)\end{array}$ & $\begin{array}{c}0.005 \\
(0.007)\end{array}$ & $\begin{array}{l}-0.004 \\
(0.014)\end{array}$ \\
\hline High AIO & $\begin{array}{c}0.116^{* * *} \\
(0.043)\end{array}$ & $\begin{array}{c}0.097^{* * * *} \\
(0.034)\end{array}$ & $\begin{array}{c}0.010 \\
(0.018)\end{array}$ & $\begin{array}{c}0.006 \\
(0.005)\end{array}$ & $\begin{array}{c}0.009 \\
(0.006)\end{array}$ & $\begin{array}{c}0.004 \\
(0.004)\end{array}$ & $\begin{array}{l}-0.010 \\
(0.014)\end{array}$ \\
\hline Constant & $\begin{array}{c}0.121^{* * *} \\
(0.024) \\
\end{array}$ & $\begin{array}{c}0.051^{* * *} \\
(0.016)\end{array}$ & $\begin{array}{c}0.045^{* * *} \\
(0.014) \\
\end{array}$ & $\begin{array}{l}0.004^{*} \\
(0.003)\end{array}$ & $\begin{array}{l}0.004^{*} \\
(0.002)\end{array}$ & $\begin{array}{l}0.003^{* *} \\
(0.002) \\
\end{array}$ & $\begin{array}{c}0.014 \\
(0.014) \\
\end{array}$ \\
\hline Observations & 60 & 60 & 60 & 60 & 60 & 60 & 60 \\
\hline & 0.096 & 0.085 & 0.018 & 0.019 & 0.114 & 0.008 & 0.025 \\
\hline Adjusted $\mathrm{R}^{2}$ & 0.065 & 0.053 & -0.016 & -0.015 & 0.083 & -0.027 & -0.009 \\
\hline \multicolumn{8}{|l|}{ Panel B: 2015} \\
\hline Medium AIO & $\begin{array}{l}0.205^{* *} \\
(0.088)\end{array}$ & $\begin{array}{l}0.121^{* *} \\
(0.060)\end{array}$ & $\begin{array}{c}0.008 \\
(0.031)\end{array}$ & $\begin{array}{c}0.015 \\
(0.015)\end{array}$ & $\begin{array}{l}0.070^{* *} \\
(0.033)\end{array}$ & $\begin{array}{l}0.008^{* *} \\
(0.004)\end{array}$ & $\begin{array}{l}-0.018 \\
(0.021)\end{array}$ \\
\hline High AIO & $\begin{array}{c}0.290^{* * *} \\
(0.091)\end{array}$ & $\begin{array}{c}0.256^{* * *} \\
(0.087)\end{array}$ & $\begin{array}{c}0.009 \\
(0.032)\end{array}$ & $\begin{array}{l}0.031^{*} \\
(0.018)\end{array}$ & $\begin{array}{c}0.006 \\
(0.004)\end{array}$ & $\begin{array}{c}0.001 \\
(0.002)\end{array}$ & $\begin{array}{l}-0.015 \\
(0.023)\end{array}$ \\
\hline Constant & $\begin{array}{c}0.348^{* * *} \\
(0.048) \\
\end{array}$ & $\begin{array}{c}0.175^{* * *} \\
(0.039)\end{array}$ & $\begin{array}{c}0.113^{* * *} \\
(0.025)\end{array}$ & $\begin{array}{l}0.016^{* *} \\
(0.007) \\
\end{array}$ & $\begin{array}{c}0.004 \\
(0.003) \\
\end{array}$ & $\begin{array}{c}0.002 \\
(0.001)\end{array}$ & $\begin{array}{l}0.038^{*} \\
(0.020)\end{array}$ \\
\hline Observations & 60 & 60 & 60 & 60 & 60 & 60 & 60 \\
\hline $\mathrm{R}^{2}$ & 0.104 & 0.120 & 0.002 & 0.035 & 0.097 & 0.081 & 0.018 \\
\hline Adjusted $\mathrm{R}^{2}$ & 0.072 & 0.089 & -0.033 & 0.001 & 0.066 & 0.049 & -0.016 \\
\hline \multicolumn{8}{|l|}{ Panel C: 2016} \\
\hline Medium AIO & $\begin{array}{l}0.203^{* *} \\
(0.083)\end{array}$ & $\begin{array}{c}0.172^{* * *} \\
(0.050)\end{array}$ & $\begin{array}{c}0.013 \\
(0.039)\end{array}$ & $\begin{array}{l}0.022^{* *} \\
(0.011)\end{array}$ & $\begin{array}{c}0.017 \\
(0.013)\end{array}$ & $\begin{array}{l}0.008^{*} \\
(0.005)\end{array}$ & $\begin{array}{l}-0.029 \\
(0.028)\end{array}$ \\
\hline High AIO & $\begin{array}{l}0.180^{* *} \\
(0.085)\end{array}$ & $\begin{array}{c}0.173^{* * *} \\
(0.058)\end{array}$ & $\begin{array}{l}-0.012 \\
(0.043)\end{array}$ & $\begin{array}{c}0.017 \\
(0.011)\end{array}$ & $\begin{array}{c}0.032 \\
(0.030)\end{array}$ & $\begin{array}{c}0.003 \\
(0.003)\end{array}$ & $\begin{array}{l}-0.033 \\
(0.026)\end{array}$ \\
\hline Constant & $\begin{array}{c}0.300^{* * *} \\
(0.050)\end{array}$ & $\begin{array}{c}0.100^{* * *} \\
(0.017)\end{array}$ & $\begin{array}{c}0.119^{* * *} \\
(0.031) \\
\end{array}$ & $\begin{array}{c}0.014^{* * *} \\
(0.005)\end{array}$ & $\begin{array}{c}0.013 \\
(0.009) \\
\end{array}$ & $\begin{array}{l}0.003^{*} \\
(0.001)\end{array}$ & $\begin{array}{l}0.051^{* *} \\
(0.024) \\
\end{array}$ \\
\hline Observations & 59 & 59 & 59 & 59 & 59 & 59 & 59 \\
\hline & 0.074 & 0.104 & 0.008 & 0.042 & 0.019 & 0.043 & 0.045 \\
\hline Adjusted $\mathrm{R}^{2}$ & 0.040 & 0.072 & -0.027 & 0.008 & -0.016 & 0.009 & 0.011 \\
\hline
\end{tabular}

Notes: Robust standard errors (HC3) reported in parentheses. ${ }^{*} \mathrm{p}<0.1 ;{ }^{* *} \mathrm{p}<0.05 ;{ }^{* * *} \mathrm{p}<0.01$ 
Table E.7: Robustness: ITT effect of intensity of observation on the use of CDF

\begin{tabular}{|c|c|c|c|c|c|c|c|}
\hline & \multicolumn{7}{|c|}{ Dependent variable: } \\
\hline & $\begin{array}{l}\text { Utilization } \\
\text { (1) }\end{array}$ & $\begin{array}{l}\text { Public goods } \\
\text { (2) }\end{array}$ & $\begin{array}{l}\text { Private goods } \\
\text { (3) }\end{array}$ & $\begin{array}{c}\text { Donations } \\
\text { (4) }\end{array}$ & $\begin{array}{c}\text { Transfers to LG } \\
\text { (5) }\end{array}$ & $\begin{array}{c}\text { Monitoring/Office expenses } \\
\text { (6) }\end{array}$ & $\begin{array}{c}\text { Unclear } \\
(7)\end{array}$ \\
\hline Medium AIO & $\begin{array}{c}0.184^{* * *} \\
(0.054)\end{array}$ & $\begin{array}{c}0.129^{* * *} \\
(0.038)\end{array}$ & $\begin{array}{c}0.012 \\
(0.025)\end{array}$ & $\begin{array}{l}0.015^{* *} \\
(0.006)\end{array}$ & $\begin{array}{c}0.040^{* * *} \\
(0.013)\end{array}$ & $\begin{array}{l}0.007^{* *} \\
(0.003)\end{array}$ & $\begin{array}{l}-0.019 \\
(0.015)\end{array}$ \\
\hline High AIO & $\begin{array}{c}0.197^{* * *} \\
(0.060)\end{array}$ & $\begin{array}{c}0.179^{* * *} \\
(0.050)\end{array}$ & $\begin{array}{c}0.001 \\
(0.029)\end{array}$ & $\begin{array}{l}0.018^{* *} \\
(0.008)\end{array}$ & $\begin{array}{c}0.018 \\
(0.012)\end{array}$ & $\begin{array}{c}0.003 \\
(0.002)\end{array}$ & $\begin{array}{l}-0.021 \\
(0.014)\end{array}$ \\
\hline Constant & $\begin{array}{c}0.266^{* * *} \\
(0.031)\end{array}$ & $\begin{array}{c}0.111^{* * *} \\
(0.019)\end{array}$ & $\begin{array}{c}0.096^{* * *} \\
(0.021) \\
\end{array}$ & $\begin{array}{c}0.012^{* * *} \\
(0.004)\end{array}$ & $\begin{array}{l}0.008^{* *} \\
(0.004)\end{array}$ & $\begin{array}{c}0.003^{* * *} \\
(0.001)\end{array}$ & $\begin{array}{c}0.037^{* * *} \\
(0.013)\end{array}$ \\
\hline Observations & 60 & 60 & 60 & 60 & 60 & 60 & 60 \\
\hline $\mathrm{R}^{2}$ & 0.127 & 0.134 & 0.006 & 0.057 & 0.085 & 0.072 & 0.060 \\
\hline Adjusted $\mathrm{R}^{2}$ & 0.096 & 0.104 & -0.029 & 0.023 & 0.053 & 0.039 & 0.027 \\
\hline
\end{tabular}

Notes: Robust standard errors clustered at the district level are reported in parentheses. ${ }^{*} \mathrm{p}<0.1 ;{ }^{* *} \mathrm{p}<0.05 ;{ }^{* * *} \mathrm{p}<0.01$ 
Table E.8: Average ITT effects of intensity of observation on CDF use with covariate adjustments

\begin{tabular}{lccc}
\hline \hline & \multicolumn{3}{c}{ Dependent variable: } \\
\cline { 2 - 4 } & Utilization & Public goods & Private goods \\
& $(1)$ & $(2)$ & $(3)$ \\
\hline Medium AIO & $0.203^{* * *}$ & $0.144^{* * *}$ & 0.020 \\
High AIO & $(0.058)$ & $(0.038)$ & $(0.024)$ \\
& $0.169^{* * *}$ & $0.163^{* * *}$ & 0.0004 \\
Voter density (\# voters/Area (km. sq.)) & $(0.059)$ & $(0.045)$ & $(0.024)$ \\
& -0.00001 & 0.00001 & -0.00000 \\
Margin of victory (2008) & $(0.00003)$ & $(0.00003)$ & $(0.00002)$ \\
& 0.032 & -0.005 & 0.033 \\
Education (primary or less) & $(0.125)$ & $(0.116)$ & $(0.029)$ \\
Employed & -0.121 & 0.464 & -0.463 \\
Cement wall & $(0.963)$ & $(0.936)$ & $(0.334)$ \\
& -1.463 & $-1.813^{*}$ & $0.527^{*}$ \\
Pop. in agriculture & $(1.145)$ & $(1.075)$ & $(0.308)$ \\
Constant & -0.226 & -0.117 & 0.081 \\
& $(0.258)$ & $(0.206)$ & $(0.079)$ \\
\hline Observations & -0.124 & -0.033 & 0.032 \\
Adjusted R ${ }^{2}$ & $(0.370)$ & $(0.300)$ & $(0.097)$ \\
\hline \hline & $1.278^{* *}$ & 0.667 & 0.182 \\
& $(0.618)$ & $(0.518)$ & $(0.250)$ \\
\hline & 60 & 60 & 60 \\
& 0.209 & 0.236 & 0.155 \\
& 0.084 & 0.116 & 0.023 \\
\hline
\end{tabular}

Notes: Robust standard errors (HC 3 ) reported in parentheses. ${ }^{*} \mathrm{p}<0.1 ;{ }^{* *} \mathrm{p}<0.05 ;{ }^{* * *} \mathrm{p}<0.01$ 


\section{E.3 Average ITT effects of AIO on other expenses}

As I noted in section 3.3, in addition to spending on public and private goods, legislators also dedicated part of their CDF to other expenses related to their work as MPs. The careful coding of MPs' expense sheets provides further insights into whom legislators are accountable to. In this section, I examine the effect of the intense election monitoring on these additional categories of spending and discuss the implications for political responsiveness.

Four additional spending categories arose from my coding: donations to support local groups to undertake projects or activities; transfers towards local government projects and activities; monitoring of constituency projects and office expenses; and unclear expenses. Between 2014 and 2016, the proportion of CDFs that MPs spent on each of these expenses were $2.5 \%, 3 \%$, $0.7 \%$, and $2.1 \%$, respectively (see Table I.2).

The first expenditure category concerns payments to local religious groups and traditional authorities (i.e., chiefs). It also includes support to youth organizations to organize various skillsbuilding workshops, health awareness campaigns, and soccer tournaments. In a unique study of the accountability pressures that Ghanaian legislators face, Lindberg (2010) finds that religious leaders and civil society groups hardly held legislators to account in any meaningful way. Nonetheless, religious leaders invited MPs to attend their functions and donate to their projects. The CDF records provide empirical evidence for this claim. Also, the data show that incumbents give funds to help repair the palaces or organize traditional festivals. Traditional leaders may also request donations from legislators. The incentives for MPs to donate to chiefs may be twofold. First, chiefs may "control" how constituents under their jurisdiction vote (Lindberg, 2010). Second, chiefs control lands and other resources (community labor) that MPs often need to commission infrastructure projects (Baldwin, 2013). Therefore, MPs may be responsive to the chief to curry favors to win votes and facilitate the provision of public goods.

The second form of the expense that appeared on MPs' records were funds that were transferred to the local government that oversees the legislator's account. These expenses came in three 
main forms. First, MPs donated part of their funds to support activities that are typically organized (and paid for) by the local government. These included payment for national events held locally such as the national Independence Day and Farmers' Day celebrations. Second, the local administrator transferred funds from the MPs' CDF account to pay for some operating expenses of the local government including the repair works on local government offices, and fuel to operate government vehicles, as well as maintenance of machinery. It is not clear whether the consent of the MP is sought before such payments are made. Third, some expenses were recorded as 'loans' deducted from an MP's CDF account to his or her, perhaps cash-strapped, local government (interview with DACF officials). Together, these expenses may represent an MP's support to public service provision in their constituencies, but because the local government is directly responsible for such activities, I consider them to be separate. Also, MPs may agree to such payments to help their local government to curry favors in the implementation of their own projects.

Third, MPs are allowed to use a part of their funds to conduct monitoring of ongoing projects in their constituencies. These projects may be MP-initiated or initiated by the central government, which would form part of their oversight functions. Legislators may use such inspections to ensure that commissioned infrastructure projects are completed on time or assess the status of such projects to report to constituents or the appropriate executive agency for action. Therefore, spending on monitoring would serve to indicate the amount of effort a legislator dedicates to supervising public goods in their constituency. I also find that part of the CDF was devoted to renting office spaces and covering operating expenses including paying staff salary. The records on office expenses provide evidence on which MPs has established a personal office in their constituencies. Creating an office in one's constituency may indicate how attentive an MP is to the needs of her constituents. Individual constituents can visit these offices to register their concerns.

Finally, there were expenses that I could not easily classify because the beneficiaries or purposes were unclear. These expenses included an MP's direct purchase of items such as TV sets, cutlasses, etc. Similar purchases that indicated the reason for such acquisitions suggest that 
these items may be distributed to community centers (e.g., TV sets) or to farmers during national farmers' day celebration (cutlasses). However, MPs may also hand them out to their supporters. Accordingly, I coded such expenses as unclear. Other items included the purchase of building materials, which legislators can donate to communities or individuals. Also, there were records of the acquisition of food items (e.g., bags of rice, oil etc.) with no stated beneficiaries. In some case, where an adequate description was given, it appears that MPs donate such food items to Muslim communities during the Ramadan season, however this remains speculative.

Table E.9 displays the effect of the intensity of election monitoring on these other expense categories. Columns (1), (2), (3), and (4) show the results for donation to local groups, transfers to local governments, monitoring and office expenses, and unclear expenses, respectively. To be consistent with the main analysis in the paper, Panel A shows the results for the two treatment arms while Panel B disaggregates the results by the three treatment arms (for reference). The results shows that MPs elected in intensely-monitored elections (high-AIO) donated 1.7 percentage points (pp) more of their funds to local groups compared to those in low-AIO (Column (1)), which suggests that fairer election may induce politicians to respond to parochial interests in their constituencies. While some of these expenses may help address issues such as youth unemployment (i.e. skill-building workshops), community health, or curry favors with chiefs to provide public works, they may also serve clientelistic purposes. Future research can address such goals more systematically.

Second, the results in Column (2) indicate that MPs elected in intensely-monitored elections donated to the local government about $3 \mathrm{pp}$ of their funds compared to their counterparts elected in low-AIO. Again, the results can be taken to indicate that fairer elections encourage MPs to help their local governments to provide services in their constituencies. Activities such as Independence Day and Farmers' Day celebrations allow MPs to claim credit for their support of the local government and communities. 
Third, while the proportion of CDF dedicated to MPs monitoring activities and maintaining an office in their constituency was less than one percent, the results in Column (3) suggest that fairer elections increased incumbents' spending on these issues by about a half a percentage point. This effect is not substantively large but corroborates the general findings in this paper that fairer elections encourage politicians to put in more effort to address constituents' demands.

Finally, I do not find any statistically significant difference between treatments regarding the proportion of CDF spending that I could not easily classify. Such a null finding on this category may serve to indicate, reassuringly, that the local governments in the different treatment conditions were no different regarding the clarity of their record keeping.

Table E.9: ITT effect of intensity of observation on the use of CDF for other types of expenses

\begin{tabular}{|c|c|c|c|c|}
\hline & \multicolumn{4}{|c|}{ Dependent variable: } \\
\hline & $\begin{array}{l}\text { Donations to local groups } \\
\text { (1) }\end{array}$ & $\begin{array}{l}\text { Transfers to LGs } \\
\text { (2) }\end{array}$ & $\begin{array}{l}\text { Monitoring and office expenses } \\
\text { (3) }\end{array}$ & $\begin{array}{c}\text { Unclear expenses } \\
(4)\end{array}$ \\
\hline \multicolumn{5}{|c|}{ Panel A: Two treatment arms } \\
\hline $\begin{array}{l}\text { High AIO } \\
\text { (Medium \& High) }\end{array}$ & $\begin{array}{c}0.017^{* * *} \\
(0.006)\end{array}$ & $\begin{array}{c}0.029^{* * *} \\
(0.010)\end{array}$ & $\begin{array}{l}0.005^{* *} \\
(0.002)\end{array}$ & $\begin{array}{l}-0.020 \\
(0.015)\end{array}$ \\
\hline Constant & $\begin{array}{c}0.012^{* * *} \\
(0.004)\end{array}$ & $\begin{array}{l}0.008^{*} \\
(0.004) \\
\end{array}$ & $\begin{array}{c}0.003^{* * *} \\
(0.001) \\
\end{array}$ & $\begin{array}{l}0.037^{* *} \\
(0.014) \\
\end{array}$ \\
\hline Observations & 60 & 60 & 60 & 60 \\
\hline $\mathrm{R}^{2}$ & 0.054 & 0.050 & 0.038 & 0.059 \\
\hline Adjusted $\mathrm{R}^{2}$ & 0.037 & 0.034 & 0.022 & 0.043 \\
\hline \multicolumn{5}{|c|}{ Panel B: Three treatment arms } \\
\hline Medium AIO & $\begin{array}{l}0.015^{* *} \\
(0.007)\end{array}$ & $\begin{array}{c}0.040^{* * *} \\
(0.013)\end{array}$ & $\begin{array}{l}0.007^{* *} \\
(0.003)\end{array}$ & $\begin{array}{l}-0.019 \\
(0.016)\end{array}$ \\
\hline High AIO & $\begin{array}{l}0.018^{* *} \\
(0.009)\end{array}$ & $\begin{array}{c}0.018 \\
(0.012)\end{array}$ & $\begin{array}{c}0.003 \\
(0.002)\end{array}$ & $\begin{array}{l}-0.021 \\
(0.015)\end{array}$ \\
\hline Constant & $\begin{array}{l}0.012^{* * *} \\
(0.004)\end{array}$ & $\begin{array}{l}0.008^{*} \\
(0.004)\end{array}$ & $\begin{array}{c}0.003^{* * *} \\
(0.001)\end{array}$ & $\begin{array}{l}0.037^{* *} \\
(0.014)\end{array}$ \\
\hline Observations & 60 & 60 & 60 & 60 \\
\hline $\mathrm{R}^{2}$ & 0.085 & 0.112 & 0.093 & 0.068 \\
\hline Adjusted $\mathrm{R}^{2}$ & 0.053 & 0.081 & 0.061 & 0.035 \\
\hline
\end{tabular}

Notes: ${ }^{*} \mathrm{p}<0.1 ;{ }^{* *} \mathrm{p}<0.05 ;{ }^{* * *} \mathrm{p}<0.01$ 
F Testing the mechanisms through which electoral integrity affect MPs' behavior

Table F.1: The intensity of observation has no effect on the characteristics of elected candidates

\begin{tabular}{lccccc}
\hline \hline & \multicolumn{5}{c}{ Intensity of observation } \\
Incumbents Characteristics & $\mathrm{N}$ & Low & Medium & High & P-value \\
\hline \# Parliamentary Terms-incumbent MP & 60 & 1.4615 & 2.1667 & 1.7826 & 0.6131 \\
Female & 60 & 0.0769 & 0.1667 & 0.00 & 0.2652 \\
Minister & 60 & 0.1538 & 0.2083 & 0.00 & 0.0953 \\
Incumbent Party MP & 60 & 0.3846 & 0.7083 & 0.4783 & 0.8666 \\
Age & 60 & 47.6923 & 50.2917 & 45.4348 & 0.2309 \\
Highest education & 60 & 5.0769 & 5.1667 & 5.1304 & 0.9073 \\
\hline
\end{tabular}

Note: Data on MPs' gender, age, and education was coded from the handbook "Know Your MPs (2013-2017)." (Vieta, 2013). I coded incumbents' term in office and party affiliation using election results obtained from Ghana's Electoral Commission. I coded ministerial status from parliamentary records. While there are substantive differences across treatment regarding MPs' gender, ministerial position, and co-partisanship with the president (and thus the local mayor), Table F.2 shows that only the latter is significantly associated with the dependent variable (CDF spending). Voters may have chosen candidates who belonged to the incumbent party, who they believe can spend more of their CDF. However, the main results in this paper do not substantively change when I account for co-partisanship with the local mayor (see Table E.5). The group means and p-values corresponding to the F-test statistic of all three treatment conditions are shown in the last column of the table. 
Table F.2: Association between MPs characteristics and CDF spending

\begin{tabular}{|c|c|c|c|c|c|c|c|}
\hline & \multicolumn{7}{|c|}{ Dependent variable: } \\
\hline & \multicolumn{7}{|c|}{ CDF spending } \\
\hline & (1) & (2) & (3) & (4) & $(5)$ & (6) & (7) \\
\hline \# Parliamentary Terms-incumbent MP & $\begin{array}{l}-0.001 \\
(0.027)\end{array}$ & & & & & & $\begin{array}{c}0.019 \\
(0.029)\end{array}$ \\
\hline Female & & $\begin{array}{c}0.037 \\
(0.105)\end{array}$ & & & & & $\begin{array}{c}0.022 \\
(0.112)\end{array}$ \\
\hline Minister & & & $\begin{array}{c}0.131 \\
(0.111)\end{array}$ & & & & $\begin{array}{c}0.025 \\
(0.139)\end{array}$ \\
\hline Incumbent Party MP (NDC) & & & & $\begin{array}{c}0.216^{* * *} \\
(0.050)\end{array}$ & & & $\begin{array}{c}0.202^{* * *} \\
(0.058)\end{array}$ \\
\hline Age & & & & & $\begin{array}{l}0.007^{*} \\
(0.004)\end{array}$ & & $\begin{array}{c}0.002 \\
(0.004)\end{array}$ \\
\hline Highest Education & & & & & & $\begin{array}{c}0.033 \\
(0.029)\end{array}$ & $\begin{array}{c}0.019 \\
(0.026)\end{array}$ \\
\hline Constant & $\begin{array}{c}0.416^{* * *} \\
(0.058) \\
\end{array}$ & $\begin{array}{c}0.412^{* * *} \\
(0.031) \\
\end{array}$ & $\begin{array}{c}0.400^{* * *} \\
(0.030)\end{array}$ & $\begin{array}{c}0.296^{* * *} \\
(0.030) \\
\end{array}$ & $\begin{array}{c}0.091 \\
(0.173) \\
\end{array}$ & $\begin{array}{c}0.245 \\
(0.150)\end{array}$ & $\begin{array}{c}0.061 \\
(0.226)\end{array}$ \\
\hline Observations & 60 & 60 & 60 & 60 & 60 & 60 & 60 \\
\hline $\mathrm{R}^{2}$ & 0.00001 & 0.002 & 0.036 & 0.238 & 0.053 & 0.021 & 0.259 \\
\hline Adjusted $\mathrm{R}^{2}$ & -0.017 & -0.015 & 0.020 & 0.224 & 0.037 & 0.004 & 0.175 \\
\hline
\end{tabular}

Table F.3: Suggestive evidence that MPs elected in higher-intensity of observation are more likely to report they saw an observer at a polling station they visited

\begin{tabular}{lcc}
\hline \hline & \multicolumn{2}{c}{ Actual Intensity of Observation } \\
& Low & High \\
\hline MP saw Observers & $41.67(5)$ & $58.82(20)$ \\
MP did not see observers & $58.33(7)$ & $41.18(14)$ \\
\hline
\end{tabular}

Notes: Specific question: "Did you personally see observers at some of the polling stations you visited?" N=46 MPs, Chi-squared $=1.05, \mathrm{P}$-value $=0.31$ 
Table F.4: Suggestive evidence that MPs were aware of the intensity of observation within their constituencies

\begin{tabular}{|c|c|c|c|}
\hline & \multicolumn{3}{|c|}{ Intensity of Observation } \\
\hline & Low & High & $I T T$ \\
\hline \multirow[t]{2}{*}{ MPs estimate of intensity of observation } & 0.133 & 0.283 & 0.150 \\
\hline & $(0.153)$ & $(0.312)$ & $(0.136)$ \\
\hline $\mathrm{N}$ & 3 & 15 & \\
\hline \multirow[t]{2}{*}{ Empirical intensity of observation } & 0.145 & 0.249 & $0.104^{* * *}$ \\
\hline & $(0.054)$ & $(0.077)$ & $(0.021)$ \\
\hline $\mathrm{N}$ & 13 & 47 & \\
\hline
\end{tabular}

Note: Table F.4 (upper panel) report the average of MPs' estimates of the proportion of polling stations in their constituencies that were monitored by election observers with standard deviations reported in parentheses. Their estimates were in response to the question: For every twenty (20) polling stations in your constituency, how many would you say were monitored by domestic election observers. Table F.4 (lower panel) also provide the average of the empirical saturation of observation across the three treatment intensities below these estimates with standard deviations reported in parentheses. Empirical intensity of observation refers to the actual proportion of polling stations within the entire constituency, and not the experimental sample, that were monitored by observers. ${ }^{*} \mathrm{p}<0.1{ }^{* *} \mathrm{p}<0.05 ;{ }^{* * *} \mathrm{p}<0.01$ 
Table F.5: The intensity of election observation in a constituency neither affected citizens' pressures on MPs or government officials to provide public goods and services

Dependent variable:

\begin{tabular}{|c|c|c|c|c|c|c|}
\hline & $\begin{array}{c}\text { Contacted } \\
\text { MP } \\
(1)\end{array}$ & $\begin{array}{c}\text { Attended Community } \\
\text { Meeting } \\
(2)\end{array}$ & $\begin{array}{c}\text { Joined Group } \\
\text { to Raise Issue } \\
\text { (3) }\end{array}$ & $\begin{array}{l}\text { Requested Government } \\
\text { Action } \\
\text { (4) }\end{array}$ & $\begin{array}{c}\text { Contacted Government } \\
\text { Official } \\
(5) \\
\end{array}$ & $\begin{array}{l}\text { Voters' Duty that } \\
\text { MPs' Work } \\
\text { (6) }\end{array}$ \\
\hline High Intensity of Observation & $\begin{array}{l}-0.020 \\
(0.034)\end{array}$ & $\begin{array}{l}-0.022 \\
(0.087)\end{array}$ & $\begin{array}{l}-0.063 \\
(0.051)\end{array}$ & $\begin{array}{l}-0.041 \\
(0.049)\end{array}$ & $\begin{array}{c}0.003 \\
(0.028)\end{array}$ & $\begin{array}{c}0.026 \\
(0.056)\end{array}$ \\
\hline Constant & $\begin{array}{c}0.123^{* * *} \\
(0.029) \\
\end{array}$ & $\begin{array}{c}0.453^{* * *} \\
(0.077) \\
\end{array}$ & $\begin{array}{c}0.406^{* * *} \\
(0.042) \\
\end{array}$ & $\begin{array}{c}0.170^{* * *} \\
(0.045) \\
\end{array}$ & $\begin{array}{c}0.132^{* * *} \\
(0.023) \\
\end{array}$ & $\begin{array}{c}0.358^{* * *} \\
(0.047) \\
\end{array}$ \\
\hline Adjusted $\mathrm{R}^{2}$ & -0.001 & -0.002 & 0.001 & 0.0003 & -0.002 & -0.002 \\
\hline
\end{tabular}

Notes: Table F.5 presents results from analysis of Ghana's Afrobarometer Round 6 data conducted in 2014. I analyze questions related to potential increase in citizens pressures on MPs within constituencies to deliver public goods as a results of the treatment. For easy analysis and interpretation of results, I coded these questions as dummies indicating whether citizens took the stated action. The specific questions are as follows: Column (1): "During the past year, how often have you contacted any of the following persons about some important problem or to give them your views: A Member of Parliament"; Columns (2)-(3): "Here is a list of actions that people sometimes take as citizens. For each of these, please tell me whether you, personally, have done any of these things during the past year ": Attended a community meeting (Column (2)), and Got together with others to raise an issue (Column (3)). Columns (4)- (5) : "Here is a list of actions that people sometimes take as citizens when they are dissatisfied with government. For each of these, please tell me whether you, personally, have done any of these things during the past year. If not, would you do this if you had the chance?": Joined others in your community to request action from government" (Columns (4)) ; and Contacted a government official to ask for help or make a complaint (Column (5)). Column (6): "Who should be responsible for: Making sure that, once elected, Members of Parliament do their jobs?" [Coding: The voters (1) as oppose to The president/executive or The Parliament/local council, or their political party (0)]. Standard errors are clustered at the constituency level. ${ }^{*} \mathrm{p}<0.1 ;{ }^{* *} \mathrm{p}<0.05 ;{ }^{* * *} \mathrm{p}<0.01$ 
Table F.6: Effect of AIO on the number of candidates and female candidates in 2016

\begin{tabular}{lcc}
\hline \hline & \multicolumn{2}{c}{ Dependent variable: } \\
\cline { 2 - 3 } & Number of candidate & Number of Female candidates \\
& $(1)$ & $(2)$ \\
\hline Medium AIO & -0.058 & 0.199 \\
& $(0.344)$ & $(0.226)$ \\
High AIO & 0.258 & 0.311 \\
& $(0.361)$ & $(0.209)$ \\
Constant & $4.308^{* * *}$ & $0.385^{* *}$ \\
& $(0.247)$ & $(0.146)$ \\
\hline Observations & 60 & 60 \\
$\mathrm{R}^{2}$ & 0.017 & 0.026 \\
Adjusted $\mathrm{R}^{2}$ & -0.017 & -0.008 \\
\hline \hline Note: & & ${ }^{*} \mathrm{p}<0.1 ;{ }^{* *} \mathrm{p}<0.05 ;{ }^{* * *} \mathrm{p}<0.01$ \\
& &
\end{tabular}

\section{G Effect of expectation of intense monitoring on CDF spending}




\begin{tabular}{lcc|cc}
\hline \hline & \multicolumn{4}{c}{ Intensity of Observation } \\
& \multicolumn{3}{c}{ LP received letter to expect high observation } \\
\hline \multirow{2}{*}{ Expenditure category } & No & Yes & No & Yes \\
\hline Public goods & 60,555 & 47,405 & 136,225 & 144,356 \\
& $(25,063)$ & $(33,126)$ & $(115,993)$ & $(132,087)$ \\
Private goods & 43,314 & 68,621 & 53,617 & 70,067 \\
& $(39,418)$ & $(60,492)$ & $(64,456)$ & $(67,154)$ \\
Donations to local groups & 12,927 & 4,769 & 16,816 & 17,849 \\
& $(11,714)$ & $(7,128)$ & $(22,861)$ & $(23,975)$ \\
Transfers to local government & 1,375 & 8,958 & 15,933 & 22,964 \\
& $(2,750)$ & $(19,345)$ & $(30,258)$ & $(66,514)$ \\
Monitoring and office expense & 0 & 1,926 & 4,004 & 4,781 \\
& $(0)$ & $(2,717)$ & $(8,852)$ & $(9,537)$ \\
Unclear purposed expenditure & 14,786 & 31,533 & 14,888 & 4,867 \\
& $(29,572)$ & $(48,624)$ & $(35,424)$ & $(12,633)$ \\
\hline Total & 132,957 & 163,213 & 241,482 & 264,885 \\
& $(46,187)$ & $(104,513)$ & $(158,274)$ & $(165,813)$ \\
\hline $\mathrm{N}$ & 4 & 9 & 25 & 21 \\
\hline \hline
\end{tabular}

Table G.1: Average legislator CDF spending by intensity of observation and expectation of future high monitoring in 2016 
Table G.2: Average treatment effect of letter on other expense categories

\begin{tabular}{|c|c|c|c|c|}
\hline & \multicolumn{4}{|c|}{ Dependent variable: } \\
\hline & $\begin{array}{l}\text { Donations to local groups } \\
\text { (1) }\end{array}$ & $\begin{array}{l}\text { Transfers to LGs } \\
\text { (2) }\end{array}$ & $\begin{array}{l}\text { Monitoring and office expenses } \\
\text { (3) }\end{array}$ & $\begin{array}{c}\text { Unclear expenses } \\
\text { (4) }\end{array}$ \\
\hline Received letter (=1) & $\begin{array}{c}-0.0005 \\
(0.012)\end{array}$ & $\begin{array}{c}0.014 \\
(0.027)\end{array}$ & $\begin{array}{c}0.002 \\
(0.005)\end{array}$ & $\begin{array}{l}-0.012 \\
(0.015)\end{array}$ \\
\hline High (medium and high) AIO & $\begin{array}{l}0.019^{* *} \\
(0.009)\end{array}$ & $\begin{array}{c}0.028 \\
(0.021)\end{array}$ & $\begin{array}{l}0.006^{*} \\
(0.003)\end{array}$ & $\begin{array}{l}-0.034 \\
(0.025)\end{array}$ \\
\hline Constant & $\begin{array}{c}0.015 \\
(0.010) \\
\end{array}$ & $\begin{array}{c}0.003 \\
(0.020) \\
\end{array}$ & $\begin{array}{c}0.001 \\
(0.003) \\
\end{array}$ & $\begin{array}{l}0.060^{* *} \\
(0.025)\end{array}$ \\
\hline Observations & 59 & 59 & 59 & 59 \\
\hline $\mathrm{R}^{2}$ & 0.028 & 0.016 & 0.020 & 0.047 \\
\hline Adjusted $\mathrm{R}^{2}$ & -0.006 & -0.019 & -0.015 & 0.013 \\
\hline
\end{tabular}

Notes: Units are weighted by the inverse probability treatment that accounts for the block randomization procedure. ${ }^{*} \mathrm{p}<0.1 ;{ }^{* *} \mathrm{p}<0.05 ;{ }^{* * *} \mathrm{p}<0.01$

Figure G.1: Distribution of boostrapped estimates of the difference-in-difference in means
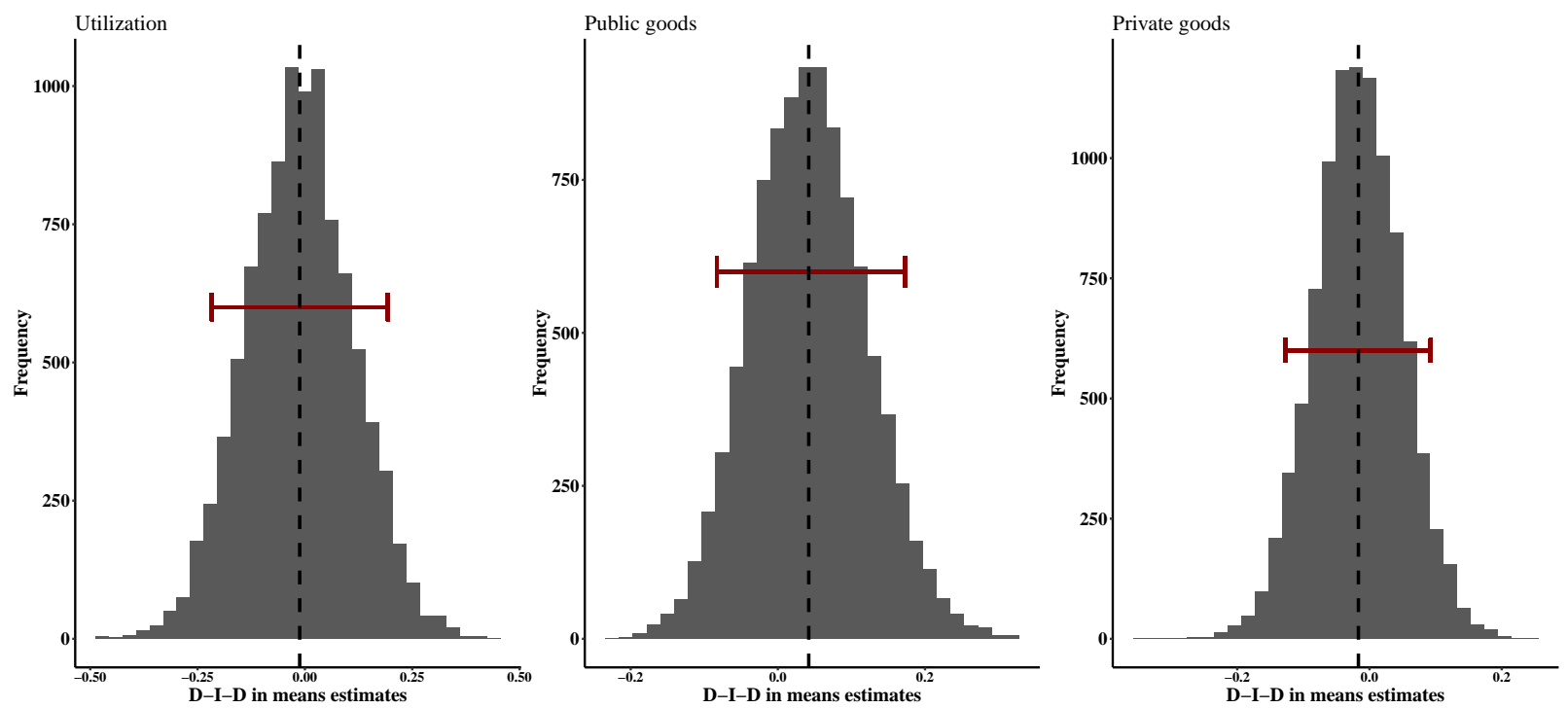


\section{H Total causal effect of observers on fraud and violence}

\section{H.1 Saturation design: two-stage randomization of observers}

In this section, I fully describe the research design reported in Asunka et al. (2019). The experimental design involves a two-stage randomization of treatment (i.e., observation). In the first stage, we assigned the 60 constituencies in our study to one of three intensity of observation (IO) levels: low, medium, or high. We then randomly sampled 30 percent of polling stations from each of our selected constituencies to form our study sample. In low intensity constituencies, CODEO agreed to send observers to 30 percent of polling stations in the sample. In the medium and high intensities, CODEO deployed observers to 50 percent and 80 percent of polling places of the study samples, respectively. We assigned the 60 constituencies to low IO with 20 percent probability and to medium and high IOs with 40 percent probabilities. ${ }^{34}$ Thirteen constituencies were assigned to low IO, while 24 and 23 were assigned to medium and high, respectively. Figure H.1 shows the treatment conditions of constituencies in the sample. CODEO also deployed monitors to the remain constituencies outside our sampled constituencies using their own protocols.

\footnotetext{
${ }^{34}$ Our decision to adopt these probabilities was based on how we compute spillover effects of observers. See authors for details.
} 


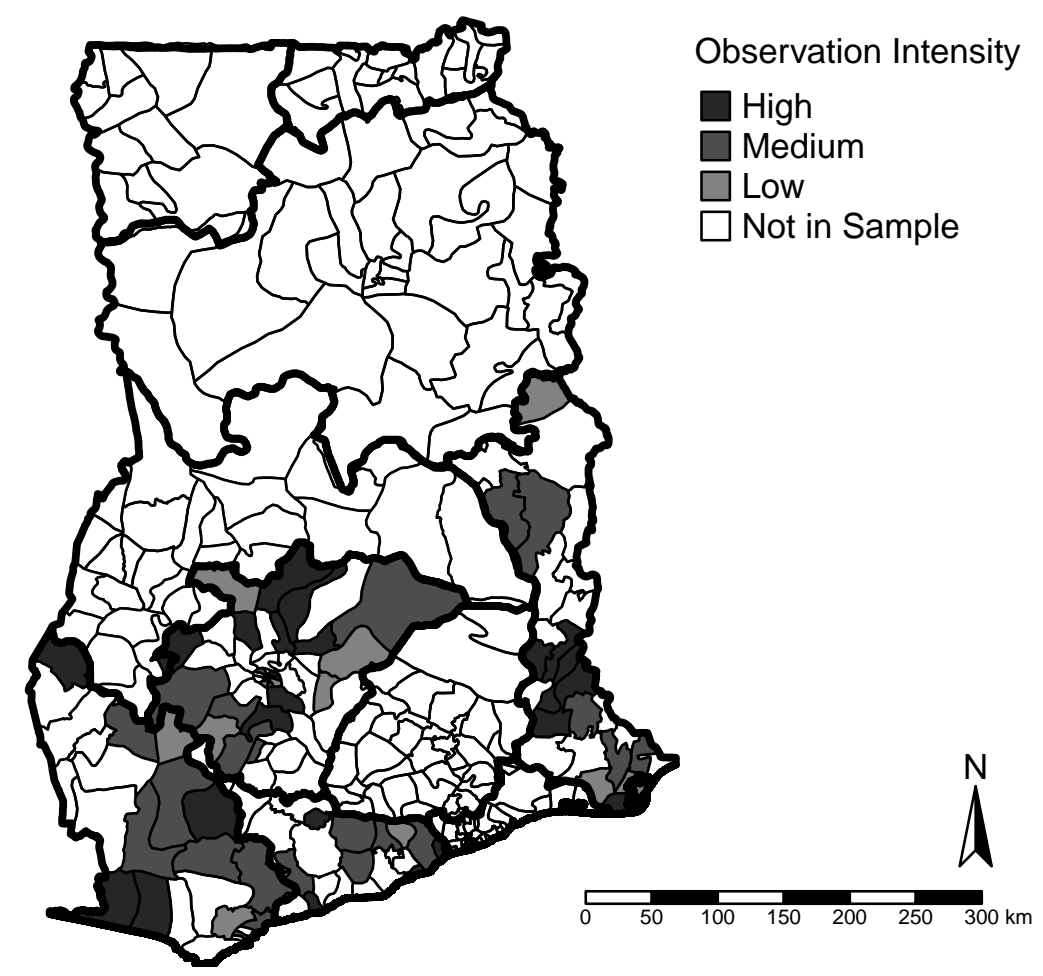

Figure H.1: Map of Ghana: treatment conditions of constituencies

In the second stage, we assigned our sampled polling stations nested within each of the 60 constituencies to treatment (i.e., observation) with probabilities based on the intensities assigned to their constituencies in the first stage. Therefore, the actual concentration of observers in a constituency is $m * 0.3 * P S$, where $P S$ represent the total number of polling stations in a constituency and $m \in\{0.3,0.5,0.8\}$ represent the assigned intensity of observation. There were 2,310 polling stations in the sample and 1,292 were assigned to treatment. Figure H.2 shows the distribution of the proportion of polling stations in the entire constituencies assigned to receive observers by treatment saturation. 
Figure H.2: Distribution of the proportion of polling stations in constituencies assigned to treatment by saturation

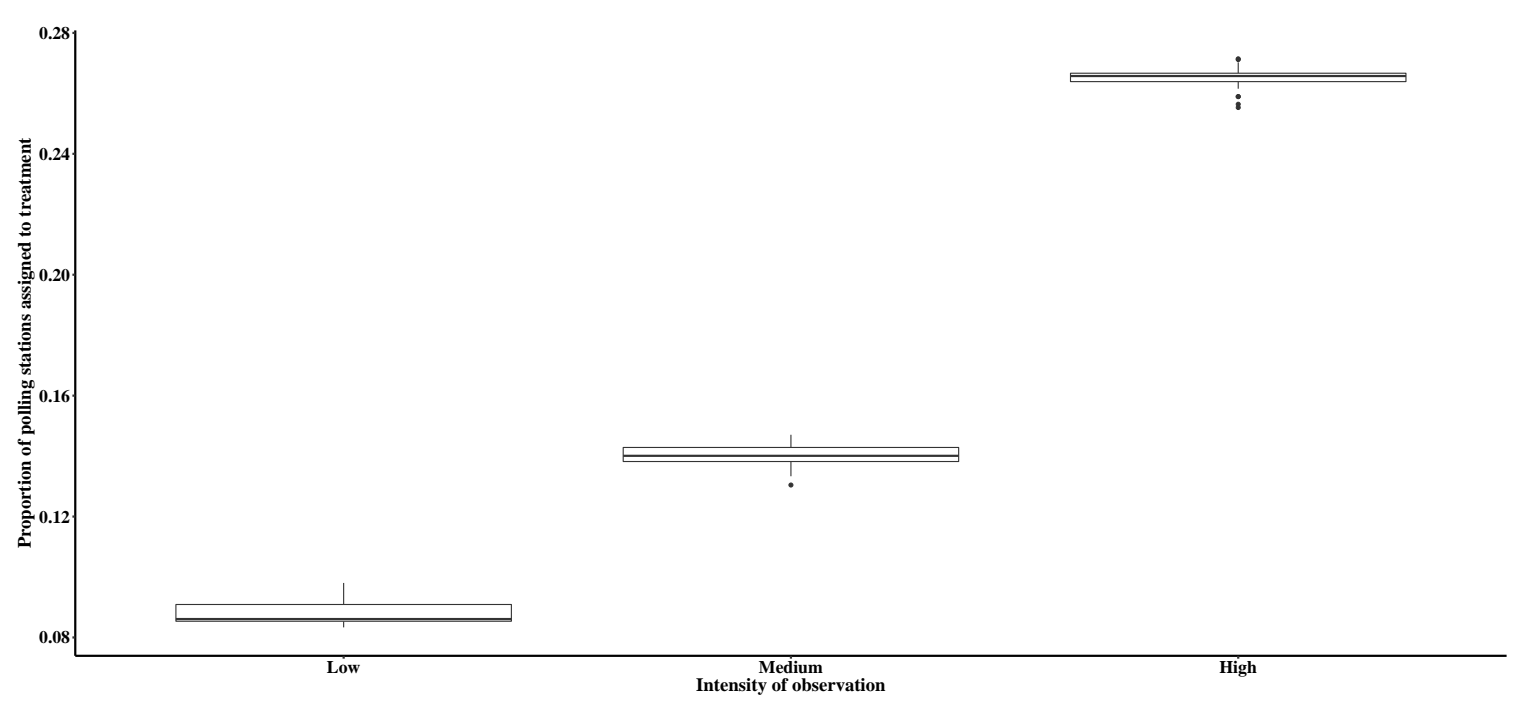

\section{H.2 Measuring the total causal effect of intensity of observation on electoral fraud}

To estimate the total average causal effect of observers at the constituency level, TCE, I compare the average fraud and violence outcomes for all stations (treated and control) at medium (high) IO constituencies to the average outcome in control units in low IO constituencies. The control stations in the low IO constituencies serve as the estimate of the level of fraud in the absence of observers at a given IO taking into account potential spillover effects. Thus, I calculate the TCE $(m)$ as follows:

$$
T C E(\mathrm{~m})=\mathrm{E}\left(Y_{i j} \mid M_{j}=m\right)-\mathrm{E}\left(Y_{i j} \mid T_{i j}=0, M_{j}=\text { low }\right)
$$

where $\mathrm{E}\left(Y_{i j} \mid M_{j}=\mathrm{m}\right)$ is the average level of fraud or violence for polling station $i$ located in constituency $j$ with intensity of observation $m \in\{$ medium, high $\} . \mathrm{E}\left(Y_{i j} \mid T_{i j}=0, M_{j}=\right.$ low $)$ measures the average outcome for all control stations in low IO constituencies. $T_{i j}=t$ represents the 
treatment status of polling station $i$ located in constituency $j$, where $t \in\{$ treated $=1$, control $=0\}$. 35

\section{H.3 First-stage results of treatment}

Table H.1 reports the treatment effect of IO on fraud and violence. I include the results for indicators of fraud and violence, turnout and intimidation of voters during voting, reported in (Asunka et al., 2019). To be sure, turnout is not fraudulent in itself. It only serve as an indicator of fraud insofar as they systematically vary with randomly placed observers. That is, in the absence of fraud in the form of multiple voting and ballot stuffing, we should expect similar turnout rates and vote counts for parties, on average, in treated (monitored) and control (unmonitored) polling stations.

Columns (1) and (2) report the TCEs of intensity of the IO on turnout and intimidation of voters in the full sample. Columns (3 and 4) and (5 and 6) breaks these results by levels of electoral competition at the constituency level. These first-stage results (discussed in section 3) suggest that increasing the intensity of observation in a constituency reduces overall levels of fraud and violence. Further, they justify using IO as an instrument for the integrity of elections.

\footnotetext{
${ }^{35}$ Based on the operational structures of political parties in Ghana, we assume that spillover effects will be confined within constituencies. That is, we assume no interference across constituencies.
} 
Table H.1: Higher intensity of election observation reduces constituency-level fraud and violence

\begin{tabular}{|c|c|c|c|c|c|c|}
\hline & \multicolumn{6}{|c|}{ Dependent variable: } \\
\hline & $\begin{array}{c}\text { Turnout } \\
\text { (1) }\end{array}$ & $\begin{array}{l}\text { Full sample } \\
\text { Intimidation of voters } \\
\qquad(2)\end{array}$ & $\begin{array}{c}\text { Comp } \\
\text { Turnout } \\
\text { (3) }\end{array}$ & $\begin{array}{l}\text { titive constituencies } \\
\text { Intimidation of voters } \\
\text { (4) }\end{array}$ & $\begin{array}{l}\text { Non-con } \\
\text { Turnout } \\
\text { (5) }\end{array}$ & $\begin{array}{l}\text { petitive constituencies } \\
\text { Intimidation of voters } \\
\text { (6) }\end{array}$ \\
\hline Medium intensity of observation & $\begin{array}{c}-0.056^{*} \\
(0.032)\end{array}$ & $\begin{array}{l}-0.004 \\
(0.049)\end{array}$ & $\begin{array}{c}-0.095^{*} \\
(0.054)\end{array}$ & $\begin{array}{c}0.104 \\
(0.080)\end{array}$ & $\begin{array}{l}-0.032 \\
(0.034)\end{array}$ & $\begin{array}{l}-0.069 \\
(0.049)\end{array}$ \\
\hline High intensity of observation & $\begin{array}{c}-0.055^{*} \\
(0.030)\end{array}$ & $\begin{array}{l}-0.054 \\
(0.036)\end{array}$ & $\begin{array}{c}-0.102^{*} \\
(0.053)\end{array}$ & $\begin{array}{c}0.015 \\
(0.027)\end{array}$ & $\begin{array}{l}-0.026 \\
(0.031)\end{array}$ & $\begin{array}{c}-0.091^{*} \\
(0.048)\end{array}$ \\
\hline Constant & $\begin{array}{c}0.889^{* * *} \\
(0.027) \\
\end{array}$ & $\begin{array}{c}0.102^{* * *} \\
(0.035) \\
\end{array}$ & $\begin{array}{c}0.920^{* * *} \\
(0.049) \\
\end{array}$ & $\begin{array}{l}0.039^{*} \\
(0.023) \\
\end{array}$ & $\begin{array}{c}0.871^{* * *} \\
(0.026) \\
\end{array}$ & $\begin{array}{c}0.135^{* * *} \\
(0.047) \\
\end{array}$ \\
\hline Observations & 1,622 & 1,554 & 667 & 639 & 955 & 915 \\
\hline $\mathrm{R}^{2}$ & 0.005 & 0.009 & 0.012 & 0.025 & 0.002 & 0.012 \\
\hline Adjusted $\mathrm{R}^{2}$ & 0.003 & 0.008 & 0.009 & 0.022 & -0.0005 & 0.010 \\
\hline
\end{tabular}

Notes: I use two indicators of election-day fraud and violence: turnout and intimidation during voting. The unit of analysis is the polling station. Columns 1 and 2 shows the results for these two indicators in the full sample while columns 3 and 4, and 5 and 6 shows those for competitive and non-competitive constituencies, respectively. The Total Causal Effect (TCE) represents the overall effect of observers within constituencies monitored adjusting for potential spillover effects. Standard errors reported in parentheses are clustered at the constituency level. ${ }^{*} p<0.1 ;{ }^{* *} p<0.05$; ${ }^{* * *} p<0.01$.

\section{Measuring responsiveness: use of Constituency Development Funds}

I use legislators' spending of their state-provided CDFs as my measure of responsiveness regarding constituency service. I use monthly reports of MPs' expenses to record and classify the type of goods and services to which MPs allocate their funds. Figures I.1 and I.2 provide examples of the expense sheets I coded. These records submitted by the local government (District Assembly) of the MPs are available at the Ghana District Assemblies' Common Fund Administration (DACF) at Accra in Ghana. I coded MPs expenses between 2014 and 2016 that were available in the archives of the DACF office. Between this period I coded 2,160 months of expenditure sheets for 60 MPs. Table I.1 shows the six main expenditure types as well as their sub-categories and my coding rule.

\section{I.0.1 Summary statistics of expenses}

Table I.2 presents the summary statistics of MPs' use of their CDF in general (total spending) and across different expenditure categories (Panel A). The total amount of funds that MPs expect 


\section{JUARY 2014 ASSEMBLY: MAMPONG On UNICARAR \\ MENTS \\ C}

\begin{tabular}{|c|c|c|c|c|c|c|}
\hline Date & Payee & Particulars of Payments & Folio & P.V. No. & Chq. No. & Bank \\
\hline \multirow[t]{2}{*}{$16-1-14$} & bocteng Yaw & Being funarciel essist- & & 9 & 640307 & $1200 \cdot 0$ \\
\hline & Ounsu stephen & ance $t=$ students & & & & \\
\hline & & & & & & \\
\hline \multirow[t]{3}{*}{$6-01-14$} & Boakengtans & Being payment in resp- & & 02 & 640308 & $1500 \cdot 00$ \\
\hline & Oursugtephen & rect of Ashanti ups faot- & & & & \\
\hline & & bell club. & & & & \\
\hline \multirow{2}{*}{$6-01-14$} & Boateng faw & Beirs donetins to & & $\theta_{3}$ & 640309 & 2500.05 \\
\hline & Osnusustephen & - cherdes & & & & \\
\hline \multirow[t]{2}{*}{$16-01-14$} & K. Ofori bur- & - Beins payment lo supp & & ore & 610310 & 2200.0 \\
\hline & mooh & one of te mosque pro ject & & & & \\
\hline \multirow[t]{3}{*}{$b-01-14$} & K. Oforibwo- & - Being payment of Fin- & & 05 & 640311 & 1700.0 \\
\hline & moh & ancielassistant to & & & & \\
\hline & & students & & & & \\
\hline \multirow{4}{*}{$6-91-16$} & Blessed Home & e being 100 bags of cement & & 06 & 640312 & 2.294 .25 \\
\hline & fuper Cement & in support of ve censtru- & & & & \\
\hline & & ction of terdersquarters & & & & \\
\hline & & ar Kyekyewere & & & & \\
\hline $16-01-14$ & URA & $5 \%$ WHT & & & 640313 & 120.75 \\
\hline $13-9-14$ & cura & $5 \%$ WHT & & & 640317 & 7126.00 \\
\hline \multirow[t]{4}{*}{$6-01-14$} & Goaf tint & Being 100 bags of Cem & & or & 640314 & 2294.25 \\
\hline & & ent in support of const & & & & \\
\hline & & ruction of a community & & & & \\
\hline & & tentre for Bosofon & & & & \\
\hline $6-9-14$ & arA & $5 \%$ WH & & & 640315 & $120 \cdot 75$ \\
\hline \multirow[t]{4}{*}{$14-01-14$} & Edwoin Back & Being paymentinty & & of & 640318 & $19,000 \cdot 00$ \\
\hline & & pect of $a 10$-seater & & & & \\
\hline & & KVIP place of converuence & & & & \\
\hline & & for Kyvempass commits & & & & \\
\hline $24-01-14$ & aRA & $5 \% \omega H T$ & & & 640319 & $1000 \cdot 4=$ \\
\hline \multirow[t]{10}{*}{$: 1-91-14$} & $N L B$ & Banlc charges & & & & 60.60 \\
\hline & & 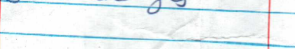 & & & & $33990+=$ \\
\hline & & & & & & $34116 \cdot 20$ \\
\hline & & Bel cld & & & & 9285.64 \\
\hline & & & & & & 43401.64 \\
\hline & & & & & & \\
\hline & & & & & & \\
\hline & & & & & & \\
\hline & & +2 & & & & \\
\hline & & & & & & \\
\hline
\end{tabular}

Figure I.1: Exhibit 1: MPs' CDFs expenditure sheet

Notes: MPs' CDFs expenditure sheets are month-by-month reports of itemized spending by an individual legislator. These sheets are submitted by MPs' local governments to the national fund administrator. 
MENTS

ASSEMBLY: SEKYERE KUMA

\begin{tabular}{|c|c|c|c|c|c|c|}
\hline Date & Payee & Particulars of Payments & Folio & P.V. No. & Chq. No. & Bank \\
\hline \multirow[t]{2}{*}{ o.210lut } & Gideon & Beng financial suppons & ito & onlotuf & 687462 & 200.00 \\
\hline & $\begin{array}{l}\text { Appraes } \\
\text { (Chawles Anpian) }\end{array}$ & $\begin{array}{l}\text { Chartes Applac. (blind) at } \\
\text { his house mojeit. }\end{array}$ & completes & & & \\
\hline & & & & & & \\
\hline \multirow{2}{*}{0.2100104} & Herbert & Bemg finamcial assist & ance, a & osholus & 687464 & 400.00 \\
\hline & A. Boaten & stradent at offinso Co & l. of. Edur & & & \\
\hline \multirow[t]{2}{*}{$02 / 10 / 14$} & Secdorf & Being fmaincial a saistan. & $Q, a$ & ozluolut & 687465 & $300 \cdot 00$ \\
\hline & Amoakohene & student of Univer sitis of & f Chana & & & \\
\hline \multirow{3}{*}{ B/olut } & & & & & & \\
\hline & $\begin{array}{l}\text { Dade a se } \\
\text { Communit }\end{array}$ & Berng tinanaial support t & or electri- & ortwolut & 687466 & 700.00 \\
\hline & & 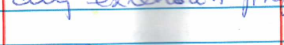 & & & & \\
\hline \multirow{2}{*}{$13 / \omega / 14$} & Dadease & Bering financial support to & $r$ renovatio & ostuolue & 687467 & $1,200 \cdot 00$ \\
\hline & Communily & of DlA 'A' Jts block & & & & \\
\hline \multirow[t]{2}{*}{13 lolut } & Akotoru & Berins financial support for & toilet & $06 / 10$ uf & 687468 & $1,000,00$ \\
\hline & Community & project & & & & \\
\hline & & & & & & \\
\hline \multirow{2}{*}{ Blotur } & Akrofoso & Being financial Suggent for & Completion & oflolut & 687469 & $1,000,00$ \\
\hline & Unit Commitis & of talet project & & & & \\
\hline \multirow{3}{*}{ isloolue } & & Bem financial assistant & fortho & $0 \times 1014$ & 687470 & \\
\hline & $\begin{array}{l}\text { Pepeade } \\
\text { Cormunity }\end{array}$ & $\begin{array}{l}\text { Bemg tinanceal adsistor. } \\
\text { Construction } K V \mid P\end{array}$ & & 08 indit & & $1,000 \cdot 00$ \\
\hline & & & & & & \\
\hline \multirow[t]{2}{*}{20 holut } & Ether & Being financial assistan & 2, a student & oqhohy & 687471 & 400.00 \\
\hline & Gyebye & at SD.A College of $f$ id & ucation & & & \\
\hline \multirow{4}{*}{ zoholut } & Twenetronk. & acial assistan. & \& to Dapacal & wholut & 687472 & 300.00 \\
\hline & Koduch & Salomer A. a shudef & $\downarrow$ at & & & \\
\hline & stts & TK SEIS. & & & & \\
\hline & & & & & & \\
\hline \multirow[t]{3}{*}{ 2ololut } & Tweneboal & Being finamial assistan & a to & ilulus & 687473 & $300 \cdot 00$ \\
\hline & koduah & Osei framcis. & & & & \\
\hline & stts & & & & & \\
\hline \multirow[t]{2}{*}{ 2olvoluf } & Ejisu & Being finanical assistat & hee to & $12 \ln \ln 4$ & 687474 & 300.07 \\
\hline & stts & Frank Adu Pokn. & & & & \\
\hline
\end{tabular}

Figure I.2: Exhibit 2: MPs' CDFs expenditure sheet

Notes: MPs' CDFs expenditure sheets are month-by-month reports of itemized spending by an individual legislator. These sheets are submitted by MPs' local governments to the national fund administrator. 
Table I.1: Classification of MPs' spending of Constituency Development Funds

\begin{tabular}{|c|c|c|}
\hline Type & Categories & Criteria \\
\hline \multirow[t]{4}{*}{ Public goods } & Education & $\begin{array}{l}\text { Construction or repair of school buildings, extra classes for } \\
\text { schools, mock exams for final year students, and textbooks and } \\
\text { other school supplies distributed to schools. }\end{array}$ \\
\hline & Health & $\begin{array}{l}\text { Construction or repair of local clinics, clearing of community } \\
\text { dumpster, immunization exercises, and health awareness pro- } \\
\text { grams. }\end{array}$ \\
\hline & $\begin{array}{l}\text { Repair and construc- } \\
\text { tion }\end{array}$ & $\begin{array}{l}\text { Road, bridges, water pumps, and purchase of construction ma- } \\
\text { terials to support community initiated projects (electoral area is } \\
\text { specified). }\end{array}$ \\
\hline & Safety and Security & $\begin{array}{l}\text { Police operations (i.e., providing security for community events) } \\
\text { and providing street lights or replacing street bulbs. }\end{array}$ \\
\hline \multirow[t]{4}{*}{ Personal goods } & Education & $\begin{array}{l}\text { Scholarship for "needy but brilliant" students, including schol- } \\
\text { arships for education abroad. Also include sponsorship for ap- } \\
\text { prenticeships (driving school, hairdressing, and dressmaking). }\end{array}$ \\
\hline & Health & Medical bills for individuals (including medical surgeries). \\
\hline & Business & $\begin{array}{l}\text { Support constituents to start their own businesses including } \\
\text { farms and retail shops. }\end{array}$ \\
\hline & Needy & $\begin{array}{l}\text { Replacing roofing sheets, and pocket money (general financial } \\
\text { assistance). }\end{array}$ \\
\hline \multirow[t]{2}{*}{ Donation to groups } & $\begin{array}{l}\text { Religious/traditional } \\
\text { authorities }\end{array}$ & $\begin{array}{l}\text { Donation to church fundraising activities (e.g., church building } \\
\text { and annual harvest). Donation to traditional festivals, funerals, } \\
\text { and repairs of the chief's palace. }\end{array}$ \\
\hline & Youth organizations & Sponsor capacity building workshops and soccer tournaments. \\
\hline \multirow[t]{2}{*}{$\begin{array}{l}\text { Transfers to District } \\
\text { Assembly }\end{array}$} & $\begin{array}{l}\text { Organization of na- } \\
\text { tional events locally }\end{array}$ & $\begin{array}{l}\text { Payment for national events held locally, including indepen- } \\
\text { dence day celebration and national farmers' day celebration. }\end{array}$ \\
\hline & Operational cost & $\begin{array}{l}\text { Repair works on local government buildings and infrastructure, } \\
\text { fuel local government vehicles and maintenance of machinery. } \\
\text { Transfers to local government account often stated as a loan. }\end{array}$ \\
\hline \multirow[t]{2}{*}{$\begin{array}{l}\text { Monitoring and Of- } \\
\text { fice Expense }\end{array}$} & $\begin{array}{l}\text { Monitoring of MPs' } \\
\text { project }\end{array}$ & $\begin{array}{l}\text { Paid directly to MPs to cover their inspection of projects in their } \\
\text { constituency. }\end{array}$ \\
\hline & Office expense & $\begin{array}{l}\text { Office building rent, operational expenses, and staff salary for } \\
\text { MPs' office in the constituency. }\end{array}$ \\
\hline $\begin{array}{l}\text { Unclear Purpose } \\
\text { Expenditure }\end{array}$ & $\begin{array}{l}\text { Beneficiary or pur- } \\
\text { pose of payment is } \\
\text { unclear }\end{array}$ & $\begin{array}{l}\text { Examples include: MP direct purchase (e.g., TV sets, cutlasses, } \\
\text { etc.) for which the Fund Manager deducted amounts; purchase } \\
\text { of building materials for which the purpose was not stated; pur- } \\
\text { chase of motorbikes with no stated beneficiary or purpose; pur- } \\
\text { chase of food items (e.g., bags of rice, oil etc.) with no stated } \\
\text { beneficiaries; and transfers to individuals or business organiza- } \\
\text { tions with no stated service provided or materials supplied. }\end{array}$ \\
\hline
\end{tabular}


in any particular fiscal year is contained in a legislation referred to as the District Assemblies Common Fund Formula, which is passed each year. Funds are then released to MPs in four tranches during the fiscal year. In anticipation of these disbursements, MPs may provide benefits to their constituencies and reimbursed their creditors when funds are released. When MPs make direct purchases, the FA deducts the amount used before transferring the remaining (net amount) to MPs' CDF account managed by their local governments. These deductions are reflected in the records submitted by the DA and often unclear what goods were purchased or who the target beneficiaries.

Table I.2 Panel B shows the summary statistics of the dependent variables used in my analysis, which I created using the data on expenditure. Utilization measures the proportion of allocated funds (i.e., GHC 1, 264, 987) spent between 2014 and 2016. Public Goods and Private Goods measures the proportion of allocated funds used by an MP to provide public and private goods, respectively. 


\begin{tabular}{lccccc}
\hline Statistic & N & Mean & St. Dev. & Min & Max \\
\hline Panel A: CDF Spending & & GHC & GHC & GHC & GHC \\
Public goods & 60 & 290,414 & 233,426 & 0 & $1,169,500$ \\
Private goods & 60 & 128,136 & 91,951 & 0 & 447,886 \\
Donation to local groups & 60 & 31,201 & 37,499 & 0 & 185,489 \\
Transfers to local government & 60 & 37,391 & 66,637 & 0 & 344,885 \\
Monitoring and office expenses & 60 & 8,371 & 13,826 & 0 & 60,681 \\
Unclear purposed expenditure & 60 & 26,703 & 42,834 & 0 & 198,811 \\
Total spending & 60 & 522,216 & 283,345 & 111,400 & $1,308,597$ \\
& & & & & \\
Panel B: Dependent variables & & & & & \\
Utilization & 60 & 0.415 & 0.223 & 0.088 & 1.034 \\
Public goods & 60 & 0.231 & 0.184 & 0.000 & 0.925 \\
Private good & 60 & 0.102 & 0.072 & 0.000 & 0.354 \\
Donation to local groups & 60 & 0.025 & 0.030 & 0.000 & 0.147 \\
Transfers to local government & 60 & 0.030 & 0.053 & 0.000 & 0.273 \\
Monitoring and office expenses & 60 & 0.007 & 0.011 & 0.000 & 0.048 \\
Unclear expenses & 60 & 0.021 & 0.034 & 0.000 & 0.157 \\
\hline \hline
\end{tabular}

Table I.2: Summary statistics of MPs' use of their CDFs between 2014 and 2016

Notes: Table I.2 shows the summary statistics of the use of CDFs by MPs. Part A presents the summary statistics of legislators' itemized expenses as well as their total expenditure in actual amounts. Part B shows the proportion of available funds between 2014 and 2016, GHC 1,264,987 that were used up by MPs in general (Utilization) as well as on the different expenditure types. Amounts are in Ghana Cedis (GHC)(the exchange rate was GHC3.72= \$1 in August 2014 according to http:// freecurrencyrates.com/en/exchange-rate-history/USD-GHS/2014/ yahoo). 


\section{J Interviews with MPs}

I conducted interviews with 47 out of 60 MPs in my sample between November 2015 and January 2016. The purpose of these interviews was twofold. First, it was to assess MPs' responsiveness to their constituents indicated by how they report allocating their time. Second, it was to examine some potential mechanism that drives the results in this study. I show some of the interview results on the latter in Section F. In this section, I report on the first. The results broadly support the findings presented in the paper that MPs elected in intensely monitored constituencies provide greater constituency services.

Table J.1 shows MPs' self-reported levels of provision of constituency services (Part A) and legislative activities (Part B). In Part A, I show results for the following: (1) the percentage of MPs' times spent in the constituency (during parliamentary sessions); (2) number of times they visit their constituency in a year; (3) whether they have applied for external funds to support constituency development projects; and (4) whether they organize monthly meetings to listen to constituents demands. In Part B, I report results on whether an MP has spoken frequency (7 or more) during their term in office on: (1) National policy or project implementation issues; and (2) Constituency development issues.

The results show that MPs elected from intensely monitored constituency report to spend a higher proportion of their time in their constituencies compared to those elected from low-intensity observation constituencies. They also visit more annually. Also, representatives elected from high-integrity elections report to seek external funds to support projects in their constituencies and organize meetings frequently (monthly) to listen to their constituents concerns. While not all estimates on these indicators are statistically significant, they appear substantively large. Together, these results suggest that high-election integrity increases the level of effort legislators exert in constituency services. However, while those elected in intensely-monitored elections also appear 
to report slightly more activities in the legislature, these differences are neither substantively nor statistically significant. 


\begin{tabular}{|c|c|c|c|c|}
\hline & \multirow[b]{2}{*}{$\begin{array}{c}\text { Full sample } \\
\text { (1) }\end{array}$} & \multicolumn{2}{|c|}{ Actual Intensity of Observation } & \multirow{2}{*}{$\begin{array}{l}\text { ITT } \\
\text { (4) }\end{array}$} \\
\hline & & $\begin{array}{l}\text { Low } \\
(2)\end{array}$ & $\begin{array}{l}\text { High } \\
\text { (3) }\end{array}$ & \\
\hline \multicolumn{5}{|l|}{ Constituency Services } \\
\hline Percentage of MPs' time spent in constituency & $\begin{array}{c}41 \\
(11.34)\end{array}$ & $\begin{array}{c}34.33 \\
(10.57)\end{array}$ & $\begin{array}{l}43.29 \\
(10.8)\end{array}$ & $\begin{array}{l}8.95^{* *} \\
(3.17)\end{array}$ \\
\hline \# of MP visits to constituency annually & $\begin{array}{c}38.35 \\
(12.03)\end{array}$ & $\begin{array}{c}33.82 \\
(15.01)\end{array}$ & $\begin{array}{c}39.77 \\
(10.8)\end{array}$ & $\begin{array}{c}5.95 \\
(5.09)\end{array}$ \\
\hline MP applied for donor funds to support constituency & $\begin{array}{c}0.28 \\
(0.45)\end{array}$ & $\begin{array}{c}0.17 \\
(0.39)\end{array}$ & $\begin{array}{c}0.31 \\
(0.47)\end{array}$ & $\begin{array}{c}0.15 \\
(0.14)\end{array}$ \\
\hline MP organizes monthly constituents' meeting & $\begin{array}{c}0.62 \\
(0.49)\end{array}$ & $\begin{array}{c}0.4 \\
(0.52)\end{array}$ & $\begin{array}{c}0.69 \\
(0.47)\end{array}$ & $\begin{array}{c}0.29 \\
(0.19)\end{array}$ \\
\hline \multicolumn{5}{|l|}{ Legislative Activities } \\
\hline National policy or project implementation & $\begin{array}{c}0.38 \\
(0.49)\end{array}$ & $\begin{array}{c}0.25 \\
(0.45)\end{array}$ & $\begin{array}{c}0.43 \\
(0.50)\end{array}$ & $\begin{array}{c}0.18 \\
(0.16)\end{array}$ \\
\hline MP raise concerns of constituency & $\begin{array}{c}0.38 \\
(0.49)\end{array}$ & $\begin{array}{c}0.33 \\
(0.49)\end{array}$ & $\begin{array}{c}0.40 \\
(0.50)\end{array}$ & $\begin{array}{c}0.07 \\
(0.17)\end{array}$ \\
\hline $\mathrm{N}$ & 47 & 12 & 35 & \\
\hline
\end{tabular}

Table J.1: Higher-intensity of observation increases MPs' constituency services, but have no effect on MPs' legislative activities

Note: Table J.1 presents result from a survey of MPs on their constituency services and legislative activities. A standard instrument was used to conduct these interviews with the help of research assistants. Columns (1)-(3) report the means and standard deviation (in parentheses) for each MPs self-reported activities in the Full sample, and Low and High intensely-monitored constituencies, respectively. Columns (4) report the average ITT effects (difference in means) of the treatment with robust standard errors (HC2). ${ }^{*} \mathrm{p}<0.1 ;{ }^{* *} \mathrm{p}<0.05 ;{ }^{* * *} \mathrm{p}<0.01$ 
Table J.2 display results for how MPs report spending their time on the top three activities that take the most of their time when they visit their constituency. I provided MPs with six items (and they were free to add other activities). I gave MPs the following options: holding a oneto-one meeting with constituents; holding community with constituents; holding meetings with community leaders; holding meetings with party executives; inspecting constituency projects; and attending social events such as funerals, religious activities, traditional festivals, etc. They were first to choose the three activities and then divide their 100 percent working time to these three things. For most of these activities, I find no significant difference among MPs across the treatment who chose them, suggesting they dedicate a similar amount of time. Interesting, among the few MPs who chose "inspecting constituency projects" as one of their three key activities, those elected in intensely-monitored constituencies spend a higher percentage of their time on this activity. They, however, dedicate less time to social events such as funerals and church services. These results support my claim that high-integrity elections encourage legislators to exert a higher effort in providing public goods (works) to their constituents. 


\begin{tabular}{|c|c|c|c|c|}
\hline & \multicolumn{4}{|c|}{ Intensity of Observation } \\
\hline & $\begin{array}{l}\text { Full sample } \\
\text { (1) }\end{array}$ & $\begin{array}{l}\text { Low } \\
\text { (2) }\end{array}$ & $\begin{array}{l}\text { High } \\
\text { (3) }\end{array}$ & $\begin{array}{r}I T T \\
(4)\end{array}$ \\
\hline Holding one-to-one meeting with your constituents & $\begin{array}{c}38.32 \\
(12.42)\end{array}$ & $\begin{array}{c}36.30 \\
(10.55)\end{array}$ & $\begin{array}{c}39.29 \\
(13.35)\end{array}$ & $\begin{array}{c}2.99 \\
(4.61)\end{array}$ \\
\hline Holding community meeting with your constituents & $\begin{array}{c}34.77 \\
(14.70)\end{array}$ & $\begin{array}{c}30.38 \\
(16.47)\end{array}$ & $\begin{array}{c}36.36 \\
(14.07)\end{array}$ & $\begin{array}{c}5.99 \\
(6.94)\end{array}$ \\
\hline Holding meetings with community leaders & $\begin{array}{l}19.09 \\
(4.91)\end{array}$ & $\begin{array}{c}15 \\
(7.07)\end{array}$ & $\begin{array}{c}20 \\
(4.33)\end{array}$ & $\begin{array}{c}5 \\
(7.23)\end{array}$ \\
\hline Holding meetings with party executives & $\begin{array}{c}34.82 \\
(13.83)\end{array}$ & $\begin{array}{c}32.50 \\
(11.90)\end{array}$ & $\begin{array}{c}35.33 \\
(14.48)\end{array}$ & $\begin{array}{c}2.83 \\
(7.72)\end{array}$ \\
\hline * Inspecting constituency projects & $\begin{array}{c}26.33 \\
(10.23)\end{array}$ & $\begin{array}{l}10 \\
()\end{array}$ & $\begin{array}{l}29.60 \\
(7.13)\end{array}$ & $\begin{array}{c}19.60^{* *} \\
()\end{array}$ \\
\hline Attending events such as funerals, church services, durbars (festivals), etc. & $\begin{array}{c}32.71 \\
(12.54)\end{array}$ & $\begin{array}{c}38.55 \\
(12.14)\end{array}$ & $\begin{array}{l}30.57 \\
(12.19\end{array}$ & $\begin{array}{l}-7.98 * \\
(4.46)\end{array}$ \\
\hline
\end{tabular}

Table J.2: When visiting their constituency, MPs elected from higher-intensity observation districts spend more time on inspecting constituency development projects, and less on attending social events

Note:Table J.2 presents results from a survey of MPs on how they divide their time when they visit their constituencies. MPs were provided with all the activities in the table and asked to choose the top three that took most of their time. They were then asked to allocate what proportion of their time they assigned to their top three choices. The specific question was: "When in your constituency, which THREE of the following activities take up the most of your time? Please tell me what percentage of your time you spend on each of these three:. " Table J.2 Columns (1)-(4) reports the means and standard deviations (in parentheses) of the time MPs report they allocate to each of these activities, if they selected it as one of their top three, in the Full sample, and Low, Medium, and High intensely monitored constituencies, respectively. Columns (5) and (6) report the ITT effects of intensity of observation in Medium and High IO constituencies, respectively along with robust standard errors. ${ }^{*} \mathrm{p}<0.1 ;{ }^{* *} \mathrm{p}<0.05 ;{ }^{* * *} \mathrm{p}<0.01$ 


\section{K Power analysis for main effects}

In this section, I use simulations to estimate the probability of detecting statistically significant effects of the various hypothesized effects in my main analysis. With the benefit of observing the outcomes in the control group (i.e., the mean and standard errors), I specified hypothesized effects between zero and 30 percent and estimated the statistical power for each. Figures K.1 and K.2 shows the power for two and three treatment arms. In the latter, I take an experiment as generating significant effects when the coefficients associated with medium and high are both greater than zero and their associated $p$-values are also $\leq 0.05$. The parameters (i.e., outcomes in control reported in Table E.2) for estimating the statistical power were as follows:

- Number of simulations $=10,000$

- Utilization $\rightarrow N \sim(\mu=0.266, s d=0.032)$

- Public goods $\rightarrow N \sim(\mu=0.111, s d=0.019)$

- Private goods $\rightarrow N \sim(\mu=0.096, s d=0.021)$

However, I am aware of the potential pitfalls of using post-hoc estimates from a single experiment to estimate the power of the results of the same study. The key idea is that because the estimates from this single study represent a noisy measure of the relevant parameters to conduct a power analysis, it may lead to over-optimism about the statistical power (see a discussions on this issues by Andrew Gelman: https://statmodeling.stat.columbia.edu/2019/01/13/ post-hoc-power-calculation-like-shit-sandwich/). 
Figure K.1

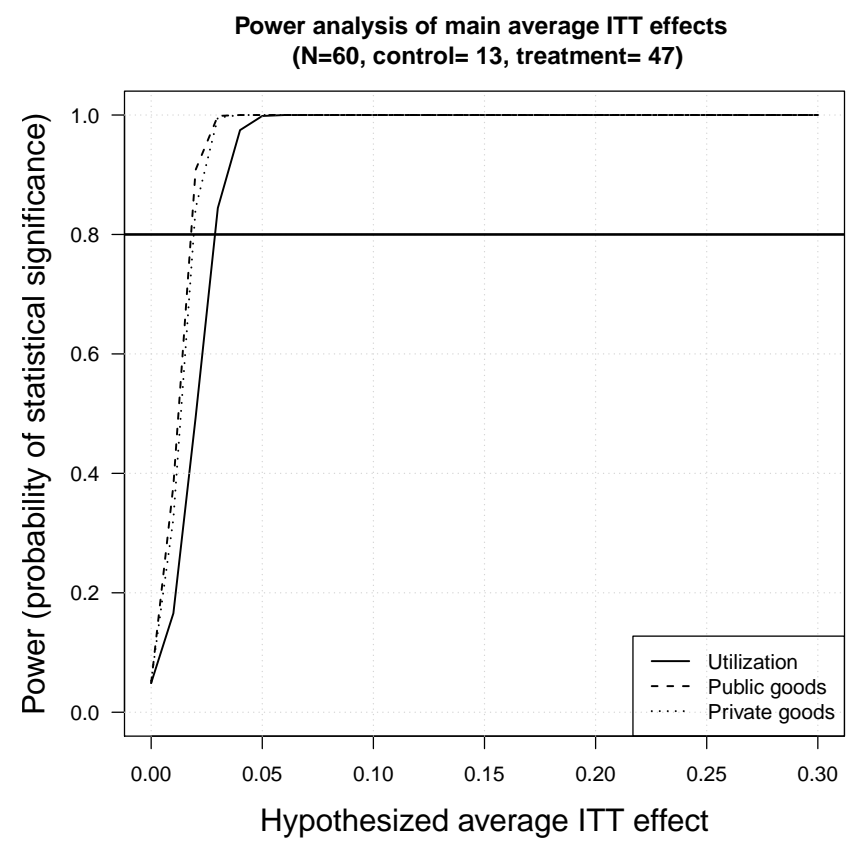

Figure K.2

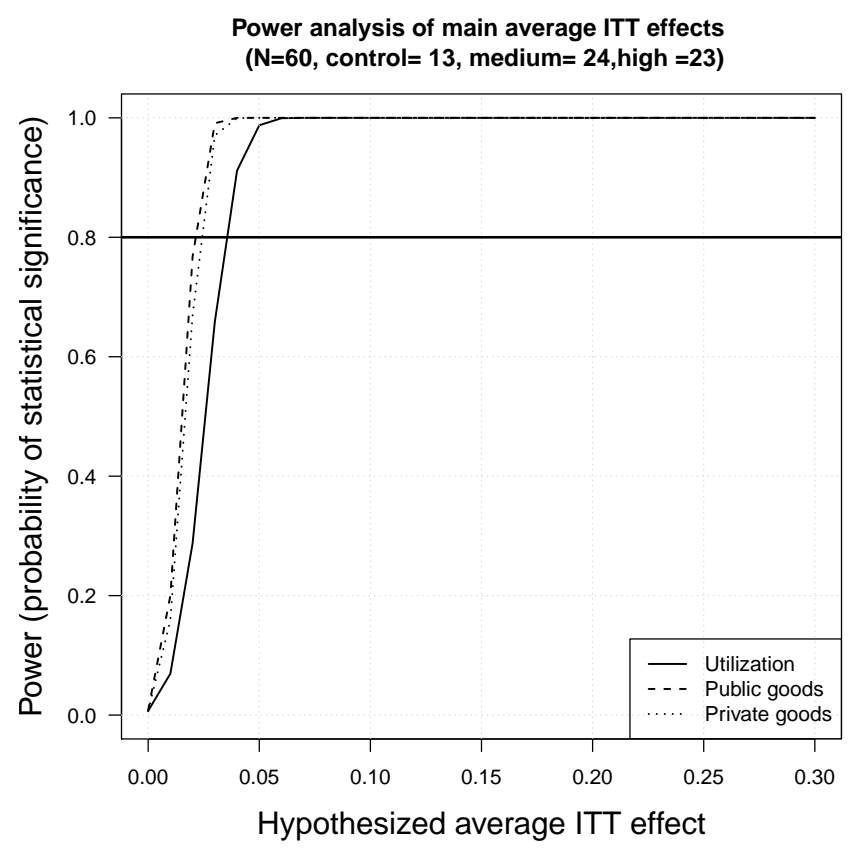

